\title{
FACULTY BURNOUT AND ITS RELATIONSHIP TO SOCIAL AND INSTITUTIONAL SUPPORT
}

\author{
A Dissertation \\ presented to \\ the Faculty of the Graduate School \\ at the University of Missouri-Columbia \\ In Partial Fulfillment \\ of the Requirements for the Degree \\ Doctor of Education \\ by \\ BROOKE HILDEBRAND CLUBBS \\ Dr. Melissa Odegard-Koester, Dissertation Supervisor \\ MAY 2020
}




\section{FACULTY BURNOUT}

The undersigned, appointed by the dean of the Graduate School, have examined the Dissertation entitled

\section{FACULTY BURNOUT AND ITS RELATIONSHIP TO SOCIAL AND INSTITUTIONAL SUPPORT}

presented by Brooke Hildebrand Clubbs

a candidate for the degree of doctor of education and hereby certify that, in their opinion, it is worthy of acceptance.

Dr. Melissa Odegard-Koester

Dr. Bret D. Cormier

Dr. Kirsten LaMantia

Dr. John C. Lammers

Dr. Sally J. Spalding 


\section{FACULTY BURNOUT}

\section{DEDICATION}

I would like to dedicate this work to my teachers, my students, my colleagues, and my family. This product is for, and because of, them. I have wanted to be a teacher since I witnessed the magic powers my first-grade teacher, Mrs. Helen Denault seemed to wield. I had the good fortune to have many other excellent educators along my journey, especially Mrs. Mildred

Burchfield, Mr. Will Rezba, Dr. Thomas Harte, Dr. Simin Cwick, Dr. Sonny Bell, and Dr. Lauren Weiner. I'm honored to share the title of teacher with them. I also would not be where I am without my first teachers: my mom, Susanne Hildebrand, my dad, the late James Hildebrand, and my maternal grandmother, the late Rell Yohnka. My students always inspire me to do better. I wanted to research burnout so I could discover how to help myself so I could give them my best. My colleagues are some of the most dedicated and hard-working people I know. I hope my findings can help all of them find their spark so they continue doing what they love and changing lives. My family, ironically, had to cope with my absence more often as I worked on researching work-life balance. My husband, Bob, was an incredible partner and source of support, despite initially wondering WHY I would want another terminal degree. I hope our children understood that as hard as I worked to become Dr. Clubbs, my most precious title will always be Mother of Avery Rell, Eli Hildebrand, and Lily Hope. 


\section{ACKNOWLEDGEMENTS}

I would like to thank each member of my dissertation committee. First, my advisor, Dr. Melissa Odegard-Koester (Mel), provided me with invaluable help on the qualitative research design. She cheered me on, as well as helped me keep up with the timeline I set for myself. Dr. Bret Cormier gave me the perspective of a fellow EdD and motivated me to "cross the Rubicon.” Dr. Kirsten LaMantia encouraged me to look at future projects that could help more people as I designed my survey. Dr. John Lammers was instrumental in helping me focus the study, always knew just which source would be the one I needed, and served as an excellent consultant on my quantitative analysis. Dr. Sally Spalding was the best editor I could ask for and never failed to encourage me with one word: "Champion!"

I have incredible gratitude for Dr. Eu Gene Chin, who helped me design my data analysis method and guided me through each step in SPSS. My statistics are much more sophisticated because of his expertise. I could not have done this without him. I would also like to thank my sister, Krista Davidson, “Team \#1B” from our first summer of coursework at Mizzou, my fellow Southeast area cohort members, and my colleagues in the Department of Communication Studies \& Modern Languages for their support throughout this process, as well as all of my colleagues who participated in my survey and/or interviews.

Finally, I am grateful for all the little things that contributed to my self-care during my time as a doctoral student: prayer, our dogs, running, "Yoga with Adriene", Winking Owl Shiraz, and the original Broadway cast recording of Hamilton. With their help, as Lin-Manuel Miranda would say, "I wrote my way out." 
TABLE OF CONTENTS

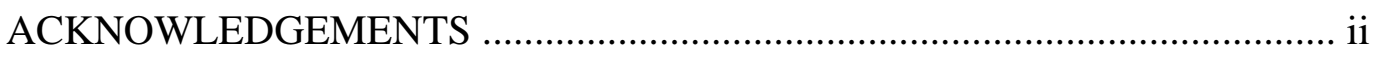

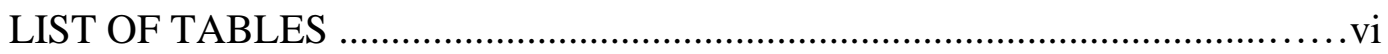

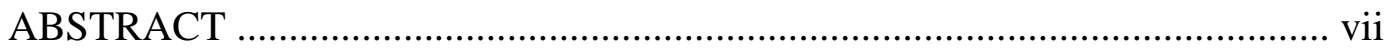

\section{Chapter}

1. INTRODUCTION TO THE DISSERTATION-IN-PRACTICE ......................1

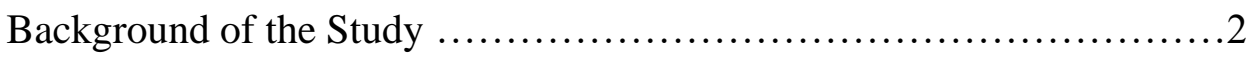

Statement of the Problem .............................................5

Existing Gap in the Literature .....................................

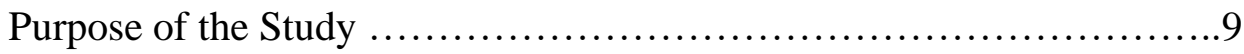

Research Questions and Hypothesis ................................9

Conceptual/Theoretical Framework ..................................10

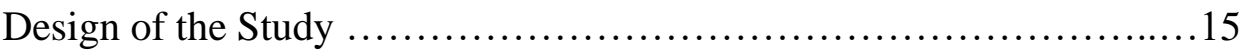

Limitations, Assumptions, and Design Controls ........................25

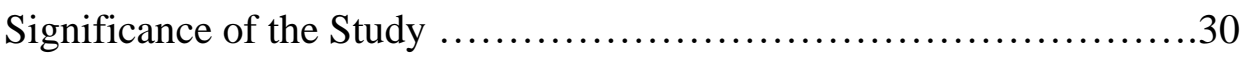

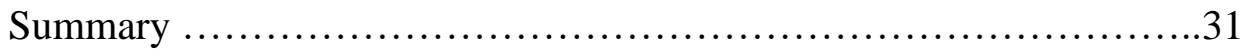

References ........................................................

2. PRACTITIONER SETTING FOR THE STUDY ………………...........52

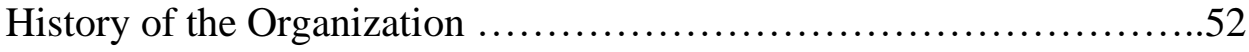

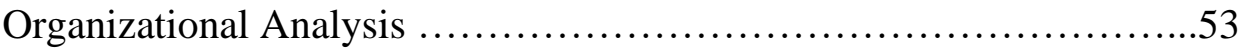

Leadership Analysis ............................................58

Implications for Research in the Practitioner Setting ....................59

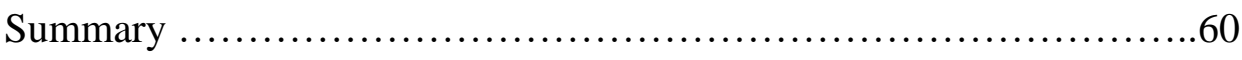

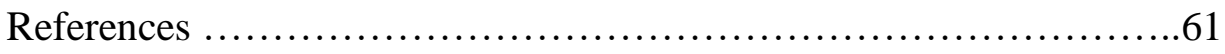

3. SCHOLARLY REVIEW FOR THE STUDY .........................63 
Review of Extant Scholarship ....................................64

Studies Related to Burnout Interventions ......................... 77

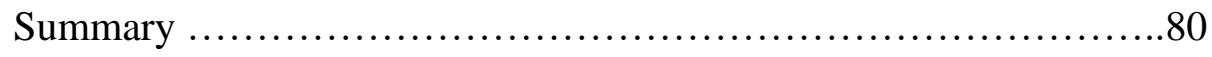

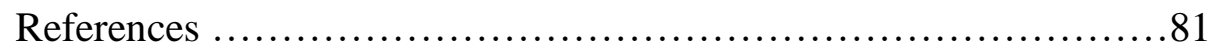

4. CONTRIBUTION TO PRACTICE.....................................99

Original Plan for Dissemination of Practitioner Contribution .........99

Current Plan ...................................................... 101

Type of Document .............................................. 103

Rationale for this Contribution Type ............................103

Outline .......................................................... 104

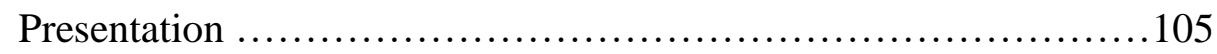

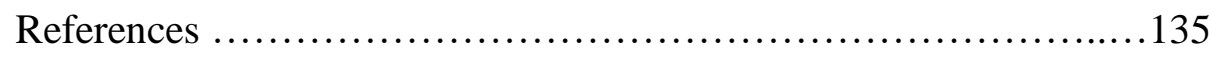

5. CONTRIBUTION TO SCHOLARSHIP ............................138

Original Plan ................................................ 138

Current Plan for Submission ...................................140

Submission-Ready Article .....................................142

References for Section Five Narrative ...........................202

6. SCHOLARLY PRACTITIONER REFLECTION.....................204

Influence of the dissertation process on my practice as an educational

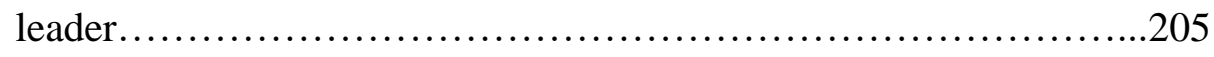

Influence of the dissertation process on me as a scholar .............209

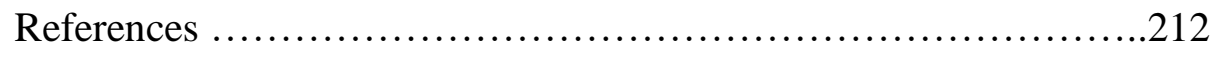




\section{APPENDIX}

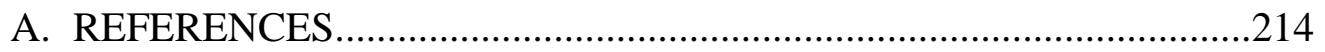

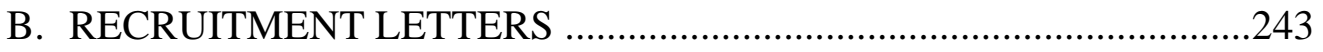

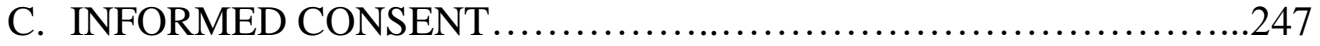

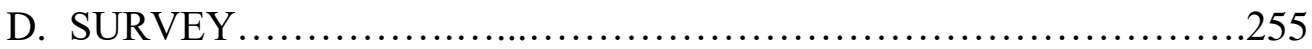

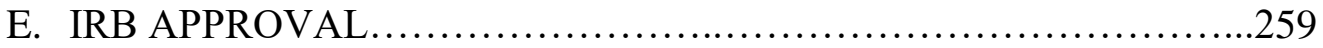

F. EXAMPLE OF INTERVIEW TRANSCRIPTS........................261

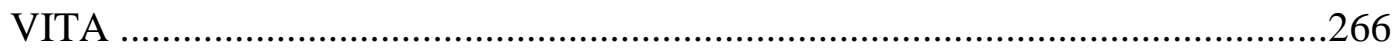




\section{LIST OF TABLES}

Table Page

1. Descriptive Statistics: Faculty Status and College 186

2. College and Average Global Burnout Score ................................................187

3. Maximum Model for Backward-Chunkwise Elimination Procedure.............188

4. Backward Single Variable Elimination Procedure..........................189

5. Themes and Subcategories from Interviews

190 


\begin{abstract}
The purpose of this sequential explanatory study was to determine if there was a relationship between faculty burnout, social support, institutional support, or salary, as well as establish if any college at a regional public university in the Midwest was less burned out than the others. Participants $(n=111)$ completed a survey that contained qualifying as well as demographic questions, Maslach's Burnout Inventory, Cutrona \& Russell's Social Provisions Scale, and the institutional support section of Conklin \& Desselle's Multidimensional Work Satisfaction Scale. Social support in the form of guidance and reassurance of worth, as well as institutional support, were found to mitigate burnout. The College of Education, Health \& Human Studies had a lower burnout score than other colleges. In semi-structured interviews with faculty, it was determined that personal accomplishment, as well as colleagues, department chairs, and deans who create a culture of support, can reduce burnout.

Keywords: Faculty, Burnout, Social Support, Institutional Support
\end{abstract}




\title{
Faculty Burnout and Its Relationship to Social and Institutional
} Support

\author{
Dissertation-in-Practice
}

Brooke Hildebrand Clubbs

Department of Educational Leadership \& Policy Analysis, University of Missouri 


\section{Faculty Burnout and Its Relationship to Social and Institutional Support}

\section{SECTION ONE:}

\section{INTRODUCTION TO THE DISSERTATION-IN-PRACTICE}

\section{Background of the Study}

In his 2014 faculty time allocation study, John Ziker found that the average professor spent a little over 60 hours a week working. Thirty percent of that time was dedicated to email and meetings. Given the increased time allocated to administrative tasks, Ziker (2014) argued that the days of the ivory tower are a distant memory. A zeitgeist in higher education has changed the demands on faculty and in turn, the composition of their work schedules. Most recently, President Barack Obama brought significant national attention to the importance of postsecondary degree attainment in an address to Congress on February 24, 2009. Considered a focusing event for the current national college completion movement, or completion agenda (Horowitz \& Phillips, 2014; Rubin, 2018), the address set he goal of again having the highest proportion of college graduates in the world by 2020 (Rubin, 2018).

Despite the Obama Administration's noble goal, state governments continue to cut higher education funding to the point that the cost is split nearly equally between state appropriations and student 
payment of tuition and fees (Doyle, 2013; Fabricant \& Brier, 2016;

Mueller, 2011), thereby raising the cost of college for the average student.

Additionally, there is an increased public demand for greater

accountability from universities (Barrett, 2014; Rosser, 2004). Thus,

contemporary faculty now find that the completion agenda has made the

focus of academia improving student outcomes while also driving down

costs (Conklin \& Desselle, 2007; Fabricant \& Brier, 2016; Gagliardi, et

al., 2018).

These cost-saving measures have decreased the number of fulltime faculty even while the number of students continues to increase (Childress, 2019; Cooper, 2019; Fabricant \& Brier, 2016; Hill \& Spinella, 2018; Lounder et al., 2011; Zahneis, 2018). As a result, the amount of time available for faculty to spend per student, per paper, and per class has necessarily declined. This decline has led faculty to choose between two equally troubling outcomes: a decline in the quality of their teaching and advising work or a decline in their wellbeing as they attempt to manage a growing workload (Black, 2004; Sabagh, et al., 2018). Because of the increased time demand for teaching and related responsibilities, faculty have seen substantial reductions in the time available for research and service as well as creative, rather than task-oriented, engagement with colleagues (Padilla \& Thompson, 2016). It comes as little surprise then, that Lounder et al. found that as "autonomy decreases and faculty work becomes more technocratic, a propensity develops for the job to become 
less attractive. In turn, this suggests a likelihood of reduced investment in work by current faculty members, as well as discouraged aspirations for talented rising scholars" (2011, p.24).

In addition to disincentivizing the recruitment and retention of new faculty, cost-saving measures have also reduced the number of support staff. This creates additional burdens for already overworked faculty by adding administrative tasks to their growing list of duties. Heavy teaching loads, community-based research, and professional service responsibilities may constitute an overwhelming set of role expectations (Kingston-Mann \& Sieber, 2001). According to Newport's February 2019 piece in the Chronicle of Higher Education:

To keep up with this administrative overload, professors also often add a 'second shift' to their schedule, returning to work at night, as well as on weekends and vacations, to catch up on the neverending onslaught of demands on their time and attention. In the short term, this scheduling sleight of hand keeps departments functioning without requiring additional faculty or support staff but at the expense of long-term burnout and dissatisfaction (para. 27).

While this phase of the completion agenda is new, the rise of faculty burnout as the completion agenda takes root is hardly new. Fifteen years ago, when careers in academia often still included the possibility of tenure and sabbaticals, Lackritz (2004) found burnout was already a 
concern for faculty. In his assessment of burnout at one public university, approximately $20 \%$ of all faculty members reported feeling the highest levels of burnout (Lackritz, 2004). Even farther back, in 1998, Johnsrud and Heck examined three primary areas of faculty worklife concerns: an attack on their professional priorities, a lack of confidence in their institutions to support and protect their personal and professional interests, and erosion of their quality of life. With the emergence of the completion agenda and cost-saving measures in recent years, faculty burnout is more likely, and thus, the focus of this study.

\section{Statement of the Problem}

In the late 1970s, psychoanalyst Herbert Freudenberger coined the term "burnout" to compare his feelings of exhaustion in response to stress with the way his patients' cigarettes sometimes burned out while they were holding them (King, 2016). While burnout has been the focus of many studies in the last four decades, and an inventory was developed to measure it (Maslach, et al., 1981; Maslach, et al., 1996) the concept of burnout was often disputed and not officially recognized as a mental disorder (Heinemann \& Heinemann, 2017). The World Health Organization only recently recognized burnout as, a syndrome conceptualized as resulting from chronic workplace stress that has not been successfully managed. It is characterized by three dimensions: 1) feelings of energy depletion or exhaustion; 2) increased mental distance from one's job, or 
feelings of negativism or cynicism related to one's job; and 3) reduced professional efficacy. (2018; para. 1).

Research in health and organizational communication have examined the role of social support, both at work and in personal relationships, in mitigating burnout (Chao, et al., 2011;

Faulkner \& Davies, 2005; Fradelos, et al., 2014; Jones \& Griep, 2018; Lammers, et al., 2013; Wei et al., 2012). To combat burnout, healthcare organizations have tried a variety of interventions including facilitated discussion groups (Brian \& Carter, 2004), mindful meditation (Tollinche, 2013), and retreats (Henry, 2014). Interestingly, these interventions fit a pattern noted by Maslach and her fellow researchers: removing the worker from the job, or providing individual strategies for the worker, in which one either strengthens one's internal resources or changes one's work behaviors (2001). This is particularly paradoxical given that research has found that situational and organizational factors play a bigger role in burnout than individual ones (Bermejo-Toro, et al., 2016;

Bowling, et al., 2015; Kim \& Rehg, 2018; Larson et al., 2019; Maslach, et al., 2001; Moeller \& Chung-Yan, 2013; Sabagh, et al., 2018). According to Dr. Elaine Cheung in an interview with National Public Radio, employers can play a big role in addressing burnout by paying attention to whether employees have a sense of community and agency at work, strong social relationships, a collegial environment, a workload 
that's not too burdensome, and a healthy work-life balance (Chatterjee \& Wroth, 2019).

\section{Existing Gap in the Literature}

Although over 1.5 million people are employed as faculty at colleges and universities in the United States (NCES, 2016.), with a few notable exceptions (Daly \& Dee, 2006; Djurkovic, et al., 2008;

Finkelstein, et al., 2016; Flaherty, 2017a; 2017b; Levin \& Shaker, 2011; Lounder, et al., 2011; Padilla \& Thompson, 2016), little research has focused on how larger changes within higher education affect faculty and how faculty cope with those changes. Extending this line of inquiry is important given that faculty burnout is a problem not only on the individual level but on the institutional level as well. Higher levels of burnout are associated with higher employee turnover (Daly \& Dee, 2006; Mullen, et al., 2018; Watanabe \& Falci, 2016). High rates of faculty turnover can be expensive not only due to the monetary cost of recruiting, training, socialization investments, and the disruption of displacement (Mobley, 1982), but are also costly to the reputation of an institution and the quality of instruction (Daly \& Dee, 2006; Ramasamy \& Abdullah, 2017). Faculty turnover can also result in reduced integration within the academic department, disruption of course offerings, and diminished morale among those employees who remain in the organization (Mobley, 1982; Price, 1997). 
These disruptions caused by faculty burnout can have a direct impact on program enrollment as they jeopardize the important connections between students and faculty that encourage student retention (Bennett, 2017; Tinto \& Goodsell-Love, 1993). Additionally, faculty burnout jeopardizes the time required for scholarship, professional development, and class preparation that are crucial to maintaining a high level of instructional quality (Gamson \& Chickering, 1991; Tinto \& Goodsell-Love, 1993), such as active and collaborative learning techniques, engaging students in experiences, emphasizing higher-order cognitive activities, interacting with students, challenging students academically, and valuing enriching educational experiences (Umbach \& Wawrzynski, 2005). As Rusty Stahl commented in his online 2017 article for Fund the People, an organization focused on maximizing investment in the non-profit workforce, rather than asking "What happens if I invest in people and they leave?", administrators should consider "What if I don't invest in them, and then they stay?" (para.13). In other words, both turnover and burnout could diminish the value faculty can contribute to the organization.

In academia, faculty are encouraged to combat burnout with faculty social hours, book clubs, and otherwise reduce their stress (Gooblar, 2018a), ignoring that their institution bears some responsibility in creating the burnout (Gooblar, 2018b). As of yet, few studies have focused specifically on increasing resilience to, or mitigating, burnout in the particular subgroup of university faculty (Watts \& Robertson, 2011). 
This study, which seeks to integrate research on support and faculty

burnout, answers Dutton \& Ragins' (2007) call to “build bridges across silos of scholarship" on exploring positive relationships at work between peers and supervisors (p. 5).

\section{Purpose of the Study}

Determining the greatest mitigator of faculty burnout, as well as best practices for colleges and departments to support faculty against burnout, could guide university leadership as they adapt to the completion agenda. It could also produce strategies to reduce some of the completion agenda's more deleterious effects: faculty burnout and turnover, the loss of positive relationships at work, negative impacts on faculty's physical, emotional, and social well-being, and, ultimately, a decrease in student retention.

\section{Research Questions and Hypothesis}

Thus, this research seeks to address the following quantitative questions:

RQ 1. Is there a relationship between social support and faculty burnout?

RQ2. Is there a relationship between institutional support and faculty burnout?

RQ3. Is there a relationship between salary tier and faculty burnout?

RQ4. Are some university colleges' faculty less likely to burnout than others? 
The following qualitative question will also be addressed:

RQ5. What are the characteristics of the college(s) that are less likely to have faculty burnout?

HO1. Institutional support will be the greatest mitigator of faculty burnout.

\section{Conceptual/Theoretical Framework}

To explore these questions, this study utilizes the following conceptual and theoretical frameworks: burnout, social support, the buffering hypothesis, and institutional support, which is also known as perceived organizational support. In this section, I provide a brief description of each, using supporting material from the seminal works regarding each concept.

\section{Burnout}

While the World Health Organization recently redefined burnout and clarified that it "refers specifically to phenomena in the occupational context and should not be applied to describe experiences in other areas of life" (2018), its casual use remains in the popular lexicon to describe everything from millennial ennui related to dating sites (Bolanos, 2019; Petersen, 2019) to a lack of enthusiasm for preparing healthy foods (Millard, 2019). This misuse can sometimes dilute the public's perception of the seriousness of burnout. 
Unlike depression, which tends to pervade every domain of a person's life, burnout is a problem that is specific to the work environment (Freudenberger, 1977). Although it is unclear precisely what causes burnout, Maslach, et al. (2001) postulate that the best and most idealistic workers experience burnout-e.g., "You have to have been on fire to burn out" (p.405). This interpretation implies that dedicated people commit too much in support of their ideals, which leads to exhaustion, depersonalization, and the feeling of a lack of personal achievement when their sacrifice is insufficient to achieve their goals. Meaningful work can have a negative effect on employee's well-being, as employees feel so invested in their work that they push themselves beyond their limits resulting in strain and susceptibility to burnout (Jones \& Griep, 2018; Reevy \& Deason, 2014). Because Freudenberger (1977) believed that burnout is particularly linked to specific working environments and organizational contexts, he proposed intervening at an organizational rather than just an individual level. His recommendations included shorter working hours, regular job rotation, and frequent supervision and staff training (Heinemann \& Heinemann, 2017).

\section{Social Support and the Buffering Hypothesis}

The resource to prevent burnout that has been studied most extensively is social support. Specifically, consistent findings and a strong body of literature demonstrate that a lack of social support is linked to burnout (Bremer \& Brooks, 2018; Maslach, et al., 2001). Social support 
includes a broad category of communicative behaviors that are enacted to provide assistance to another person or persons (Moss, 1973; Thompson \& Thompson, 2014). Social support has also been defined as the exchange of resources with the intent to enhance well-being (Shumaker \& Brownell, 2010). Faulkner and Davies (2005) divide types of support into four broad components: appraisal (helping individuals to evaluate the personal relevance or impact of their circumstances), emotional (providing encouragement and enhancing self-esteem), instrumental (providing tangible resources to remove, or significantly reduce, the stressful situation experienced by an individual), and informational (providing individuals with information enabling them to deal with their problems). Weiss (1974) characterized six categories of relational provisions of social support: attachment (a sense of security), social integration (network membership), opportunity for nurturance (taking responsibility for the well-being of a child), reassurance of worth (which attest to an individual's competence in a social role), a sense of reliable alliance (kin ties), and the obtaining of guidance (access to a trustworthy figure who can furnish emotional support and assist in developing a plan of action).

Social support from coworkers can buffer the effects of job stressors (Lee, et al., 2019; Schulz, et al., 2018). The role of social support on mitigating negative outcomes has been theorized extensively using the buffering hypothesis (Cassel, 1976; Cobb, 1976) which asserts that 
"social support provides protection against the stress that produces psychological or physiological disorder or disease or reduces job performance" (Craighead \& Numeroff, 2004, para. 1). Key sources of social support in the workplace include coworkers, leaders, and the organization itself (Lee, et al. 2019). According to the cross-domain buffering hypothesis of social support, social support from a different domain (e.g., coworker or organizational support) should be particularly effective at reducing the negative consequences of a stressor from another domain (Duffy, et al., 2002). For example, if a supervisor is alternately ambivalent and supportive, the support from the supervisor does not protect a worker from stress. However, if a coworker is supportive when a supervisor is ambivalent, the support does reduce the negative consequences of the stress the worker may experience (Lee, et al., 2019). While not all studies have found social support to have this buffering effect with burnout (Padilla \& Thompson, 2016) and the hypothesis has been characterized as a "brick without clay" (Taris, 2006, p. 99), a review of research regarding the Job Demand-Control (Support)Model (JDCS) found buffering effects do exist (Häusser, et al., 2010).

\section{Institutional Support}

Several studies suggest that, in addition to social support, institutional or organizational support can have protective factors against faculty burnout. In 1986, Eisenberger, Huntington, Hutchison, \& Sowa 
developed a measurement for perceived organizational support (POS).

Their measurement was based on the social exchange view that:

employees' commitment to the organization is strongly influenced by their perception of the organization's commitment to them.

Perceived organizational support is assumed to increase the employee's affective attachment to the organization and his or her expectancy that greater effort toward meeting organizational goals will be rewarded. (p. 500).

In their study, they found employees form global beliefs concerning the extent to which the organization values their contributions and cares about their well-being and that such perceived organizational support reduces absenteeism (Eisenberger, et al., 1986). Bryan, et al. (2006) found that "visibility within the organization, perceived opportunities for growth, and participation in decision-making were all related to perceived respect" (p. 815). Heffernan \& Heffernan (2019) found that professional development and career support available to academics played major roles in their career satisfaction. Djurkovic, et al. (2008) reported perceived organizational support moderates the relationship between workplace bullying and victims' intention to leave. While the terms "organizational support" and "institutional support" are often used interchangeably throughout the literature on work and wellbeing (Simmons, 2014), Conklin \& Desselle (2007) created a domain in their faculty work satisfaction scale entitled "Institutional Support and 
Reward" (p. 5), which is why I have chosen to use the term "institutional support" for this study.

These concepts---burnout, social support, the buffering hypothesis, and institutional support---make up the framework of this study. Additionally, burnout serves as the dependent variable, while social support and institutional support serve as independent variables in my study design.

\section{Design of the Study}

To answer the research questions, I conducted a mixed-methods sequential explanatory study which began with the quantitative data collection and analysis in the form of a survey and proceeded to the qualitative data collection and analysis in the form of interviews (Creswell, 2014; Ivankova, et al., 2006; Mayoh \& Onwuegbuzie, 2015). Using this type of mixed methods research design provides a more complete understanding of my research problem than a quantitative or qualitative approach alone (Creswell, 2014). To complete this study, I solicited and acquired permission from the IRB for research with human subjects, as well as obtained informed consent from all participants for both the quantitative survey and the qualitative interviews.

\section{Setting}

River City University (RCU), located in the Midwest, was founded in 1873 as a teaching college. It now offers 269 areas of 
undergraduate and graduate study taught by over 393 faculty (RCU HR, personal communication, September 20, 2019). In the fall of 2019, RCU reported a head-count enrollment of 10,637 at its main and regional campuses combined, down from 11,071 students a year ago and 11,501 students in 2017 (Bliss, 2019). While RCU boasts a 75.3\% retention rate, the enrollment reflects state-wide trends: head-count enrollment at state colleges has declined by about $10 \%$ over the five-year period ending in 2018 (Bliss, 2019). Adjusted for inflation, state funding for public fouryear colleges in the state where RCU is located has dropped $46 \%$ per student since 2000 (Okeson-Haberman, 2019).

RCU has a traditional bureaucratic structure with a Board of Regents, President, Provost, College Deans, and Department Chairs (RCU Office of Institutional Research, n.d.). Academic reorganization occurred at the university during 2017-2018 and took effect in the 2018-2019 school year (RCU Newswire, 2018).

\section{Participants}

An online survey created with Fink's (2017) step-by-step guidelines was conducted. Fink's informed consent form for an online survey that defines and describes the limits of confidentiality, how the data will be used, how the data will be secured, and whom to contact with questions was provided to participants before beginning the survey (2017). All faculty at 
RCU were sent an e-mail with a link to the questionnaire (Conklin \& Desselle, 2007; Cutrona \& Russell, 1987; Maslach \& Jackson, 1981; Maslach, et al., 1996). Respondents were filtered by a qualifying question at the beginning of the survey so that only the faculty who have ever attended one of the faculty development days or any of the other professional development events hosted and organized by RCU's Center for Scholarship in Teaching and Learning continued to the rest of the survey. Limiting survey respondents solely to those who have taken advantage of at least one of these professional development opportunities provided a population that was, at one point in time, interested in improving in their roles as faculty. Thus, faculty who answered "yes" to the question about their participation in faculty development opportunities are likely those who fit Maslach's description that "you have to have been on fire to burnout" (Maslach, et al., 2001, p. 405).

In addition to survey feedback, secondary data sets were used to create thick description, modeled by Geertz (1973). Every five years, RCU participates in the Chronicle of Higher Education's “Best Colleges to Work For" survey, conducted by ModernThink (Chronicle of Higher Education, 2018). Because RCU participated in this survey, I had access to RCU's report. The report included profiles and general demographics of survey respondents, benefits satisfaction, and employee comments, as well as a comparison with our results from previous years. Because results were broken down by faculty and staff, I could use this 
information for thick description of what it is like to be a faculty member at RCU.

The study's thick description also included pre-existing data pulled from faculty comment cards requested by RCU's faculty senate in the fall of 2018. On the cards, faculty were encouraged to anonymously list their three primary concerns or complaints they had about the treatment of faculty and staff at RCU. Faculty Senate Chair, R.R. Mascot reported that the extended collection period yielded 96 individual response cards plus 3 compiled responses (personal communication, October 20, 2018). The total sample population (for both polls) was 144 individuals. In 2016, before faculty retirement incentives and the recent slow-down in rehiring, there were 410 permanent full-time faculty positions at RCU (RCU Fact Book, 20172018).

According to RCU's human resource office, in fall 2019, there are 393 permanent fulltime faculty members (personal communication, September 20, 2019). However, R.R. Mascot was using the 2016 census as a minimum benchmark, and assuming that only full-time faculty members participate in departmental meetings to determine that the response rate for the combined Faculty Senate Department Poll was at least $35.1 \%$ of the total full-time faculty population. Responses were analyzed by R. R. Mascot using the constant comparative techniques of grounded theory as described by Creswell (2014) and Strauss and Corbin 
(1998). Each response was analyzed to determine irreducible content units, which were open-coded and sorted to identify a minimum number of common categories. (R.R. Mascot, personal communication, October 20, 2018). The most common category comments fell into was communication and shared governance concerns. This qualitative data could also be used for thick description of what it is like to be a faculty member at RCU.

\section{Data Collection Tools}

Keeping in mind that a "well-designed, easy-to-use survey always contributes to reliability and validity" (Fink, 2017, p. 11), my 45-item survey questionnaire was created by adapting the following instruments: the Maslach Burnout Inventory-Educators Survey (Maslach \& Jackson, 1981; Maslach, et al., 1996), the short form of the Social Provisions Scale (Cutrona \& Russell, 1987), and questions from the second domain of the Multidimensional Work Satisfaction Scale developed by Conklin \& Desselle (2007). I secured permission to use these scales from their authors.

Burnout was measured using the 22-item MBI-Educators Survey (MBI-ES) which addresses three scales: emotional exhaustion (EE) which measures feelings of being emotionally overextended and exhausted by one's work, depersonalization (DP) which measures an unfeeling and impersonal response toward recipients of one's instruction, and personal accomplishment (PA) which measures feelings of competence and 
successful achievement in one's work (Maslach, et al., 1996). Higher scores on the EE and DP subscales indicate higher burnout, while higher scores on PA indicate lower burnout (Szigeti et al., 2017). The global burnout score was determined by reversing the PA scores and adding them with EE and DP scores (Mészáros et al., 2014; Periard, 2016; Szigeti et al., 2017). I paid MindGarden for permission to use the MBI-ES for this study.

Perceived social support was measured using the short version of the Social Provisions Scale (SPS) which includes 10 items tapping five of the six types of provisions available from the general social network, including reliable alliance (practical help), guidance (informational support), attachment (emotional support), social integration (belonging to a group of similar peers), and reassurance of worth (esteem support) (Cutrona \& Russell, 1987). A score for each social provision is derived such that a high score indicates that the individual is receiving that provision and can be tabulated as a global social support score (Cutrona \& Russell, 1987) I received permission from Dr. Cutrona and Dr. Russell to use the SPS for this study.

Institutional support was measured by using questions adapted from the second domain of the Multidimensional Work Satisfaction Scale (MWSS) developed by Conklin \& Desselle (2007). The full MWSS has 6 domains and 25 items, but because I only used the second domain, "Institutional Support and Reward" (Conklin \& 
Desselle, 2007, p. 5) participants were asked to rate just 6 items within it: general support from my department/division chair, general support from my dean, general support from upper administration, including provost and president, institutional efforts in support of the career development of their faculty, salary competitive with other schools, and distribution of rewards (i.e., salary) based on merit. The average of these items created the institutional support score. I received permission from Dr. Desselle to adapt and use this scale for this study.

I also asked demographic questions including salary, faculty status (Renewable NonTenure Track which is known as RNTT, Tenure Track, Tenured), gender, age, race, ethnicity, and sexual orientation. However, because this combination of demographic questions could run the risk of revealing identities, I designed the questionnaire so that participants could skip most of the demographic questions. Status, salary, and college were only required to complete before moving on to the next questionnaire item. Status was required because, at this time, I only wanted to study full-time faculty, not adjunct faculty or graduate assistants. Salary was an important independent variable to measure because there was a possibility that the only support that may make a difference in reducing burnout is salary. Rewards can come to faculty in multiple forms other than monetary compensation, such as student learning and engagement. However, salary, retirement, and job security are important issues that affect faculty satisfaction (Rosser, 2004). Participants were grouped by 
college because I wanted to discover if some colleges were more resistant to burnout than others. In their studies on faculty intention to leave, Johnsrud \& Rosser found sources of support can vary dramatically by college, department, and discipline, and the perceived inequities can be demoralizing to faculty members (Johnsrud \& Rosser, 2002; Rosser, 2004; 2005).

While I only used the salary and college as independent variables in this particular study, I wanted to have the other demographic information for future research. The psychological wellbeing of RNTT faculty is an emerging area of study, given that they now make up the majority of the academic workforce (Reevy \& Deason, 2014; Seipel \& Larson, 2018). Asking participants to describe their gender, rather than select their biological sex on the questionnaire served two purposes. The experience of women in academia is an area of interest, as recent research examines the toll of sexism on the physical and mental health of female academics (Mountz, 2016; Price \& Kerschbaum, 2017) and other research has shown queer-spectrum and trans-spectrum faculty often experience uninviting work environments (Garvey \& Rankin, 2018; Rankin, et al., 2010). Finally, there are varying reports on the impact of the generation gap among university faculty (Brown; 2017; Fogg, 2009), as well as on women who are part of Generation X in particular (Calhoun, 2020).

Future studies could examine the role of marginalization and the mental load of university faculty; so I added demographic questions 
regarding race, ethnicity, and sexual orientation. I realized I ran the risk of losing participants who found the questions too personal, so I provided multiple assurances of anonymity and that participants are not required to answer the questions.

Based on the survey results, I determined which particular college was associated with lower burnout scores. I conducted the qualitative portion of this sequential explanatory mixed methods study by creating semi-structured interview questions, based on the work of Seidman (2013). I interviewed faculty within most of the departments of that college to discover if any common factors could be responsible for a culture of institutional support that reduces burnout. If a particular college was not associated with lower burnout than the others, I would have instead looked to see if a particular college was associated with higher institutional support and conducted interviews accordingly. I would have done this because perceptions faculty members have of their worklife have a direct impact on their morale (Rosser, 2004). I would not have evaluated colleges whose faculty had high social support scores, as the social support may have come from family and friends outside the university. My informed consent form for the qualitative portion of the study reinforced the purpose of the study, how the data would be used, and how anonymity would be maintained. 


\section{Data Analysis}

A frequency analysis was conducted to create descriptive statistics regarding the two demographic characteristics of the respondents being used for this study: salary and college. Mean scores of burnout were cross-tabulated for each college. The faculty in the college with the lowest burnout scores were singled out for semi-structured interviews to determine common characteristics that may create a culture of support and reduce burnout. Rather than performing a correlation analysis between the outcome variable of burnout and the predictor variables (i.e., salary, college, social support, and institutional support) before conducting a multiple linear regression in two separate steps, a more streamlined procedure for model building, known as a backwardchunkwise elimination procedure (Kleinbaum et al., 2008) was employed. In the first step of the backward elimination procedure, the maximum model was fit as the base model, with $\mathrm{p}=\mathrm{k}$ predictors (where $\mathrm{p}$ refers to the number of predictors in the candidate model and $\mathrm{k}$ refers to the number of predictors in the maximum model). The second step included fitting all p-1 variables models, defined by deleting one variable from the base model. For each model, the added-last test was computed for the candidate variable. Then, the minimum test statistic, Fp, was found for each candidate variable. If statistically significant (Fp > FCRIT), the procedure stopped and model $\mathrm{p}$ is chosen as the final model. If not statistically significant Fp < FCRIT), the predictor was deleted with the 
minimum test statistic, and $\mathrm{p}$ was reduced by one. In this case, the second step was returned to and the process was repeated until a final model was determined. A notable advantage of a backward elimination procedure is that it reduces the likelihood of producing an underfitting model (i.e., producing a model with an incomplete list of predictor variables, which leads to biased estimates). Overfitting a model, on the other hand, may lead to erroneous predictors being included in the model, but still yields unbiased estimates compared to an underfitting model.

The semi-structured interviews were recorded and transcribed, using the Temi application on the iPhone (Rev, 2019). Temi is a secure application that protects participants' privacy, as recordings are securely stored and transmitted using TLS 1.2 encryption, the highest level of security available (Temi, 2019.) Files are transcribed by machines and are never seen by a human; other Temi users can't see other users' files unless a user shares links to their Temi transcripts ("Are my files private and secure?", 2019). I then utilized open-coding of this data, looking for responses to the research questions and reoccurring themes. After that, I used analytical coding to develop the codes into large overarching ideas (Merriam \& Tisdell, 2016).

\section{Limitations, Assumptions, and Design Controls}

One of the obvious limitations of this study was that it looks at only one regional public university in the Midwest. One of the inherent assumptions is that I am a participant-observer (Yin, 2009) as the data is 
being gathered at the institution I am employed. Because all research is value-bound, it was essential that my values were examined (Lincoln \& Guba, 1985). This was why the quantitative aspect of the study was so important. Rather than solely relying on my impressions and experiences, I looked to the survey results. However, because this was a sequential explanatory study, I also conducted interviews to dig deeper (Creswell, 2014). In those instances, I strived to focus on the content of the interview rather than my relationship with the participant, who was a colleague.

In quantitative studies, validity and reliability are the goals while in qualitative studies, reliability and trustworthiness are the targets. Quantitative validity can be obtained through a set of logical procedures. Qualitative research, on the other hand, according to Maxwell (2005), treats validity as a relative term that is a goal, not a guaranteed result. The key to validity, concerning qualitative interpretation, pertains to possible threats to the researcher's interpretations of the phenomenon (Maxwell, 2005). To ensure my results were valid, reliable, and trustworthy, I employed statistical significance testing (Creswell, 2014), reflexive journaling (Creswell, 2014; Lincoln \& Guba, 1985; Meyer \& Willis, 2019), and member checking (Creswell, 2014; Lincoln \& Guba, 1985).

Statistical significance testing reports whether or not observed scores reflect a pattern other than chance. A statistical test is considered significant if the results are unlikely to have occurred by chance, and the null hypothesis of "no effect" can be rejected. While individually my 
instruments have been established as having content and construct validity and reliability (Conklin \& Desselle 2007, 2010; Gottlieb \& Bergen, 2010; Peirce et al., 2012; Perera, 2016; Schaufeli, et al., 2001; Walkey, et al., 1987), because I am combining the instruments, I needed to reestablish validity and reliability during data analysis (Creswell, 2014). I also do this by providing the instrument in my appendix (Creswell, 2014).

Reflexivity refers to a qualitative researcher reflecting on "how their role in the study and their personal background, culture, and experiences hold potential for shaping their interpretation, such as the themes they advance and the meaning they ascribe to data" (Creswell, 2014, p. 186). Reflexive journaling can support the navigation of procedural and ethical challenges (Meyer \& Willis, 2019) of being a participant researcher. A reflexive journal can include memos about the researcher's thought processes, data analysis, rationales, turning points, as well as personal reactions and experiences. These reflections provide the necessary descriptive data to establish transparency which can later be used by readers to determine the transferability of the researcher's findings (Lincoln \& Guba, 1985). I kept a reflexive journal throughout the data collection process, with special attention to my reactions following each of the semi-structured interviews.

Member checking occurs when the researcher takes the major findings, such as the themes, back to interview participants to see if they feel they are accurate (Creswell, 2014). 
Member checks provide "the opportunity to assess intentionality" (Lincoln \& Guba, 1985, p. 314). Member checks ensured that the essence of the participants' meanings was articulated and interpreted accurately by the researcher. They also ensured that no participants' reality was ignored.

Through statistical significance testing (Creswell, 2014), reflexive journaling (Creswell, 2014; Lincoln \& Guba, 1985; Meyer \& Willis, 2019), and member checking (Creswell, 2014; Lincoln \& Guba, 1985), I provided transparency as a participant-researcher. I also established the validity, reliability, and trustworthiness of my study.

\section{Definition of Key Terms}

In addition to the concepts of burnout, social support, the buffering hypothesis, and institutional support which have been previously defined and explained, this study also uses the terms:

Adjunct refers to faculty who are not full-time employees of the university. Instead of a salary, they are paid per class they teach.

Administration refers to the people in supervisory positions. The chain of command for faculty is first their department chair, then the dean of their college, followed by the provost and finally, the president. However, many other people in administrative roles affect faculty, including, but not limited to, the vice president of finance and administration, the vice provost, and the director of the budget office. 
Campus refers to school buildings, grounds, and the surrounding area.

College refers to a collection of departments governed by a dean.

Dean refers to the head of a college, or collection of departments.

Department refers to a division of university faculty devoted to a particular academic discipline.

Other terms for this are academic unit and program.

Faculty refers to people who teach at the university.

Renewable Non-Tenure Track (RNTT) refers to faculty who are full-time employees and receive a salary with benefits but are not eligible for tenure. They include but are not limited to, faculty who teach remedial and/or introductory courses for which a terminal degree may not be required, and faculty at regional campuses. They are also referred to as instructors.

Tenure is intended to protect the freedom of teaching and research. It is also intended to provide sufficient security to make the profession attractive to highly qualified individuals. Faculty who are hired in tenuretrack positions hold an approved terminal degree and additional credentials as required by the position as determined by the department. They teach upper-level undergraduate and graduate classes. They start with the title of assistant professors, and as they achieve each benchmark 
associated with tenure and promotion, they are called associate professors and full professors.

University refers to a collection of colleges, governed by a provost and president.

\section{Significance of the Study}

According to the National Center for Educational Statistics, in the academic year 2016-17, there were 3,895 degree-granting institutions in the United States with first-year undergraduates: 2,395 were 4-year institutions offering programs at the bachelor's or higher degree level and 1,500 were 2-year institutions offering associate's degrees and other certificates (2018). From fall 1999 to fall 2016, the total number of faculty in degree-granting postsecondary institutions increased by 51 percent (from 1.0 to 1.5 million). Thus, the issue of faculty burnout potentially impacts millions of faculty and millions of more students.

\section{Scholarship}

The topic of faculty burnout is beginning to get more attention in popular sources, but there has not been as much scholarly research about the topic. As of yet, few studies have focused specifically on increasing resilience to, or mitigating, burnout in the particular subgroup of university faculty (Heinemann \& Heinemann, 2017; Watts \& Robertson, 2011). This study, which seeks to integrate research on social support and faculty burnout, answers Dutton \& Ragins' (2007) call to “build bridges 
across silos of scholarship" on exploring positive relationships at work (p.

$5)$.

\section{Practice}

Providing an evidence-based analysis of the mitigators of faculty burnout could provide insight for burnout researchers, but also guide university leadership. Decreasing burnout can reduce faculty turnover and improve student retention as well. In practice, sharing the results of the study and encouraging faculty to apply literature-based best-practices could reduce faculty burnout. It may also foster positive relationships at work and have a positive impact on the physical, emotional, and social well-being of faculty.

\section{Summary}

Utilizing a conceptual framework made up of research on burnout, social support, the buffering hypothesis, and institutional support, I conducted a mixed-methods sequential explanatory study to determine if there is a relationship between faculty burnout, social support, institutional support, and demographic factors, specifically salary and college. After administering a quantitative survey to faculty, the responses underwent frequency analysis, cross-tabulation of means, and backward elimination procedure with the chunkwise method to predict how much burnout would decrease based upon each increase in the independent variables. Colleges with the lowest burnout scores were singled out for semi-structured interviews to determine common characteristics that may 
create a culture of support and reduce burnout. Determining the greatest mitigator of faculty burnout and best practices for academic units to support faculty could guide university leadership to reduce faculty burnout and turnover, foster positive relationships at work, have a positive impact on faculty physical, emotional and social wellbeing, and, ultimately, improve student retention as well. 


\section{References}

Barrett, S. H. (2014). Accountability in higher education: A comparison of public perceptions to state higher education performance. ProQuest.

Bennett, E. A. (2017). The relationship between first-year student retention and type of faculty at a four-year public research university: A profile of three academic colleges. [Doctoral dissertation, Ohio University]. https://etd.ohiolink.edu/.

Bermejo-Toro, L., Prieto-Ursúa, M., \& Hernández, V. (2016). Towards a model of teacher wellbeing: Personal and job resources involved in teacher burnout and engagement. Educational Psychology, 36(3), 481-501.

Black, S. (2004). Stroking stressed-out teachers. Education Digest: Essential Readings Condensed for Quick Review, 69(5), 28-32.

Bolanos, H. (2019). Dating app burnout: When swiping becomes a chore. National Public Radio. https://www.npr.org/2019/06/26/736344196/dating-app-burnoutwhen-swiping-becomesa-chore

Bowling, N. A., Alarcon, G. M., Bragg, C. B., \& Hartman, M. J. (2015). A meta-analytic examination of the potential correlates and consequences of workload. Work \& Stress, 29(2), 95-113. 
Bremer, B. A., \& Brooks, L. J. (2018). Social support as a coping strategy. In Salem Press Encyclopedia of Health. Salem Press.

Brian, A., \& Carter, E. S. (2004). Once again, Vanderbilt NICU in Nashville leads the way in nurses' emotional support. Pediatric Nursing, 30(6), 471-472. https://www.ncbi.nlm.nih.gov/pubmed/15704595.

Bryan F. J., Hester, K., Barnett, T., Frey, L., \& Relyea, C. (2006). Perceived organizational support and perceived external prestige: Predicting organizational attachment for university faculty, staff, and administrators. Journal of Social Psychology, 146(3), 327347. https://doi.org/10.3200/SOCP.146.3.327-347

Brown, S. (2017). How generations X, Y, and Z may change the academic workplace. Chronicle of Higher Education, 64(4). https://www.chronicle.com/article/How-Generations-XYZ/241185.

Ada Calhoun. (2020). Why we can't sleep. Grove Press.

Cassel, J. (1976). The contribution of the social environment to host resistance. American Journal of Epidemiology, 104(2), 107-123. https://doi.org/10.1093/oxfordjournals.aje.a112281

Center for Scholarship in Teaching and Learning. (n.d.). https://cstl.semo.edu/cstl/FacultyDevelopment/ 
Chao S. F., McCallion P., \& Nickle, T. (2011). Factorial validity and consistency of the Maslach Burnout Inventory among staff working with persons with intellectual disability and dementia. Journal of Intellectual Disability Research 55(5), 529-536 https://www.ncbi.nlm.nih.gov/pubmed/21418367.

Chatterjee, R., \& Wroth, C. (2019, May 28). WHO redefines burnout as a "syndrome" linked to chronic stress at work. National Public Radio. https://www.npr.org/sections/healthshots/2019/05/28/727637944/ who-redefines-burnout-as-a-syndrome-linked-to-chronicstress-atwork

Childress, H. (2019, March 27). This is how you kill a profession. The Chronicle of Higher Education. https://www.chronicle.com/interactives/2019-03-27-childress

Chronicle of Higher Education, The. (2018). Great colleges to work for 2018. https://www.chronicle.com/interactives/greatcolleges 18

Cobb, S. (1995). Social support as a moderator of life stress. In A. M. Eward, J. E. Dimsdale, B. T. Engel, D. R. Lipsitt, D. Oken, J. D. Sapira, ... H. Weiner (Eds.), Toward an integrated medicine: Classics from "Psychosomatic Medicine," 1959-1979. (pp. 377397). American Psychiatric Association. 
Conklin, M. H., \& Desselle, S. P. (2007). Development of a multidimensional scale to measure work satisfaction among pharmacy faculty members. American Journal of Pharmaceutical Education, 71(4), 1-9. https://www.ncbi.nlm.nih.gov/pmc/articles/PMC1959201/.

Craighead, W.E. \& Nemeroff, C.B. (Eds.). (2004). The concise Corsini encyclopedia of psychology and behavioral science (3rd ed.). Wiley.

Creswell, J. W. (2014). Research design: Qualitative, quantitative, and mixed methods approaches (4th ed.). SAGE.

Cutrona, C.E., \& Russell, D. W., (1987). The provisions of social relationships and adaptation to stress. In W.H Jones \& D. Perlman (Eds.), Advances in personal relationships. A research annual. (Vol. 1, pp. 37-67). JAI Press.

Daly, C. J., \& Dee, J. R. (2006). Greener Pastures: Faculty turnover intent in urban public universities. The Journal of Higher Education, 77(5), 776-803.

Doyle, W.R. (2013). Playing the numbers: State funding for higher education: Situation normal? Change, 45(6), 58. https://doi.org/10.1080/00091383.2013.842112

Duffy, M.K., Ganster, D.C., \& Pagon, M. (2002). Social undermining in the workplace. The Academy of Management Journal, 45(2), 331. 
Dutton, J.E. \& Ragins, B. R. (Eds.) (2007). Exploring positive relationships at work. Lawrence Erlbaum Associates.

Eisenberger, R., Huntington, R., Hutchison, S., \& Sowa, D. (1986).

Perceived organizational support. Journal of Applied Psychology, 71(3), 500-507. https://doi.org/10.1037/00219010.71 .3 .500

Eisenberger, R., \& Stinglhamber, F. (2011). Perceived organizational support: Fostering enthusiastic and productive employees. American Psychological Association, 2011.

Fabricant, M., \& Brier, S. (2016). Austerity blues: Fighting for the soul of public higher education. Johns Hopkins University Press.

Faulkner, M., \& Davies, S. (2005). Social support in the healthcare setting: the role of volunteers. Health \& Social Care in the Community, 13(1), 38-45. https://doi.org/10.1111/j.13652524.2005.00526.x

Fink, A. (2017). How to conduct surveys: A step-by-step guide (6th ed).: SAGE.

Finkelstein, M. J., Conley, V. M., \& Schuster, J. H. (2016). The faculty factor: Reassessing the American academy in a turbulent era. Johns Hopkins University Press.

Fogg, P. (2009). When generations collide. Education Digest, 74(6), 2530. 
Fradelos, E., Mpelegrinos, S., Mparo, C., Vassilopoulou, C., Argyrou, P., Tsironi, M., \& Theofilou, P. (2014). Burnout syndrome impacts on quality of life in nursing professionals: The contribution of perceived social support. Progress in Health Sciences, 4(1), 102-109.

Freudenberger, H. J. (1977). Speaking from experience. Training \& Development Journal, 31(7), 26.

Gagliardi, J.S., Parnell, A., \& Carpenter-Hubin, J. (2018). The analytics revolution in higher education: Big data, organizational learning, and student success. Stylus.

Gamson, Z. F., \& Chickering, A. W. (1991). Applying the seven principles for good practice in undergraduate education. JosseyBass Higher and Adult Education Series.

Garvey, J. C., \& Rankin, S. (2018). The Influence of campus climate and urbanization on queer-spectrum and trans-spectrum faculty intent to leave. Journal of Diversity in Higher Education, 11(1), 67-81.

Geertz, C. (1973). The interpretation of cultures: Selected essays. Basic Books.

Gooblar, D. (2018a, April 3). 4 ideas for avoiding faculty burnout. The Chronicle of Higher Education. https://www.chronicle.com/article/4-Ideas-for-AvoidingFaculty/243010 
Gooblar, D. (2018b, April 17). 3 ways colleges can help faculty members avoid burnout. The Chronicle of Higher Education. https://www.chronicle.com/article/3-Ways-CollegesCanHelp/243134.

Gottlieb, B. H., \& Bergen, A. E. (2010). Social support concepts and measures. Journal of Psychosomatic Research, 69(5), 511-520. https://doi.org/10.1016/j.jpsychores.2009.10.001

Häusser, J., Mojzisch, A., Niesel, M., \& Schulz-Hardt, S. (2010). Ten years on: A review of recent research on the Job Demand-Control (-Support) model and psychological wellbeing. Work \& Stress, 24(1), 1-35.

Heffernan, T. A., \& Heffernan, A. (2019). The academic exodus: The role of institutional support in academics leaving universities and the academy. Professional Development in Education, 45(1), 102113. https://doi.org/10.1080/19415257.2018.1474491

Heinemann, L. V., \& Heinemann, T. (2017). Burnout research: Emergence and scientific investigation of a contested diagnosis. SAGE Open, 7(1), 1-12. https://doi.org/10.1177/2158244017697154

Henry, B. J. (2014). Nursing burnout interventions. Clinical Journal of Oncology Nursing, 18(2), 211-214. https://doi.org/ 10.1188/14.CJON.211-214. 
Hill, B., \& Spinella, S. (2018, March 8). The employment picture at MU: More departures than hires. The Columbia Missourian. https://www.columbiamissourian.com/news/higher_education/theemployment-pictureat-mu-more-departures-thanhires/article_841c090c-2234-11e8-8fc9-4ffea3b094f1.html

Horowitz, J., \& Phillips, B. C. (2014). The college completion agenda: Practical approaches for reaching the big goal. Jossey-Bass.

Ivankova, N. V., Creswell, J. W., \& Stick, S. L. (2006). Using mixedmethods sequential explanatory design: From theory to practice. Field Methods, 18(1), 3-20. https://doi.org/10.1177/1525822X05282260

Johnsrud, L. K., \& Heck, R. H. (1998). Faculty worklife: Establishing benchmarks across groups. Research in Higher Education, 39(5), 539.

Johnsrud, L.K., \& Rosser, V.J. (2002). Faculty members' morale and their intention to leave: A multilevel explanation. The Journal of Higher Education, 73(4), 518.

Jones, S., \& Griep, Y. (2018) "I can only work so hard before I burn out." A time-sensitive conceptual integration of ideological psychological contract breach, work effort, and burnout. Frontiers in Psychology 9 (131), 1-14. https://doi.org/10.3389/fpsyg.2018.00131 
Kim, H., \& Rehg, M. (2018). Faculty performance and morale in higher education: A systems approach. Systems Research \& Behavioral Science, 35(3), 308.

King, N. (2016). When a psychologist succumbed to stress, he coined the term "burnout." National Public Radio. https://www.npr.org/2016/12/08/504864961/when-apsychologistsuccumbed-to-stress-he-coined-the-term-burnout

Kingston-Mann, E. \& Sieber, T. (Eds.). (2001). Achieving against the odds: How academics become teachers of diverse students. Temple University Press.

Kleinbaum, D. G., Kupper, L. L., Nizam, A., Muller, K. E. (2008). Applied Regression Analysis and Other Multivariable Methods (4th ed.). Duxbury Press.

Lackritz, J. R. (2004). Exploring burnout among university faculty: Incidence, performance, and demographic issues. Teaching and Teacher Education, 20(7), 713-729. https://doi.org/10.1016/j.tate.2004.07.002

Lammers, J. C., Atouba, Y. L., \& Carlson, E. J. (2013). Which identities matter? A mixed-method study of group, organizational, and professional identities and their relationship to burnout. Management Communication Quarterly, 27(4), 503-536. https://doi.org/10.1177/0893318913498824 
Larson, L. M., Seipel, M. T., Shelley, M. C., Gahn, S. W., Ko, S. Y., Schenkenfelder, M., ... Heitmann, M. M. (2019). The academic environment and faculty well-being: The role of psychological needs. Journal of Career Assessment, 27(1), 167-182. https://doi.org/10.1177/1069072717748667

Lee, A., Thomas, G., Martin, R., \& Guillaume, Y. (2019). LeaderMember Exchange (LMX) ambivalence and task performance: The cross-domain buffering role of social support. Journal of Management, 45(5), 1927-1957. https://doi.org/10.1177/0149206317741190

Levin, J. S., \& Shaker, G. G. (2011). The hybrid and dualistic identity of full-time non-tenuretrack faculty. American Behavioral Scientist, 55(11), 1461-1484. https://doi.org/10.1177/0002764211409382

Lincoln, Y.S., \& Gouba, E.G. (1985). Naturalistic Inquiry. SAGE.

Lounder, A., Wagaman, C., Kenyon, M., Levine, A., Meekins, M., \& O'Meara, K. (2011). Following the cuts: How is the recession affecting faculty work?. Liberal Education, 97(1), 20-29.

Maslach, C., \& Jackson, S. E. (1981). The measurement of experienced burnout. Journal of Organizational Behavior 2(2): 99-113.

Maslach, C., Jackson, S.E. \& Leiter, M.P. (1996). MBI: Maslach burnout inventory: CPP, Incorporated. 
Maslach, C., Schaufeli, W. B., \& Leiter, M. P. (2001). Job burnout.

Annual Review of Psychology, 52(1), 397-423.

https://doi.org/10.1146/annurev.psych.52.1.397

Mayoh, J., \& Onwuegbuzie, A. J. (2015). Toward a conceptualization of mixed methods phenomenological research. Journal of Mixed Methods Research, 9(1), 91-107.

Maxwell, J.A. (2005). Qualitative research design: An interactive approach. $\left(2^{\text {nd }}\right.$ ed.). SAGE.

Merriam, S. B., \& Tisdell, E.J. (2016). Qualitative research: A guide to design and interpretation. (4th ed.). Jossey-Bass.

Mészáros, V., Ádám, Sz., Szabó, M., Szigeti, R., and Urbán, R. (2014). The bifactor model of the Maslach Burnout Inventory-Human Services Survey (MBI-HSS)-An alternative measurement model of burnout." Stress \& Health: Journal of the International Society for the Investigation of Stress. 30(1), 82-88.

Meyer, K., \& Willis, R. (2019). Looking Back to Move Forward: The Value of Reflexive Journaling for Novice Researchers. Journal of Gerontological Social Work, 62(5), 578-585.

https://doi.org/10.1080/01634372.2018.1559906 
Millard, E. (2019). 5 Ways to avoid healthy food burnout. My Fitness Pal. https://blog.myfitnesspal.com/5-ways-to-avoid-healthy-foodburnout/

Mobley, W. (1982). Employee turnover: Causes, consequences, and control. Addison-Wesley.

Moeller, C., \& Chung-Yan, G. A. (2013). Effects of social support on professors' work stress. The International Journal of Educational Management; Bradford, 27(3), 188-202.

Mountz, A. (2016). Women on the edge: Workplace stress at universities in North America. Canadian Geographer, 60(2), 205-218. https://doi.org/10.1111/cag.12277

Moss, G. E. (1973). Illness, immunity, and social interaction. Wiley Interscience.

Mueller, L. (2011). Higher education funding in Missouri. [Doctoral dissertation, University of Missouri]. ProQuest Dissertations and Thesis Global.

Mullen, P. R., Malone, A., Denney, A., \& Dietz, S. S. (2018). Job stress, burnout, job satisfaction, and turnover intention among student affairs professionals. College Student Affairs Journal, 36(1), 94108. https://doi.org/10.1353/csj.2018.0006 
National Center for Educational Statistics. (2016). NCES Fast Facts Tool. https://nces.ed.gov/fastfacts/display.asp?id=61

Newport, C. (2019, February 12). Is email making professors stupid? The Chronicle of Higher Education.

https://www.chronicle.com/interactives/is-email-makingprofessors-stupid

Okeson-Haberman, A. If Missouri college students could party like its 1999, they'd save about 61\% on tuition. National Public Radio. https://news.stlpublicradio.org/post/if-missouricollege-studentscould-party-its-1999-theyd-save-about-61-tuition.

Peirce, G. L., Desselle, S. P., Draugalis, J. R., Spies, A. R., Davis, T. S., \& Bolino, M. (2012). Identifying psychological contract breaches to guide improvements in faculty recruitment, retention, and development. American Journal of Pharmaceutical Education, 76(6), 108. https://doi.org/10.5688/ajpe766108

Perera, H. N. (2016). Construct validity of the Social Provisions Scale: A bifactor exploratory structural equation modeling approach. Assessment, 23(6), 720-733. https://doi.org/10.1177/1073191115589344

Periard, D. A. (2016). A bifactor model of burnout? An item response theory analysis of the Maslach Burnout Inventory - Human Services Survey. [Doctoral dissertation, Wright 
State University]. Proquest Dissertations and Theses Global.

Petersen, A. H. (2019). How millennials became the burnout generation. Buzz Feed.

https://www.buzzfeednews.com/article/annehelenpetersen/millennialsburnoutgeneration-debt-work

Pew Research Center (2019, January 17). The generations defined. Pew Research. https://www.pewresearch.org/facttank/2019/01/17/where-millennials-end-andgeneration-zbegins/ft_19-01-17_generations_2019/

Price, M. \& Kerschbaum, S.L. (2017). Promoting supportive academic environments for faculty with mental illnesses: Resource guide and suggestions for practice. http://tucollaborative.org/wpcontent/uploads/2017/05/Faculty-with-Mental-Illness.pdf

Ramasamy, V., \& Abdullah, N. H. B. (2017). Faculty’s turnover in private higher learning Institutions: A phenomenal inquiry. Business and Economic Horizons; Prague, 13(2), 169-181.

Rankin, S. R., Weber, G., Blumenfeld, W., \& Frazer, S. (2010). 2010 state of higher education for lesbian, gay, bisexual, and transgender people. Campus Pride.

Reevy, Gretchen M., and Deason, G. (2014) Predictors of depression, stress, and anxiety among non-tenure track faculty. Frontiers in Psycholog.y 5, 1-17. https://doi.org/10.3389/fpsyg.2014.00701. 
Rev.com, Inc. (2019). Temi (version \# 1.12) [Mobile application software]. https://itunes.apple.com/us/app/temi-record-andtranscribe/id1269856195

Rosser, V.J. (2004). Faculty members' intentions to leave: A national study on their worklife and satisfaction. Research in Higher Education. 45(3): 285-309. https://doi.org/10.1023/B:RIHE.0000019591.74425.f1.

Rosser, V.J. (2005). Measuring the change in faculty perceptions over time: An examination of their worklife and satisfaction. Research in Higher Education. 46(1) 81-107. https://doi.org/10.1007/s11162-004-6290-y.

River City University Office of Institutional Research. (2017). Fast facts. http://www.semo.edu/ir/facts.html

Rubin, P. G. (2018). The policy filtering process: Understanding distinctive state responses to the national college completion agenda in the United States. Education Policy Analysis Archives, 26(60).

Sabagh, Z., Hall, N. C., \& Saroyan, A. (2018). Antecedents, correlates, and consequences of faculty burnout. Educational Research, 60(2), 131-156. https://doi.org/10.1080/00131881.2018.1461573 
Schaufeli, W. B., Bakker, A. B., Hoogduin, K., Schaap, C., \& Kladler, A. (2001). On the clinical validity of the Maslach Burnout Inventory and the Burnout Measure. Psychology \& Health, 16(5), 565.

Schulz, A. D., Schöllgen, I., \& Fay, D. (2018, July 12). The role of resources in the stressor-detachment model. International Journal of Stress Management. http://dx.doi.org/10.1037/str0000100

Seidman, I. (2013). Interviewing as qualitative research: A guide for researchers in education and the social sciences. Teachers College Press.

Seipel, M. T., \& Larson, L. M. (2018). Supporting non-tenure-track faculty well-being. Journal of Career Assessment, 26(1), 154-171. https://doi.org/10.1177/1069072716680046

Shumaker, S., \& Brownell, A. (2010). Toward a theory of social support: Closing conceptual gaps. Journal of Social Issues, 40, 11-36. https://doi.org/10.1111/j.15404560.1984.tb01105.x

Simmons, B. L. (2014). Organizational characteristics of happy organizations. In C. L. Cooper (Ed.), Wellbeing: a complete reference guide. Wiley. 
Stahl, R. (2017, November 17). What if I invest in them, and then they leave? Fund the People. http://fundthepeople.org/what-if-i-investin-them-and-then-they-leave/

Strauss, A., \& Corbin, J. (1998). Basics of qualitative research: Techniques and procedures for developing grounded theory ( 2 nd ed.). SAGE.

Szigeti, R., Noémi B., Réka B., \& Urbán R. (2017). Burnout and depressive symptoms in teachers: Factor structure and construct validity of the Maslach Burnout Inventory-Educators Survey among elementary and secondary school teachers in Hungary. Stress and Health: Journal of the International Society for the Investigation of Stress. 33(5), 530-39. https://doi.org/10.1002/smi.2737.

Taris, T.W.. (2006). Bricks without clay: On urban myths in occupational health psychology. Work and Stress, 99. https://doi.org/10.1080/02678370600893410

Temi. Are my files private and secure? (2019, September 22). Temi. http:/help.temi.com/en/articles/1594946-are-my-files-private-andsecure

Thompson, T., \& Thompson, T. (Eds.). (2014). Encyclopedia of health communication. SAGE.

Tinto, V., \& Goodsell-Love, A. (1993). Building community. Liberal Education, 79(4), 16. 
Tollinche, S. (2013). Stress buster: Introducing quiet time for neonatal nurses. JOGNN: Journal of Obstetric, Gynecologic \& Neonatal Nursing, 42 (1), S69. https://doi.org/ 10.1111/1552-6909.12154.

Umbach, P. D., \& Wawrzynski, M. R. (2005). Faculty do matter: The role of college faculty in student learning and engagement. Research in Higher Education, 46(2), 153-184. https://doi.org/10.1007/s11162-004-1598-1

Walkey, F. H., Siegert, R. J., McCormick, L. A., \& Taylor, A. J. W. (1987). Multiple replication of the factor structure of the Inventory of Socially Supportive Behaviors. Journal of Community Psychology, 15(4), 513.

Watanabe, M., \& Falci, C. D. (2016). A demands and resources approach to understanding faculty turnover intentions due to work-family balance. Journal of Family Issues, 37(3), 393-415. https://doi.org/10.1177/0192513X14530972

Watts, J., \& Robertson, N. (2011). Burnout in university teaching staff: A systematic literature review. Educational Research, 53(1), 33-50. https://doi.org/10.1080/00131881.2011.552235

Wei, Y., Chu, H., Chen, C., Hsueh, Y., Chang, Y., Chang, L., \& Chou, K. (2012). Support groups for caregivers of intellectually disabled 
family members: Effects on physical, psychological health, and social support. Journal of Clinical Nursing, 21(11/12), 16661677.

Weiss, R. (1974) The provisions of social relationships. In: Rubin, Z., Ed., Doing unto others, (pp. 17-26). Prentice Hall.

World Health Organization. (2018). International statistical classification of diseases and related health problems (11th Revision). https://icd.who.int/browse11/1-m/en

Yin, R. K. (2009). Case study research: Design and methods. SAGE.

Zahneis, M. (2018, June 29). As word of layoffs spreads, Western Illinois faculty members brace for the worst. The Chronicle of Higher Education. https://www.chronicle.com/article/AsWord-of-Layoffs-Spreads/243810

Ziker, J. (2014, April 13). How professors use their time: Faculty time allocation. https://thebluereview.org/faculty-time-allocation/ 


\section{SECTION TWO:}

\section{PRACTITIONER SETTING FOR THE STUDY}

This study took place at River City University (RCU), a regional

public university located in the Midwest. In this section, the history of the organization will be described, and an organizational, as well as leadership analysis, will be provided. I will also discuss the implications for conducting research in a setting where I work.

\section{History of the Organization}

RCU is located in River City, a city that evolved from a small village surrounded by swampland to a bustling river community over almost three centuries (Criblez \&

Dunn, 2019). RCU was founded in 1873 as a teaching college, The Third District Normal School (Criblez \& Dunn, 2019). As the school grew, its name changed several times to more accurately describe its function: from "Teachers College" in 1919 to "State College" in 1946 and finally "River City University” in 1972 (Criblez \& Dunn, 2019). In the fall of 2019, RCU reported a head-count enrollment of 10,637 at its main and regional campuses combined, down from 11,071 students a year ago and 11,501 students in 2017 (Bliss, 2019). While RCU boasts a 75.3\% retention rate, the enrollment reflects state-wide trends: head-count enrollment at state colleges has declined by about $10 \%$ over the five-year period ending in 2018 (Bliss, 2019). Academic reorganization took place at RCU in 
response to state budget cuts in 2018. Five colleges and one school were reduced into five colleges, six positions and two administrative stipends were eliminated, multiple departments were merged, and annual operating costs were reduced by $\$ 691,430$ (Hartnett, 2018; RCU Newswire, 2018).

\section{Organizational Analysis}

RCU has a traditional bureaucratic structure with a Board of Regents, President, Provost, College Deans, and Department Chairs (RCU, 2017). As such, the organization of RCU fits what Bolman \& Deal (2013) refer to as the structural frame. Bolman \& Deal (2013) describe frames as

"a coherent set of ideas or beliefs forming a prism or lens that enables you to see and understand more clearly what goes on from day to day" (p. 41).

The structural frame is undergirded by the following six assumptions:

- Organizations exist to achieve established goals and objectives.

- Organizations increase efficiency and enhance performance through specialization and appropriate division of labor.

- Suitable forms of coordination and control ensure that diverse efforts of individuals and units mesh.

- Organizations work best when rationality prevails over personal agendas and extraneous pressures. 
- Effective structures fit an organization's current circumstances.

- Troubles arise and performance suffers from structural deficits, remedied through problem-solving and restructuring (p. 45).

Using these assumptions, I will analyze the organizational structure of RCU. While Bolman \& Deal (2013) encourage "multi-frame thinking" (p.18), for this analysis, I wanted to focus on the architecture of the organization. Thus, the "design of the units and subunits, rules and roles, goals and policies" (Bolman \& Deal, 2013, p. 21) will take precedence.

RCU's goals and objectives are made clear in its mission statement which states that it "provides student-centered education and experiential learning with a foundation of liberal arts and sciences, embracing a tradition of access, exceptional teaching, and commitment to student success that significantly contributes to the development of the region and beyond" (RCU Mission \& Vision Statements, 2019, para.1). Faculty and staff have been frequently reminded of this mission statement, especially as a Higher Learning Commission visit which took place in the fall of 2019 .

The specialization and division of labor are exemplified in the vertical coordination of the organizational structure charts RCU utilizes (RCU Faculty Senate, 2019). The two main charts are the administrative 
organizational chart and the academic affairs organizational chart. The administrative chart shows the Board of Regents at the top of the pyramid, followed by the President of the University. The next layer consists of Finance and Administration, Enrollment Management and Student Success, Faculty Senate, Academic Affairs, University Advancement, and University Foundation, Intercollegiate Athletics, Institutional Research and Institutional Equity and Diversity and Dean of Students (RCU Faculty Senate, 2019). Under each of those offices are a variety of other offices and their directors (RCU Faculty Senate, 2019). The academic affairs chart shows the Provost and Faculty Senate sharing the top tier. The second tier consists of the Vice-Provost, Dean of the College of Business and Computing, Dean of the College of Education, Health and Human Studies, Dean of the College of Arts and Media, Dean of the College of Humanities and Social Sciences, Dean of the College of Science, Technology, Engineering and Mathematics, Dean of the Library, Dean of Regional Campuses, Director of Aerospace Studies and Director of Military Science (RCU Faculty Senate, 2019). Under each of the Deans are the Chairs of the departments within that college (RCU Faculty Senate, 2019).

Organizations have to use both vertical and lateral procedures for coordination. The optimal blend of the two depends on the unique challenges of the organization (Bolman \& Deal, 2013). Lateral organization is evident in the way RCU coordinates and controls the efforts of diverse groups and individuals to work in unison. Task forces, 
committees, and meetings are utilized to achieve goals. For example, while the Office of the Provost may provide the criteria for creating Course Learning Outcomes (CLOs), the Provost does not know about each subject and each class to create the CLOs. Departments attend meetings to hear about the criteria. Instructors who teach different sections of the same course may form a committee to create the CLOs for that course, while instructors who teach all the sections of a particular course will create the CLOs themselves. Thus, the goal of having standardized CLOs for every course offering at RCU is reached.

As Bolman \& Deal (2013) point out, some organizations are more susceptible to outside influences than others are. They use the example of public universities being highly vulnerable to external pressures because they have so little capacity to claim the resources they need or to shape the results they are supposed to produce. In contrast, a private Ivy League university can afford to offer low teaching loads, generous salaries, and substantial faculty autonomy because the institution is insulated by its size, elite status, and large endowment (Bolman \& Deal, 2013). RCU, thus, has the challenge of overcoming external pressures. The influence of RCU's student government and faculty senate can help rationality prevail.

The recent academic restructuring is an example of RCU modifying structures to fit current circumstances. RCU had to make strategic decisions that were concerned with the long-term direction in the 
face of financial uncertainty. Complexity and formality increase with size and age and turbulent environments require more complex, flexible structures (Bolman \& Deal, 2013). This can create a problem for an almost 150-year-old educational institution facing a financial crisis that employs "more educated and professional workers who need and want greater autonomy and discretion" (Bolman \& Deal, 2013, p. 61). In the case of academic restructuring, faculty were reminded there is "no such thing as an ideal structure" (Bolman \& Deal, 2013, p. 60).

RCU has witnessed how trouble can arise and performance can suffer from structural deficits. Efforts have been made to utilize problemsolving and restructuring to solve these problems. In addition to the example of academic restructuring, the President's office was reorganized in 2017 when the Director of Institutional Diversity and Equity became the Assistant to the President for Equity and Diversity and the Dean of Students at RCU. (RCU Newswire, 2017). This change was in line with the other efforts RCU had made to enhance equity and diversity across the campus and allowed the Offices of Institutional Equity and Diversity, and Enrollment Management and Student Success, to be more strategic in their work and better focus on key University initiatives, including increasing the retention and graduation rates of students (RCU Newswire, 2017).

There is no one best way to organize, but RCU is structured to divide work through a variety of specialized roles, functions, and units 
that are tied together using both vertical and lateral procedures. The organization strives to put people in the right roles and relationships through formal arrangements that can accommodate both collective goals and individual differences (Bolman \& Deal, 2013).

\section{Leadership Analysis}

When the faculty senate conducted a survey to determine faculty concerns, the two biggest ones were communication and shared governance (R.R. Mascot, personal communication, October $20^{\text {th }}, 2018$ ). The Chronicle of Higher Education's Great Colleges to Work For 2018 survey of RCU faculty found the domains of collaborative governance (measured by responses to five statements, such as "The role of faculty in shared governance is clearly stated and publicized") and confidence in senior leadership (measured by responses to six statements such as “Senior leadership provides a clear direction for this institution's future”) were some of RCU's weakest areas.

Some of the sources of frustration with leadership could be best explained using the Path-Goal Leadership Theory (Northouse, 2016). This theory suggests that as followers' perceptions of their abilities and competence go up, the need for directive leadership goes down. Directive leadership, which sets clear standards for performance and makes the rules and regulations clear to followers, can seem excessively controlling when followers feel competent to complete their work (Northouse, 2016). 
Another challenge for leadership is that despite integration in 1954 and efforts to recruit minority students, in the last decade, RCU's minority enrollment has remained low: 8\% African American, $2 \%$ Hispanic, and 1\% Asian (Criblez \& Dunn, 2019). However, in 2018, RCU did boast 600 international students from 63 different countries. The current university President is an immigrant and enjoys a positive relationship with minority and international students. Students often comment on appreciating his authentic leadership style, a style that is characterized by its interpersonal, relational nature (Northouse, 2016).

\section{Implications for Research in the Practitioner Setting}

One of the greatest challenges I faced in this research was being employed in the setting where the research was taking place. However, I felt this problem of practice, faculty burnout, and its mitigators was vitally important to my colleagues and me. I strived to be objective by using reflexive journaling (Meyer \& Willis, 2019) and member checking (Lincoln \& Guba, 1985).

Reflexive journaling can support the navigation of procedural and ethical challenges (Meyer \& Willis, 2019) of being a participant researcher while member checking provides an opportunity to test the credibility of the themes found during interviewing with the interviewees (Lincoln \& Guba, 1985). I engaged in reflexive journaling weekly as I contemplated my progress on the dissertation-in-practice. 
Member checking took place after I completed the initial coding of themes based on the qualitative interviews.

\section{Summary}

Through describing the history of RCU, analyzing its organizational structure, and analyzing its leadership, I have attempted to paint a picture of the practitioner setting for this study. I have also described my challenge to be an unbiased observant while conducting research in the setting where I work. The theoretical framework of this study will be further discussed to illustrate the criticality of this study. 


\section{References}

Bliss, M. (2019). RCU sees enrollment decline even with record retention rate. The Southeast Missourian. https://www.semissourian.com/story/2636602.html

Bolman, L. G., \& Deal, T. E. (2013). Reframing organizations: Artistry, choice, and leadership (5th ed.). Jossey-Bass.

Criblez, A., \& Dunn, R. (2019). The History of River City University. In First-Year Seminar: Connecting to RCU (3rd ed., pp. 17-33). Fountain Head Press.

Hartnett, K. (2018, January 22). Restructuring proposal merges colleges, realigns departments. The Arrow. https://www.southeastarrow.com/story/2479770.html

Lincoln, Y.S., \& Gouba, E.G. (1985). Naturalistic Inquiry. SAGE.

Meyer, K., \& Willis, R. (2019). Looking Back to Move Forward: The Value of Reflexive Journaling for Novice Researchers. Journal of Gerontological Social Work, 62(5), 578-585. https://doi.org/10.1080/01634372.2018.1559906

Northouse, P.G. (2016) Leadership: Theory and practice ( $7^{\text {th }}$ ed.). SAGE.

River City University Faculty Senate. (2019).

https://semo.edu/facultysenate/handbook/1f.html 
River City University Mission and Vision Statements (2019).

https://semo.edu/planning/mission-vision.html

River City University Newswire (2017). Rucker named Asst. To the President for Equity and Diversity, Dean of Students.

https://news.semo.edu/rucker-named-asst-to-the-presidentforequity-and-diversity-dean-of-students-at-southeast/

River City University Newswire (2018). Regents approve major academic reorganization. https://news.semo.edu/regents-approve-major-academicreorganization/ 


\section{SECTION THREE:}

\section{SCHOLARLY REVIEW FOR THE STUDY}

This study utilizes the following conceptual and theoretical frameworks: burnout (Freudenberger, 1977; Maslach, et al., 1981; World Health Organization, 2018); social support (Moss, 1973; Barrera, et al., 1981; Barrera, 1986; Cutrona \& Russell, 1987; Faulkner \& Davies, 2005; Maslach, et al., 2001; Weiss, 1974), the buffering hypothesis (Cassell, 1976; Cobb, 1976; Cohen \& McKay, 1984; Craighead \& Numeroff, 2004; LaRocco, et al., 1980), and institutional support (Conklin \& Desselle, 2007; Simmons, 2014) or perceived organizational support (Eisenberger, et al., 1986; Eisenberger \& Stinglhamber, 2011). Research is drawn from the areas of education, psychology, health communication, and organizational communication that focuses on burnout, social support, institutional support or perceived organizational support, and positive relationships at work (Dutton \& Ragins, 2007) or "working well" (GeistMartin \& Scarduzio, 2014), as well as faculty member's intent to leave (Rosser, 2004; 2005).

Because the context of faculty burnout takes place in the changing landscape of higher education, the literature surrounding those changes, as well as literature on faculty compensation, is included. Similarly, because burnout can affect an individual's health—their physical, mental, and social well-being (World Health Organization, 1948)—literature regarding 
how burnout impacts faculty health is reviewed in addition to literature detailing how it impacts their work and their institutions.

Specific research is included regarding the measures that will be used in the study, which are the Maslach Burnout Inventory-Educators Survey or MBI-ES (Maslach \& Jackson, 1981; Maslach, et al., 1996), the short version of the Social Provisions Survey or SPS (Cutrona \& Russell, 1987) and questions from the second domain of the multidimensional work satisfaction scale developed by Conklin \& Desselle (2007). This literature provides support for my study to determine what seems to serve as the greatest mitigator of faculty burnout, as well as what may be best practices for academic units to reduce faculty burnout and turnover. Determining these mitigators and practices may guide administrators to positively affect faculty burnout by developing policies and procedures which promote positive relationships at work and positively impact faculty health. Reducing faculty burnout could also have a positive institutional effect of increasing student retention.

\section{Review of Extant Scholarship}

\section{Burnout}

Burnout is one of the most widely discussed mental health problems in modern society; however, the legitimacy of its status as a mental health condition is still disputed (Heinemann \& Heinemann, 
2017). The casual use of "burnout" in the popular lexicon (Bolanos, 2019; Millard, 2019; Petersen, 2019) has served to dilute the public's perception of the seriousness of burnout. Despite these misgivings, the World Health Organization, in 2018, labeled burnout as a "syndrome," clarifying that it "refers specifically to phenomena in the occupational context and should not be applied to describe experiences in other areas of life" (2018). In other words, unlike depression, which tends to pervade every domain of a person's life, burnout is a problem that is specific to the work environment (Freudenberger, 1977).

Burnout can manifest in physical symptoms, such as frequent headaches, back pain, insomnia and being more susceptible to catching colds or flu (Belcastro \& Gold, 1983; Hock, 1988), as well as cognitive impairment (Golonka, et al., 2017). Burnout is also associated with paranoid ideation (Bianchi \& Janin, 2019), anxiety (Golonka et al., 2019), and negative coping behaviors, such as substance abuse (Jackson \& Maslach, 1982). Additionally, there is significant documentation in the healthcare professions that burnout is also associated with suicide (Card, 2018), which suggests that burnout may be related to suicide in other professions as well. There isn't enough data specific to suicide rates and occupation to confirm that academics are more likely to die by suicide; however, correlations may be made between lifestyle and suicide, and the changing nature of the academe can be a cause of psychological distress (Flaherty, 2013). The most common effect of burnout is depression 
(Schonfeld, et al., 2019). This close link between the development of burnout in the workplace with the development of depressive disorders that extend beyond the workplace similarly contributes to the disinclination of some scholars and mental health practitioners to code burnout as a mental health condition distinct from the depression it engenders. In fact, Bianchi, et al. propose that because burnout is hard to diagnose as a mental condition, it may not serve the goal of promoting occupational health (2019). Instead, they posited a depression construct may offer occupational health specialists a better way to monitor and protect workers' health (Bianchi, et al., 2019).

Although it is unclear precisely what causes burnout, Maslach, et al. (2001) postulated that the best and most idealistic workers are the most likely to experience burnout-e.g., "You have to have been on fire to burn out" (p.405). This interpretation implies that people who are the most dedicated to their jobs are the most likely to do too much in support of their ideals, which leads to exhaustion, depersonalization, and the feeling of a lack of personal achievement when their sacrifice is insufficient to achieve their goals. Furthermore, previously meaningful work can produce negative effects on employee's well-being, as employees feel so invested in their work that they push themselves beyond their limits resulting in strain and susceptibility to burnout (Jones \& Griep, 2018; Reevy \& Deason, 2014).

Because Freudenberger (1977) believed that burnout is particularly linked to specific working environments and organizational 
contexts, he proposed intervening at an organizational rather than just an individual level. His recommendations included shorter working hours, regular job rotation, and frequent supervision and staff training (Freudenberger, 1977; Heinemann \& Heinemann, 2017). Because colleagues impact one another, there is also concern among scholars that burnout within an institution may be "contagious" (Bakker, et al., 2005). When employees' health is affected by burnout, their organizations are affected as well. Burnout has a serious socio-economic impact in terms of decreased level of productivity, high resignation rate, and premature retirement (Golonka et al., 2019). The turnover from resignations and early retirements can be particularly detrimental in higher education, as turnover can be costly to the reputation of an institution and jeopardize the quality of instruction (Daly \& Dee, 2006; Ramasamy \& Abdullah, 2017). Also, heavy turnover results in reduced integration within the academic department, disruption of course offerings, and diminished morale among those employees who remain in the organization (Mobley, 1982; Price, 1997). These disruptions can have a direct impact on program enrollment as they risk the development of important connections between students and faculty that encourage student retention (Tinto \& Goodsell-Love, 1993).

This study utilized the 22-item MBI-Educators Survey (MBI-ES) to assess faculty burnout. The MBI-ES addresses three scales: emotional exhaustion (EE), which measures feelings of being emotionally 
overextended and exhausted by one's work, depersonalization (DP), which measures an unfeeling and impersonal response toward recipients of one's instruction, and personal accomplishment (PA), which measures feelings of competence and successful achievement in one's work (Maslach, 1996). The MBI is the most popular measurement of burnout and the validity of this scale has been confirmed through numerous studies, documented in the meta-analysis by Schaufeli, et al. in 2001. More recently, researchers have found that a model that yields a global burnout score is more reliable than the subscale scores (Mészáros et al., 2014; Periard, 2016; Szigeti et al., 2017).

\section{Social Support and the Buffering Hypothesis}

Social support is the most extensively studied resource in the prevention of burnout (Ray \& Apker, 2011). Consistent findings and a strong body of literature demonstrate that a lack of social support is linked to burnout (Bremer \& Brooks, 2018; Maslach, et al., 2001). Social support was first described by Moss (1973) as a safe communication network (Goldsmith \& Albrecht, 2011). In the last four decades, the definition of social support has evolved to include a broad category of communicative behaviors that are enacted to assist another person or persons (Thompson \& Thompson, 2014). Social support has also been defined as the exchange of resources with the intent to enhance well-being (Shumaker \& Brownell, 2010). Faulkner and Davies (2005) divide types of support into four broad components: appraisal (helping individuals to 
evaluate the personal relevance or impact of their circumstances), emotional (providing encouragement and enhancing self-esteem), instrumental (providing tangible resources to remove, or significantly reduce, the stressful situation experienced by an individual), and informational (providing individuals with information enabling them to deal with their problems). Weiss (1974) characterized six categories of relational provisions of social support: attachment (a sense of security), social integration (network membership), opportunity for nurturance (taking responsibility for the wellbeing of a child), reassurance of worth (which attest to an individual's competence in a social role), a sense of reliable alliance (kin ties), and the obtaining of guidance (access to a trustworthy figure who can furnish emotional support and assist in developing a plan of action).

Around the same time Moss (1973) was studying the linkages between illness, immunity, and social interaction, John Cassel, an epidemiologist, and Sidney Cobb, a psychiatrist, published articles arguing social ties could protect people from the negative effects of stressful events (Cassel, 1976; Cobb, 1976; Cohen \& Pressman, 2004; Goldsmith \& Albrecht, 2011), establishing the stress-buffering hypothesis. The buffering hypothesis asserts that "social support provides protection against the stress that produces psychological or physiological disorder or disease or reduces job performance" (Craighead \& Numeroff, 
2004, para. 1). In other words, social support from coworkers can buffer the effects of job stressors (Lee, et al., 2019; Schulz, et al., 2018).

Key sources of social support in the workplace include coworkers, leaders, and the organization itself (Lee, et al., 2019). The cross-domain buffering hypothesis of social support suggests social support from a different domain (e.g., coworker or organizational support) should be particularly effective at reducing the negative consequences of a stressor from another domain (Duffy, et al., 2002). For example, if a supervisor is alternately ambivalent and supportive, the support from the supervisor does not protect a worker from stress. However, if a coworker is supportive when a supervisor is ambivalent, the support does reduce the negative consequences of the stress the worker may experience (Lee, et al., 2019). Barrera (1986) distinguished between measurements of perceived vs. actual or enacted support, a distinction that has proved critical because perceived support, not its actual materialization, has been found to be largely responsible for the buffering effects of support. Not all studies have found social support to have this buffering effect with burnout (Padilla \& Thompson, 2016) and the hypothesis has been described as a "brick without clay" (Taris, 2006, p. 99). For example, the Job Demand-Control (Support) Model (JDCS) predicts work situations, characterized by high demands, low control, and low social support, to be most harmful to workers' well-being (Johnson \& Hall, 1988). Fila (2016) argued that despite its popularity and longevity, the model has been 
widely criticized for a predominance of self-report versus objective measurement, cross-sectional rather than longitudinal study design, variety and inconsistency in how the three main dimensions are measured, and a lack of consideration of individual difference variables. Yet, a metaanalysis of ten years of research regarding the JDCS found buffering effects do exist (Häusser, et al., 2010).

Because it measures perceived support and is one of the most widely used measures of perceived social support in psychological literature, the short version of Cutrona \& Russell's 1987 Social Provisions Scale (SPS) was used in this study. The SPS is based on Weiss's (1974) model of social provisions, which distinguishes the assistance-related functions of social ties (i.e., reassurance of worth, guidance, and reliable alliance) from their non-assistance-related functions (i.e., opportunity for nurturance, attachment, and social integration). The short version of the SPS is a 10-item measure that includes five of the six original SPS subscales, with one positively worded and one negatively worded item representing each. The Opportunity to Provide Nurturance subscale was omitted in the short version because it taps perceptions that one provides support to others rather than perceptions of receiving support (Gottlieb \& Bergen, 2010). Based on samples of 1792 respondents across several studies, including students, nurses, and public school teachers, the SPS showed excellent overall internal consistency (Cutrona \& Russell, 1987; Gottlieb \& Bergen, 2010) and construct validity (Parera, 2016). 


\section{Institutional Support}

In 1986, Eisenberger, et al. developed a measurement for perceived organizational support (POS) that was based on the social exchange view that "employees' commitment to the organization is strongly influenced by their perception of the organization's commitment to them. Perceived organizational support is assumed to increase the employee's affective attachment to the organization and his or her expectancy that greater effort toward meeting organizational goals will be rewarded" (p. 500). They found employees form global beliefs concerning the extent to which the organization values their contributions and cares about their well-being and that such perceived organizational support reduces absenteeism (Eisenberger, et al., 1986). Rhoades \& Eisenberger' 2002 review of over 70 studies on POS suggests that "basic antecedents of POS include fair organizational procedures, supervisor support, and favorable rewards and job conditions and that consequences include increased affective commitment to the organization, increased performance, and reduced withdrawal behaviors" (p. 712).

In their 2011 book, Eisenberger \& Stinglhamber used studies to illustrate Organizational Support Theory. This theory holds that “employees personify the organization, viewing it as having a personality with benevolent or malevolent intentions toward them" (p. 39) and that employees' perceptions of organizational support depend on whether they feel their organization is constrained by such things as government 
regulations. Organizational Support Theory maintains several features of perceived organizational support contribute to favorable consequences for employees and their organizations: felt obligation to the organization, expectation of reward for increased effort, meeting socioemotional needs, and expectation that help will be available when needed to perform one's job better (Eisenberger \& Stinglhamber, 2011).

Djurkovic, et al. (2008) reported perceived organizational support moderates the relationship between workplace bullying and victims' intention to leave. Rosser (2004) found the quality of faculty members' worklife is important to faculty members' satisfaction and explains faculty members' intentions to leave: faculty members with higher levels of satisfaction are less likely to leave their institution or their career. Bryan, et al. (2006) found that "visibility within the organization, perceived opportunities for growth, and participation in decision-making were all related to perceived respect" (p. 815). A participatory atmosphere in which employees are involved in workplace decision making, share ideas, and voice concerns are associated with lower stress and burnout (Dir, et al., 2019; Slate \& Vogel, 1997).

Similarly, Akgunduz, et al. observed participatory management increased employees' creativity and their perception of the meaningfulness of their work (2018). Heffernan \& Heffernan (2019) found that professional development and career support available to 
academics played major roles in their career satisfaction. There is some overlap between institutional support and social support, as Avanzi, et al. found group members who strongly identify with their organization are particularly likely to experience social support from their colleagues (2015). The demographic question regarding college will be included in the questionnaire to help identify if this link is apparent among faculty at RCU.

While burnout is frequently associated with professions that have a human services component, such as social work, healthcare, and teaching, Demerouti, et al. (2001) found that it could happen in any profession based on the Jobs-Demand Resource Model (J-DRM). The JDRM proposes that demanding aspects of work lead to overtaxing and exhaustion, and a lack of resources complicates the meeting of job demands which leads to withdrawal behavior (Demerouti, et al., 2001). Job demands are strains that negatively impact one's physical, emotional, and mental health and job performance, while job resources mitigate negative effects of job demands (Dir, et al., 2019). This would suggest that in addition to social support, institutional or organizational support can protect against faculty burnout.

Despite research that implicates organizational change as key factors in improving job satisfaction and individual well-being and a greater emphasis on workplace wellness in recent years (Cahalin, et al., 
2015), many organizations focus on offering programs to enhance physical health and reduce insurance expenditures rather than on changing working conditions or the organizational culture which can be inherently stressful (Geist-Martin \& Scarduzio, 2011). So, while employees are offered wellness tips at a micro-level at work, at a macro-level, the organizations do not provide other policies and practices that positively impact employee health (Geist-Martin \& Scarduzio, 2011; Montoya \& Trethewey, 2009).

While the terms "organizational support" and "institutional support" are often used interchangeably throughout the literature on work and wellbeing (Simmons, 2014), "organizational support" is more frequently used in studies on businesses, such as Wal-Mart and Costco, rather than institutions of higher learning. Conklin \& Desselle (2007) created a domain in their faculty work satisfaction scale entitled "Institutional Support and Reward" (p. 5). Because that measurement was used in the survey, the particular mitigating variable for this study was termed "institutional support." Institutional support was measured by using questions adapted from the second domain of the multidimensional work satisfaction scale developed by Conklin \& Desselle (2007). Participants were asked to rate 6 items: general support from my department/division chair, general support from my dean, general support from upper administration, including provost and president, institutional efforts in support of the career development of their faculty, salary 
competitive with other schools, and distribution of rewards (i.e., salary) based on merit. While this scale is not as frequently cited as the other measures being used for the study, it has demonstrated high degrees of construct and discriminant validity (Conklin \& Desselle, 2007, 2010; Peirce, et al., 2012), perhaps because it is specific to the type of organization - a college or university.

A component of the support one receives from the organization that employs them is the amount of monetary compensation they are given for their work. Indeed, Eisenberger \& Stinglhamber (2011) note that wage disparity is one of the signs of uncaring management. When observing disparities between administrative and faculty salaries, faculty may feel akin to the autoworkers who discovered that while they agreed to a contract that wouldn't keep up with the cost of living to prevent layoffs, managers received pay raises (Eisenberger \& Stinglhamber, 2011). There are various faculty attributes and activities that influence compensation, including academic rank, faculty productivity, discipline market pay, ability to obtain external grants, seniority or length of service to the institution, serving in administrative positions, professional service, graduate teaching, and guidance, but there may be differences in compensation that result from purely subjective factors at some institutions (Sutton \& Bergerson, 2001). Faculty satisfaction with compensation has been correlated with increased organizational commitment (Cockerham, 2016; Huang Chih-Hsuan, 2012) as well as 
increasing faculty productivity, improving cost efficiency, and enhancing their institutions' public images (Sutton \& Bergerson, 2001). Thus, an important demographic question that was included in the questionnaire asked participants to report their gross salary. The responses were later sorted into salary tiers.

\section{Studies Related to Burnout Interventions}

As discussions of burnout became more common in public and scholastic discourses, scholars from across disciplines began theorizing and studying possible interventions to help prevent or stymy burnout. Social support interventions have sought to train individuals to seek and utilize social support more effectively, improve the quality of supportive actions in primary relationships, and alter community norms regarding the communication of support and community support in groups, such as selfhelp groups (Goldsmith \& Albrecht, 2011). Social support (particularly from supervisors and co-workers) has consistently been found to be predictive of measures of physical and mental health among workers in a variety of occupations (House, 1981). Research in health and organizational communication have examined the role of social support, both at work and in personal relationships, in mitigating burnout (Chao, et al., 2011; Faulkner \& Davies, 2005; Fradelos, et al., 2014; Jones \& Griep, 2018; Lammers, et al., 2013; Wei et al., 2012). To fight burnout, healthcare organizations have tried an assortment of interventions including facilitated discussion groups (Brian \& Carter, 2004), mindful 
meditation (Tollinche, 2013), and retreats (Henry, 2014) with mixed success. Correctional officers who were involved in organizations that developed formal mentoring programs showed greater protections against burnout (Farnese, et al., 2017) and an organizational intervention to provide more flexibility for information technology workers was successful in reducing burnout (Moen et al., 2016).

Studies involving burnout intervention in educators have focused more frequently on PreK-12 teachers. A study on preschools in Italy found organizations were able to assuage the burnout of their aging workforce of teachers when they intervened by engaging them in more ergonomically designed workplaces, meeting with them for psychological counseling during the workday, and providing time for group meetings to increase support from colleagues (Sottimano, et al., 2018). PreK-12 teachers with supportive supervisors report less emotional exhaustion, more positive attitudes toward students, and greater personal accomplishment (Russell, et al., 1987).

Because of the increased emphasis on addressing student stress and trauma, more K-12 schools are finding that failing to address the mental health needs of teachers may affect their ability to address critical needs among students (Cox, et al., 2018; Hicklin, 2020). Educators in a study utilizing Mindfulness Training (MT) reported large declines in occupational stress and symptoms of burnout, anxiety, and depression (Rosser et al.,2013). Mindfulness can be thought of as, "moment-to- 
moment, non-judgmental awareness, cultivated by paying attention in a specific way, that is, in the present moment, and as non-reactively, as non-judgmentally, and as openheartedly as possible" (Kabat-Zin, 2015, p. 1481). Similarly, a professional development intervention involving a program called CARE (Cultivating Awareness and Resilience in Education) resulted in promoting resilience and improving the performance of teachers and their students in high-risk settings (Jennings et al., 2011).

However, this statement from Heinemann \& Heinemann's extensive review of burnout research reflects the current status of the literature on faculty burnout:

"The concept of burnout and its investigation in the health sciences must be put into a broader social context, and theoretically reflected. So far, no analysis of the social conditions has been conducted that might explain the rise of burnout as a metaphor or a clinical sign for working conditions in today's society... it is crucial to systematically study the social framing and societal aspects of this diagnosis.” (2017, p. 9)

This study, which examines burnout among university faculty, contributes to the body of literature that will provide a context of burnout in education. 


\section{Summary}

While there have been studies on faculty burnout which look at interventions (Black, 2004; Padilla \& Thompson, 2016; Watts \& Robertson, 2011), most of what has been written in the context of the completion agenda concludes that faculty are drowning and then proceeds to describe the water (Flaherty, 2017a; 2017b; Frisby, et al., 2015; Lackritz, 2004). For example, Herbert Childress asserts, “college faculty were not defeated after a great struggle, after a battle with a winner and a loser. College has simply been redefined, over and over, in ways that make faculty irrelevant" (2019, para. 8). However, in reviewing the literature regarding recent developments in higher education and their effect on faculty, as well as research on the concepts of burnout, social support, the buffering hypothesis, and institutional support, I believe creative solutions to burnout amid the completion agenda do exist. Not only are there numerous avenues for mitigating faculty burnout that have yet to be explored, but the existing research also has not been effectively leveraged to engender the types of institutional change that would protect against burnout. Finding a mitigator of faculty burnout through this study is a step toward improving the profession, as well as the academy and the students it serves. 


\section{References}

Akgunduz, Y., Alkan, C., \& Gök, Ö. A. (2018). Perceived organizational support, employee creativity, and proactive personality: The mediating effect of meaning of work. Journal of Hospitality and Tourism Management, 34, 105-114. https://doi.org/10.1016/j.jhtm.2018.01.004

Avanzi, L., Schuh, S. C., Fraccaroli, F., \& van Dick, R. (2015). Why does organizational identification relate to reduced employee burnout? The mediating influence of social support and collective efficacy. Work \& Stress, 29(1), 1-10. https://doi.org/10.1080/02678373.2015.1004225

Barrera, M., Sandler, I. M., \& Ramsay, T. B. (1981). Preliminary development of a scale of social support: Studies on college students. American Journal of Community Psychology, 9(4), 435-446. https://doi.org/10.1007/BF00918174

Barrera, M. (1986). Distinctions between social support concepts, measures, and models. American Journal of Community Psychology, 14, 413-445.

Belcastro, P. A., \& Gold, R. S. (1983). Teacher stress and burnout: Implications for school health personnel. Journal of School Health, 53(7), 404-407. https://doi.org/10.1111/j.17461561.1983.tb03148.x 
Bianchi, R., \& Janin, L. (2019). Burnout, depression and paranoid ideation: A cluster-analytic study. Occupational Medicine, 69(1), 35-38. https://doi.org/10.1093/occmed/kqy 150

Bianchi, R., Schonfeld, I. S., \& Laurent, E. (2019). Burnout: Moving beyond the status quo. International Journal of Stress Management, 26(1), 36-45. https://doi.org/10.1037/str0000088

Black, S. (2004). Stroking stressed-out teachers. Education Digest: Essential Readings Condensed for Quick Review, 69(5), 28-32.

Bolanos, H. (2019). Dating app burnout: When swiping becomes a chore. National Public Radio. https://www.npr.org/2019/06/26/736344196/dating-app-burnout-whenswiping-becomesa-chore

Bremer, B. A., \& Brooks, L. J. (2018). Social support as a coping strategy. In Salem Press Encyclopedia of Health. Salem Press.

Bryan F. J., Hester, K., Barnett, T., Frey, L., \& Relyea, C. (2006). Perceived organizational support and perceived external prestige: Predicting organizational attachment for university faculty, staff, and administrators. Journal of Social Psychology, 146(3), 327347. https://doi.org/10.3200/SOCP.146.3.327-347

Cahalin, L. P., Kaminsky, L., Lavie, C. J., Briggs, P., Cahalin, B. L., Myers, J., ... Arena, R. (2015). Development and implementation 
of worksite health and wellness programs: A focus on noncommunicable disease. Progress in Cardiovascular Diseases, 58, 94-101.

Card, A. J. (2018). Physician burnout: Resilience training is only part of the solution. Annals of Family Medicine, 16(3), 267-270. https://doi.org/10.1370/afm.2223

Cassel, J. (1976). The contribution of the social environment to host resistance. American Journal of Epidemiology, 104(2), 107-123. https://doi.org/10.1093/oxfordjournals.aje.a112281

Chao S. F., McCallion P., \& Nickle, T. (2011). Factorial validity and consistency of the Maslach Burnout Inventory among staff working with persons with intellectual disability and dementia. Journal of Intellectual Disability Research 55(5), 529-536. https://www.ncbi.nlm.nih.gov/pubmed/21418367.

Childress, H. (2019, March 27). This is how you kill a profession. The Chronicle of Higher Education. https://www.chronicle.com/interactives/2019-03-27-childress

Cobb, S. (1995). Social support as a moderator of life stress. In A. M. Eward, J. E. Dimsdale, B. T. Engel, D. R. Lipsitt, D. Oken, J. D. Sapira, ... H. Weiner (Eds.), Toward an integrated medicine: Classics from “Psychosomatic Medicine,” 1959-1979. (pp. 377397). American Psychiatric Association. 
Cockerham, T. (2016). Improving the compensation process in higher education: Fostering a high performing organization. [Doctoral dissertation, Capella University]. ProQuest

Dissertations and Theses Global.

Cohen, S., \& McKay, G. (1984). Social support, stress, and the buffering hypothesis. In S. E. Taylor \& J. E. Singer (Eds.), Handbook of psychology and health (Vol. 4, pp. 253-267). Erlbaum Associates.

Cohen, S., \& Pressman, S. (2004). Stress-buffering hypothesis. In N. B. Anderson (Ed.), Encyclopedia of health and behavior (Vol. 2, pp. 780-782). SAGE.

Cohen, S., \& Wills, T. A. (1985). Stress, social support, and the buffering hypothesis. Psychological Bulletin, 98(2), 310-357. https://doi.org/10.1037/0033-2909.98.2.310

Conklin, M. H., \& Desselle, S. P. (2007). Development of a multidimensional scale to measure work satisfaction among pharmacy faculty members. American Journal of Pharmaceutical Education, 71(4), 1-9. https://www.ncbi.nlm.nih.gov/pmc/articles/PMC1959201/.

Cox, A., Solomon, B., \& Parris, D. (2018, May 8). Teacher well-being is a critical and often overlooked part of school health. Child Trends. https://www.childtrends.org/teacher-wellbeing-is-a-critical-andoften-overlooked-part-of-school-health 
Craighead, W.E. \& Nemeroff, C.B. (Eds.). (2004). The concise Corsini encyclopedia of psychology and behavioral science (3rd ed.).: Wiley.

Cutrona, C.E., \& Russell, D. W., (1987). The provisions of social relationships and adaptation to stress. In W.H Jones \& D. Perlman (Eds.), Advances in Personal Relationships. A Research Annual. (Vol. 1, pp. 37-67). JAI Press.

Daly, C. J., \& Dee, J. R. (2006). Greener Pastures: Faculty turnover intent in urban public universities. The Journal of Higher Education, 77(5), 776-803.

Demerouti, E., Nachreiner, F., Bakker, A. B., \& Schaufeli, W. B. (2001). The job demands resources model of burnout. Journal of Applied Psychology, (3), 499. https://doi.org/10.1037//0021-9010.86.3.499

Dir, A. L., Saldana, L., Chapman, J. E., \& Aalsma, M. C. (2019). Burnout and mental health stigma among juvenile probation officers: The moderating effect of participatory atmosphere. Administration and Policy in Mental Health and Mental Health Services Research, 46(2), 167-174. https://doi.org/10.1007/s10488-0180902-x

Djurkovic, N., McCormack, D., \& Casimir, G. (2008). Workplace bullying and intention to leave: The moderating effect of perceived organisational support. Human Resource 
Management Journal, 18(4), 405-422.

https://doi.org/10.1111/j.1748-8583.2008.00081.x

Duffy, M.K., Ganster, D.C., \& Pagon, M. (2002). Social undermining in the workplace. The Academy of Management Journal, 45(2), 331.

Dutton, J.E. \& Ragins, B. R. (Eds.) (2007). Exploring positive relationships at work. Lawrence Erlbaum Associates.

Eisenberger, R., Huntington, R., Hutchison, S., \& Sowa, D. (1986).

Perceived organizational support. Journal of Applied Psychology, 71(3), 500-507. https://doi.org/10.1037/0021-

9010.71 .3 .500

Eisenberger, R., \& Stinglhamber, F. (2011). Perceived organizational support: Fostering enthusiastic and productive employees. American Psychological Association.

Farnese, M. L., Barbieri, B., Bellò, B., \& Bartone, P. T. (2017). Don’t abandon hope all ye who enter here: The protective role of formal mentoring and learning processes on burnout in correctional officers. Work, 58(3), 319-331. https://doi.org/10.3233/WOR172628

Faulkner, M., \& Davies, S. (2005). Social support in the healthcare setting: the role of volunteers. Health \& Social Care in the Community, 13(1), 38-45. https://doi.org/ 10.1111/j.13652524.2005.00526.x 
Fila, M. J. (2016). The job demands, control, support model: Where are we now? TKM International Journal for Research in Management, 1(1), 15-44.

Flaherty, C. (2013, January 11). After a professor's suicide. Inside Higher Ed. https://www.insidehighered.com/news/2013/01/11/campusand-academic-communities-left-wonder-why-after-professorssuicide

Flaherty, C. (2017a, April 21). Aftermath of a professor's suicide. Inside Higher Ed.

https://www.insidehighered.com/news/2017/04/21/recent-suicideprofessorsparksrenewed-discussions-about-access-mental-health

Flaherty, C. (2017b, June 8). Portrait of faculty mental health. Inside Higher Ed. https://www.insidehighered.com/news/2017/06/08/study-facultymembers-mentalhealthissues-finds-mix-attitudes-disclosing-and

Fradelos, E., Mpelegrinos, S., Mparo, C., Vassilopoulou, C., Argyrou, P., Tsironi, M., \& Theofilou, P. (2014). Burnout syndrome impacts on quality of life in nursing professionals: The contribution of perceived social support. Progress in Health Sciences, 4(1), 102109. 
Freudenberger, H. J. (1977). Speaking from experience. Training \& Development Journal, 31(7), 26.

Geist-Martin, P., \& Scarduzio, J. A. (2011). Working well: Reconsidering health communication at work. In The Routledge handbook of health communication (2nd ed., pp. 117-131).

Routledge.

Goldsmith, D. J., \& Albrecht, T. L. (2011). Social support, social networks, and health. In The Routledge handbook of health communication (2nd ed., pp. 335-348). Routledge.

Golonka, K., Mojsa-Kaja, J., Blukacz, M., Gawłowska, M., Marek, T., \& Gawłowska, M. (2019). Occupational burnout and its overlapping effect with depression and anxiety. International Journal of Occupational Medicine \& Environmental Health, 32(2), 229-244. https://doi.org/10.13075/ijomeh.1896.01323

Golonka, K., Mojsa-Kaja, J., Gawlowska, M., \& Popiel, K. (2017). Cognitive impairments in occupational burnout: Error processing and its indices of reactive and proactive control. Frontiers in Psychology, 8(May). https://doi.org/10.3389/fpsyg.2017.00676

Gottlieb, B. H., \& Bergen, A. E. (2010). Social support concepts and measures. Journal of Psychosomatic Research, 69(5), 511-520. https://doi.org/10.1016/j.jpsychores.2009.10.001 
Häusser, J., Mojzisch, A., Niesel, M., \& Schulz-Hardt, S. (2010). Ten years on: A review of recent research on the Job Demand-Control (-Support) model and psychological wellbeing. Work \& Stress, 24(1), 1-35.

Heffernan, T. A., \& Heffernan, A. (2019). The academic exodus: The role of institutional support in academics leaving universities and the academy. Professional Development in Education, 45(1), 102-

113. https://doi.org/10.1080/19415257.2018.1474491

Heinemann, L. V., \& Heinemann, T. (2017). Burnout research:

Emergence and scientific investigation of a contested diagnosis. SAGE Open, 7(1), 1-12.

https://doi.org/10.1177/2158244017697154

Henry, B. J. (2014). Nursing burnout interventions. Clinical Journal of Oncology Nursing, 18(2), 211-214. https://doi.org/10.1188/14.CJON.211-214.

Hicklin, C. (Winter 2020). Start the year right with self-care. School \& Community. 32-35.

Hock, R. R. (1988). Professional burnout among public school teachers. Public Personnel Management, 17(2), 167. https://doi.org/10.1177/009102608801700207

House, J. S. (1981). Work stress and social support. Addison-Wesley. 
Huang Chih-Hsuan (2012). The relationships between organizational commitment and satisfaction on financial compensation: A study of full-time faculty at the TransWorld University. [Doctoral dissertation, TransWorld University]. ProQuest Dissertations and Theses Global.

Jackson, S.E., \& Maslach, C. (1982). After-effects of job-related stress: Families as victims. Journal of Occupational Behaviour, 3(1), 63.

Jennings, P.A., Snowberg, K.E., Coccia, M.A., \&Greenberg, M.T. (2011). Improving classroom learning environments by cultivating awareness and resilience in education (CARE): Results of two pilot studies. The Journal of Classroom Interaction, 46(1), 37.

Johnson, J. V., \& Hall, E. M. (1988). Job strain, workplace social support, and cardiovascular disease: A cross-sectional study of a random sample of the Swedish working population. American Journal of Public Health, 78(10), 1336-1342. https://doi.org/10.2105/ajph.78.10.1336

Johnsrud, L. K., \& Heck, R. H. (1998). Faculty worklife: Establishing benchmarks across groups. Research in Higher Education, 39(5), 539.

Johnsrud, L.K., \& Rosser, V.J. (2002). Faculty members' morale and their intention to leave: A multilevel explanation. The Journal of Higher Education, 73(4), 518. 
Jones, S., \& Griep, Y. (2018) "I can only work so hard before I burn out." A time-sensitive conceptual integration of ideological psychological contract breach, work effort, and burnout. Frontiers in Psychology 9 (131), 1-14. https://doi.org/10.3389/fpsyg.2018.00131 Kabat-Zinn, J. (2015). Mindfulness. Mindfulness, 6(6), 1481-1483. https://doi.org/10.1007/s12671-015-0456-x

Lackritz, J. R. (2004). Exploring burnout among university faculty: Incidence, performance, and demographic issues. Teaching and Teacher Education, 20(7), 713-729. https://doi.org/10.1016/j.tate.2004.07.002

Lammers, J. C., Atouba, Y. L., \& Carlson, E. J. (2013). Which identities matter? A mixed-method study of group, organizational, and professional identities and their relationship to burnout. Management Communication Quarterly, 27(4), 503-536. https://doi.org/10.1177/0893318913498824

LaRocco, J. M., House, J. S., \& John R. P. French, Jr. (1980). Social support, occupational stress, and health. Journal of Health and Social Behavior, 21(3), 202-218. https://doi.org/10.2307/2136616

Lee, A., Thomas, G., Martin, R., \& Guillaume, Y. (2019). LeaderMember Exchange (LMX) ambivalence and task performance: The cross-domain buffering role of social support. 
Journal of Management, 45(5), 1927-1957.

https://doi.org/10.1177/0149206317741190

Maslach, C., \& Jackson, S. E. (1981). The measurement of experienced burnout. Journal of Organizational Behavior 2(2): 99-113.

Maslach, C., Jackson, S.E. \& Leiter, M.P. (1996). MBI: Maslach burnout inventory: CPP, Incorporated.

Maslach, C., Schaufeli, W. B., \& Leiter, M. P. (2001). Job burnout. Annual Review of Psychology, 52(1), 397-423. https://doi.org/10.1146/annurev.psych.52.1.397

Mészáros, V., Ádám, Sz., Szabó, M., Szigeti, R., and Urbán, R. (2014). The bifactor model of the Maslach Burnout Inventory-Human Services Survey (MBI-HSS)-An alternative measurement model of burnout." Stress \& Health: Journal of the International Society for the Investigation of Stress. 30(1), 82-88.

Millard, E. (2019). 5 Ways to avoid healthy food burnout. My Fitness Pal. https://blog.myfitnesspal.com/5-ways-to-avoid-healthy-foodburnout/

Mobley, W. (1982). Employee turnover: Causes, consequences, and control. Addison-Wesley.

Moen, P., Kelly, E. L., Fan, W., Lee, S.-R., Almeida, D., Kossek, E. E., \& Buxton, O. M. (2016). Does a flexibility/support organizational 
initiative improve high-tech employees' wellbeing? Evidence from the work, family, and health network. American Sociological Review, 81(1), 134-164.

Montoya, Y. L., \& Trethewey, A. (2009). Rethinking good work: Developing sustainable employees and workplaces. ASU.

http://humancommunication.clas.asu.edu/aboutus/Rethinking\%20 Work\%20DevelopingS ustainableSelf.pdf

Moss, G. E. (1973). Illness, immunity, and social interaction. Wiley Interscience.

Padilla, M. A., \& Thompson, J. N. (2016). Burning out faculty at doctoral research universities. Stress and Health, 32(5), 551-558. https://doi.org/10.1002/smi.2661

Peirce, G. L., Desselle, S. P., Draugalis, J. R., Spies, A. R., Davis, T. S., \& Bolino, M. (2012). Identifying psychological contract breaches to guide improvements in faculty recruitment, retention, and development. American Journal of Pharmaceutical Education, 76(6), 108. https://doi.org/10.5688/ajpe766108

Perera, H. N. (2016). Construct validity of the Social Provisions Scale: A bifactor exploratory structural equation modeling approach. Assessment, 23(6), 720-733. 
Periard, D. A. (2016). A bifactor model of burnout? An item response theory analysis of the Maslach Burnout Inventory - Human Services Survey. [Doctoral dissertation, Wright State University]. ProQuest Dissertations and Theses Global.

Petersen, A. H. (2019). How millennials became the burnout generation. Buzz Feed. https://www.buzzfeednews.com/article/annehelenpetersen/millennialsburnoutgeneration-debt-work

Price, J. (1997). Handbook of organizational measurement. International Journal of Manpower, 18(4/5/6), 303-558.

Ramasamy, V., \& Abdullah, N. H. B. (2017). Faculty's turnover in private higher learning Institutions: A phenomenal inquiry. Business and Economic Horizons; Prague, 13(2), 169-181.

Ray, E. B., \& Apker, J. (2011). Stress, burnout, and supportive communication: A review of research in health organizations. In The Routledge Handbook of Health Communication (2nd ed., pp. 428-440). Routledge.

Reevy, Gretchen M., and Deason, G. (2014) Predictors of depression, stress, and anxiety among non-tenure track faculty. Frontiers in Psychology 5, 1-17. https://doi.org/10.3389/fpsyg.2014.00701.

Roeser, R. W., Schonert-Reichl, K. A., Jha, A., Cullen, M., Wallace, L., Wilensky, R., Oberle, E., Thomson, K., Taylor, C., \& Harrison, J. 
(2013). Mindfulness training and reductions in teacher stress and burnout: Results from two randomized, waitlist-control field trials. Journal of Educational Psychology, 105(3), 787-804. https://doi.org/10.1037/a0032093.

Rosser, V.J. (2004). Faculty members' intentions to leave: A national study on their worklife and satisfaction. Research in Higher Education. 45(3): 285-309.

https://doi.org/10.1023/B:RIHE.0000019591.74425.f1 .

Rosser, V.J. (2005). Measuring the change in faculty perceptions over time: An examination of their worklife and satisfaction." Research in Higher Education. 46(1) 81-107. https://doi.org/10.1007/s11162-004-6290-y.

Rhoades, L., \& Eisenberger, R. (2002). Perceived organizational support: A review of the literature. Journal of Applied Psychology, 87(4), 698-714. https://doi.org/10.1037/00219010.87.4.698.

Russell, D.W., Altmaier, E., Van Velzen, D. (1987). Job-Related stress, social support, and burnout among classroom teachers. Journal of Applied Psychology. 72(2). 269-274.

Schaufeli, W. B., Bakker, A. B., Hoogduin, K., Schaap, C., \& Kladler, A. (2001). On the clinical validity of the Maslach Burnout Inventory and the Burnout Measure. Psychology \& Health, 16(5), 565. 
Schonfeld, I. S., Verkuilen, J., \& Bianchi, R. (2019). Inquiry into the correlation between burnout and depression. Journal of Occupational Health Psychology. https://doi.org/10.1037/ocp0000151

Schulz, A. D., Schöllgen, I., \& Fay, D. (2018, July 12). The role of resources in the stressor- detachment model. International Journal of Stress Management. http://dx.doi.org/10.1037/str0000100

Shumaker, S., \& Brownell, A. (2010). Toward a theory of social support: Closing conceptual gaps. Journal of Social Issues, 40, 11-36. https://doi.org/10.1111/j.15404560.1984.tb01105.x

Simmons, B. L. (2014). Organizational characteristics of happy organizations. In C. L. Cooper (Ed.), Wellbeing: a complete reference guide. Wiley.

Slate, R. N., \& Vogel, R. E. (1997). Participative management and correctional personnel: A study of the perceived atmosphere for participation in correctional decision making and its impact on employee stress and thoughts about quitting. Journal of Criminal Justice, 25(5), 397-408. https://doi.org/10.1016/S00472352(97)00023-8 
Sottimano, I., Guidetti, G., Converso, D., \& Viotti, S. (2018). We cannot be "forever young," but our children are: A multilevel intervention to sustain nursery schoolteachers' resources and well-being during their long work life cycle. Plos One, 13(11), e0206627-e0206627. https://doi.org/10.1371/journal.pone.0206627

Sutton, T. P., \& Bergerson, P. J. (2001). Faculty compensation systems. [electronic resource]: Impact on the quality of higher education. Washington, DC: ERIC Clearinghouse on Higher Education

Szigeti, R., Noémi B., Réka B., \& Urbán R. (2017). Burnout and depressive symptoms in teachers: Factor structure and construct validity of the Maslach Burnout Inventory_ Educators Survey among elementary and secondary school teachers in Hungary. Stress and Health: Journal of the International Society for the Investigation of Stress. 33(5), 530-39. https://doi.org/10.1002/smi.2737.

Taris, T.W.. (2006). Bricks without clay: On urban myths in occupational health psychology. Work and Stress, 99. https://doi.org/10.1080/02678370600893410

Thompson, T., \& Thompson, T. (Eds.). (2014). Encyclopedia of health communication. SAGE.

Tinto, V., \& Goodsell-Love, A. (1993). Building community. Liberal Education, 79(4), 16. 
Tollinche, S. (2013). Stress buster: Introducing quiet time for neonatal nurses. JOGNN: Journal of Obstetric, Gynecologic \& Neonatal Nursing, 42 (1), S69. https://doi.org/10.1111/15526909.12154.

Watts, J., \& Robertson, N. (2011). Burnout in university teaching staff: A systematic literature review. Educational Research, 53(1), 33-50. https://doi.org/10.1080/00131881.2011.552235

Wei, Y., Chu, H., Chen, C., Hsueh, Y., Chang, Y., Chang, L., \& Chou, K. (2012). Support groups for caregivers of intellectually disabled family members: Effects on physical, psychological health and social support. Journal of Clinical Nursing, 21(11/12), 16661677.

Weiss, R. (1974) The provisions of social relationships. In: Rubin, Z., Ed., Doing unto others, (pp. 17-26). Prentice Hall.

World Health Organization. (2018). International statistical classification of diseases and related health problems (11th Revision). https://icd.who.int/browse11/1-m/en 


\section{SECTION FOUR: CONTRIBUTION TO PRACTICE}

\section{Original Plan for Dissemination of Practitioner Contribution}

There are two ideal ways to share my research findings: The first is through a traditional report I would share with the recently formed task force on faculty hiring and retention at the University. The task force is made up of faculty who provide recommendations to the president and provost. The chair of the committee feels that my research is timely and relevant to the task force and has agreed to let me share a report, and possibly, recommendations with them. However, I know any report I provide to the administration may not be immediately recognized or acted upon. So, I want to try to start a culture shift from the faculty up. Thus, the second way I plan to share my findings is through the university's Center for Scholarship in Teaching and Learning (CSTL).

I am combining forces with a colleague in the English department who is also interested in faculty wellness to deliver a workshop for faculty that will combine the results of my research on faculty burnout and her work with mindfulness and self-care. We met with the director of the Center for Scholarship in Teaching and Learning (CSTL) to plan three different workshops.

The first will be a retreat during the summer CSTL offerings that would be held on one day, with a morning and afternoon session. Our goal is for this retreat to not be something to add on top of work, which is 
one of the reasons we plan to have it at the university recreation center.

This way it doesn't seem "class-like" and can be a true retreat, as many of our beginning of the school year events are called "retreats" but they are really just extra-long meetings. The second would be shorter and occur as a break-out session during the new faculty orientation, "Thrive in Five" (RCU Office of the Provost, 2019). The final workshop would also be also shorter and occur as a break-out session during the fall faculty development day that is sponsored by CSTL and occurs the week before classes begin. My colleague and I have discussed that I may find that the only variable that results in less burnout is more salary. However, we could even use that finding to focus on how to make your work life richer even if your check isn't bigger.

We would want the morning session to focus on theory and study results. The afternoon session would focus on practice, with each participant developing strategies to combat burnout individually as well as collectively. For example, we may have them compare their personal experiences to my findings and make a list of how they can seek guidance and reassurance of worth from their colleagues or chair and how they could enhance their feelings of personal accomplishment as an individual, as well as what their department might do to contribute to a shared feeling of accomplishment. They could also create a "wish list" of what types of institutional support might reduce their emotional exhaustion and depersonalization. We may do some breathing techniques and chair yoga, 
but we would want to make sure this event is accessible to all, with no level of fitness or flexibility assumed or required. Based on the feedback we receive from this first workshop via an electronic CSTL survey, we could revise and prepare for the more condensed versions of the workshop for the break-out sessions during Thrive in Five and Faculty Development Day.

At first, it may seem as if this retreat will be nothing more than part of the paradoxical pattern of removing the worker from the job, or providing individual strategies for the worker, in which one either strengthens one's internal resources or changes one's work behaviors (Maslach, et al., 2001) when situational and organizational factors play a bigger role in burnout than individual ones (Bermejo-Toro, et al., 2016; Bowling, Alarcon, et al., 2015; Kim \& Rehg, 2018; Larson et al., 2019; Maslach, et al., 2001; Moeller \& Chung-Yan, 2013; Sabagh, et al., 2018). However, the goal of the retreat is not just to promote an individual shift, but an organizational one. Perhaps if as faculty, we stop celebrating who is the busiest, start prioritizing our wellness, setting limits, developing community, and making it okay to say no, maybe we can create the social and institutional support we need to not only mitigate burnout but preempt it.

\section{Current Plan}

As we approached Spring Break 2020, when I had penciled in finishing this chapter of my dissertation, we were plunged into an 
unprecedented situation. COVID-19, the infectious disease caused by the most recently discovered coronavirus was declared a pandemic by the World Health Organization on March 11, 2020 (WHO, 2020b). This new virus and disease were unknown before the outbreak began in Wuhan, China, in December 2019, but by the second week of March, there were more than 118,000 cases in 114 countries, and 4,291 people had lost their lives (WHO, 2020a, 2020b).

People were urged to practice social distancing to prevent the spread of the virus, meaning they should avoid crowds, keep six feet of distance between themselves and others, and stay home if they feel sick (Appleby, 2020). Social distancing also meant businesses asked employees to work from home or stagger work hours, governments closed schools, sporting events were postponed, and museums, theaters, and concert halls where large groups of people gather began closing their doors (Appelby, 2020). On March 13, the beginning of spring break, RCU announced all classes would be taught remotely for the week following spring break. On March 18, the administration determined remote learning would happen for the rest of the semester and a tiered system would be used to bring small groups of students on campus to move out of their residence halls. All events on campus were canceled through May 15. 
Faculty's efforts to move online on such short notice have been termed "Panicgogy" (Kamenetz, 2020). Moving a retreat online seemed comparatively simple. I contacted our

Center for Scholarship in Teaching and Learning (CSTL) to see if they could provide the link to Google slides, and eventually, short videos created by me and my fellow workshop collaborator on the retreat project. However, I determined that now was not the time to create an executive summary for the task force on faculty hiring and retention. When we are not in the midst of a crisis, I will present my findings to that group.

\section{Type of Document}

A Google slides presentation, to be followed later by a video synopsis from me and presentation by my fellow collaborator, as well as a downloadable pdf document of resources will be uploaded to the Center for Scholarship in Teaching and Learning (CSTL) website (https://cstl.semo.edu/cstl/) for all faculty at our university by April 30, 2020.

\section{Rationale for This Contribution Type}

While situational and organizational factors play a larger role in burnout than individual ones, my findings suggest that there are things individual faculty members can do to help create a more supportive environment that reduces burnout for everyone. Thus, learning about burnout, the results of my research, and some of the practical implications would be a relevant professional development opportunity like the type 
offered by our CSTL. While it was originally planned to take place in a relaxed environment to contribute to a "retreat" type feel, social distancing has prohibited that.

\section{Outline}

Background of the Study

Research Questions

Conceptual Framework

Methods

Results

Discussion

Recommendations 


\section{Presentation}

\section{Retreat!}

\section{The results of a faculty burnout study that would have originally been presented during the CSTL Summer Institute}

Brooke Hildebrand Clubbs and Missy Nieveen-Phegley

\section{Note:}

Throughout the presentation, you will see the original work from Brooke's dissertation, as well as some thoughts about how much more relevant all of this is as she sees her colleagues working on transitioning their classes to remote learning in light of COVID-19.

Our university originally announced on Friday, March 132020 that we would move to remote learning for one week following our March 16-20 spring break. On March 18, the administration announced that March 23-27, rather than have remote learning for face to face classes, faculty could use that time to prepare to go online for the rest of the semester. Online classes would continue as normal. (C. Vargas, Personal Communication, 18 March 2020). 


\section{Outline of the Presentation}

\section{Background of the Study}

Research Questions

Conceptual Framework

Methods

Results

Discussion

Recommendations

\section{Background}

President Barack Obama brought significant national attention to the importance of postsecondary degree attainment in an address to Congress on February 24, 2009, which has been considered a focusing event for the current national college completion movement, or completion agenda (Horowitz \& Phillips, 2014; Rubin, 2018). 


\section{Background}

However, state governments continue to cut higher education funding to the point that the cost is split nearly equally between state appropriations and student payment of tuition and fees (Doyle, 2013; Fabricant \& Brier, 2016; Mueller, 2011).

There is also a public demand for greater accountability from universities (Barrett, 2014; Rosser, 2004).

\section{Background}

In his 2014 faculty time allocation study, John Ziker found that the average professor spent a little over 60 hours a week working.

Thirty percent of that time was dedicated solely to email and meetings. 


\section{Background}

In addition to disincentivizing the recruitment and retention of new faculty, cost-saving measures have also reduced the number of support staff.

This creates additional burdens for already overworked faculty by adding administrative tasks to their growing list of duties.

Heavy teaching loads, community-based research, and professional service responsibilities may constitute an overwhelming set of role expectations (Kingston-Mann \& Sieber, 2001).

\section{Background}

'To keep up with this administrative overload, professors also often add a 'second shift' to their schedule, returning to work at night, as well as on weekends and vacations, to catch up on the never-ending onslaught of demands on their time and attention. In the short term, this scheduling sleight of hand keeps departments functioning without requiring additional faculty or support staff but at the expense of long-term burnout and dissatisfaction" (Newport, 2019, para 27). 


\section{Background}

Fifteen years ago, Lackritz (2004) found burnout was already a concern for faculty. In his assessment of burnout at one public university, approximately $20 \%$ of all faculty members reported feeling the highest levels of burnout (Lackritz, 2004).

With the emergence of the completion agenda and cost-saving measures in recent years, faculty burnout is more likely.

\section{Background}

Determining the greatest mitigator of faculty burnout, as well as best practices for colleges and departments to support faculty against burnout, could:

provide guidance for university leadership as they adapt to the completion agenda produce strategies to reduce faculty burnout and turnover, the loss of positive relationships at work, negative impacts on faculty physical, emotional, and social well-being, and, ultimately, a decrease in student retention. 


\section{Research Questions}

RQ 1. Is there a relationship between social support and faculty burnout?

RQ2. Is there a relationship between institutional support and faculty burnout?

RQ3. Is there a relationship between salary tier and faculty burnout?

RQ4. Are some university colleges' faculty less likely to burnout than others?

\section{Research Questions}

RQ5. What are the characteristics of the college(s) that are less likely to have faculty burnout? 


\section{Hypothesis}

HO1. Institutional support will be the greatest mitigator of faculty burnout.

\section{Conceptual Framework}

\section{Burnout}

"refers specifically to phenomena in the occupational context and should not be applied to describe experiences in other areas of life" (WHO, 2018). 


\section{Conceptual Framework}

\section{Burnout}

Unlike depression, which tends to pervade every domain of a person's life, burnout is a problem that is specific to the work environment (Freudenberger, 1977).

Although it is unclear precisely what causes burnout, Maslach, et al. (2001) postulate that the best and most idealistic workers experience burnout-e.g., "You have to have been on fire in order to burn out" (p.405).

\section{Conceptual Framework}

Burnout is made up of three components:

Emotional Exhaustion

Depersonalization

Reduced feelings of Personal Accomplishment 


\section{Conceptual Framework}

\section{Social Support}

Social support includes a broad category of communicative behaviors that are enacted to provide assistance to another person or persons (Moss, 1973; Thompson \& Thompson, 2014).

Social support has also been defined as the exchange of resources with the intent to enhance well-being (Shumaker \& Brownell, 2010).

\section{Conceptual Framework}

\section{Social Support}

Weiss (1974) characterized six categories of relational provisions of social support:

attachment (a sense of security)

social integration (network membership)

opportunity for nuturance (taking responsibility for the well-being of a child)

reassurance of worth (which attest to an individual's competence in a social role)

a sense of reliable alliance (kin ties)

the obtaining of guidance (access to a trustworthy figure who can furnish emotional support and assist in developing a plan of action). 


\section{Conceptual Framework}

\section{Buffering Hypothesis}

The role of social support on mitigating negative outcomes has been theorized extensively using the buffering hypothesis (Cassel, 1976; Cobb, 1976) which asserts that "social support provides protection against the stress that produces psychological or physiological disorder or disease or reduces job performance" (Craighead \& Numeroff, 2004, para. 1).

\section{Conceptual Framework}

Institutional Support

"Employees' commitment to the organization is strongly influenced by their perception of the organization's commitment to them. Perceived organizational support is assumed to increase the employee's affective attachment to the organization and his or her expectancy that greater effort toward meeting organizational goals will be rewarded"

(Eisenberger, et al., 1986, p. 500). 


\section{Methods}

This is a mixed-methods sequential explanatory study which began with the quantitative data collection and analysis in the form of a survey and proceeded to the qualitative data collection and analysis in the form of semi-structured interviews (Creswell, 2014; Ivankova, et al., 2006).

\section{Methods}

The questionnaire was created by securing permission from the instruments' authors to adapt the following: the Maslach Burnout Inventory-Educators Survey (Maslach \& Jackson, 1981; Maslach, et al., 1996), the short form of the Social Provisions Scale (Cutrona \& Russell, 1987) and questions from the second domain of the Multidimensional Work Satisfaction Scale developed by Conklin \& Desselle (2007). 


\section{Methods}

Based on the survey results, a particular college was associated with lower burnout scores.

Semi-structured interviews of faculty within the departments of that college were conducted to discover if there were any common factors that could be responsible for a culture of institutional support that reduces burnout, as perceptions faculty members have of their worklife have a direct impact on their morale (Rosser, 2004).

The semi-structured interviews were recorded and transcribed, using the Temi application on the iPhone (Rev, 2019).

\section{Methods}

Data Analysis

Mean scores of burnout were cross-tabulated for each college.

Rather than performing a correlation analysis between the outcome variable of burnout and the predictor variables (i.e., salary, college, social support, and institutional support) prior to conducting a multiple linear regression in two separate steps, a more streamlined procedure for model building, known as a backward-chunkwise elimination procedure (Kleinbaum et al., 2008) was employed. 


\section{Methods}

\section{Data Analysis}

Open-coding of the interview data, was conducted, looking for responses to the research questions and reoccurring themes. After that, analytical coding was used to develop the codes into large overarching ideas (Merriam \& Tisdell, 2016).

\section{Results}

Of the 156 faculty who began the survey (39.7\% participation rate), 111 completed the burnout inventory section ( $28.2 \%$ participation rate). Some participants may have not been able to continue the survey because of disqualifying criteria, such as being a department chair, never having completed a CSTL workshop, or being full-time faculty who are not associated with a particular college (such as library faculty). 


\section{Results}

Participants

\begin{tabular}{|l|l|l|l|l|l|l|}
\hline & $\begin{array}{l}\text { Harrison } \\
\text { COBC }\end{array}$ & $\begin{array}{l}\text { Holland } \\
\text { COAM }\end{array}$ & COEHHS & COHSS & COSTEM & Total \\
\hline RNTT & 4 & 3 & 10 & 11 & 4 & 32 \\
\hline $\begin{array}{l}\text { Tenure } \\
\text { Track }\end{array}$ & 2 & 3 & 12 & 8 & 6 & 31 \\
\hline Tenured & 7 & 11 & 17 & 9 & 10 & 54 \\
\hline Total & 13 & 17 & 39 & 28 & 20 & 117 \\
\hline
\end{tabular}

\section{Results}

The global burnout score was tabulated by reverse scoring the items related to personal accomplishment (PA) and then adding those items to the emotional exhaustion (EE) and depersonalization (DP) scores 


\section{Results}

Burnout by College

\begin{tabular}{|l|l|l|l|}
\hline & Mean & N & Std. Dev. \\
\hline Harrison COBC & 73.3333 & 12 & 22.93205 \\
\hline Holland COAM & 82.6471 & 17 & 14.32629 \\
\hline COEHHS & 68.8889 & 36 & 19.13378 \\
\hline COHSS & 69.3846 & 26 & 17.07882 \\
\hline COSTEM & 77.2000 & 20 & 15.59555 \\
\hline Total & 73.0901 & 111 & 18.26051 \\
\hline
\end{tabular}

\section{Results}

It should be noted that the range of scores within the Emotional Exhaustion (EE) subscale are 0 to 16 (low); 17 to 26 (moderate) and $>27$ (high) (Garwood, et al., 2018; Maslach, et al., 1986).

Every college had an average EE score at 32 or above, indicating that the average faculty member in these colleges would have a high level of emotional exhaustion. 


\section{Results}

When interpreting the final model, the SPS subscale of guidance, SPS subscale of reassurance of worth, and institutional support were the only remaining significant predictors, thus positively answering RQ 1 (Is there a relationship between social support and faculty burnout?) and RQ 2 (Is there a relationship between institutional support and faculty burnout?).

\section{Results}

Based on the original research questions as well as these results, the following questions were asked during the semi-structured interviews to determine the answer to RQ 5: 


\section{Results}

1. How would you describe the culture of support in your department?

2. How would you describe the culture of support in your college?

3. What are some specific things colleagues have done to support you?

4. What are some specific things your department chair has done to support you?

5. What are some of the specific things upper administration has done to support you?

6. What contributes to your feelings of personal accomplishment?

\section{Results}

The participants represented five different departments (out of the seven: Child \& Family Studies, Communication Disorders, Elementary, Early \& Special Education, Kinesiology, Nutrition \& Recreation, Leadership, Middle \& Secondary Education, Nursing, and Psychology \& Counseling) in the college.

All of the participants volunteered via a recruitment e-mail. The participants included tenure-track, renewable non-tenure track (RNTT), and tenured faculty. All five of the volunteer participants were female. 


\section{Results}

The themes that emerged were:

Guidance

with the subcategories of

Colleague Guidance

Department Chair Guidance

Upper Administration Guidance

\section{Results}

\section{Reassurance of Worth}

with the subcategories of

Colleague

Department Chair

Upper Administration 


\section{Results}

\section{Personal Accomplishment}

with the subcategories of

Discipline and Research Related

Student Related

Department Related

\section{Results}

\section{Institutional Support}

with the subcategories of

Collegiality

Family Environment

Collaboration

Professional Development

Respecting Time 


\section{Discussion}

While not a theme, something else that came up during the interviews reflected concerns about institutional support in the form of salary and how feelings of personal accomplishment reduced their intention to leave.

Participant 2 commented, "We don't get paid enough. I mean, I could go become a (profession she prepares others for) and get paid more than I am right now... but, because I feel like what I am doing is making a difference... some things are more important than money."

\section{Discussion}

Social support was also an important factor in reduction of intention to leave, as Participant 3 shared, "I think the only thing that saves any of us is the culture of our department because I think we all would've been gone if it wasn't...for that." 


\section{Discussion}

Multiple participants also mentioned upper administration, and sometimes not even their department chairs, understanding the difference between the types of work, or specialties in their discipline that would necessitate more faculty Full Time Equivalent (FTE) hours being given or higher salaries being offered to recruit faculty for new programs.

\section{Recommendations}

\section{Colleagues are a very specific type of friend}

Colleagues truly understand what each other are going through because they are going through it too.

This supports Mark Granovetter's social networking theory $(1973,1983)$ which suggests that both strong ties (close friends and members of our inner circle) and weak ties (acquaintanceships) are important so that we can experience stability, loyalty, and comfort, as well as avoid having an isolated and insular perspective on the world (du Pre, 2017). 


\section{Recommendations}

Colleagues are a very specific type of friend.

Friends faculty have made through kids' play groups or who they know from the gym can't offer advice on creating a merit binder; however, they can be a source of support when faculty need a break from the stressors their colleagues are experiencing as well.

\section{Recommendations}

Mentoring is vital to provide guidance and reassurance of worth.

I originally wrote that it was clear there needs to be more consistent and careful programming in place to develop and foster these mentorships for university faculty. However, I have seen considerable impromptu online mentoring in the wake of COVID-19 prevention closures.

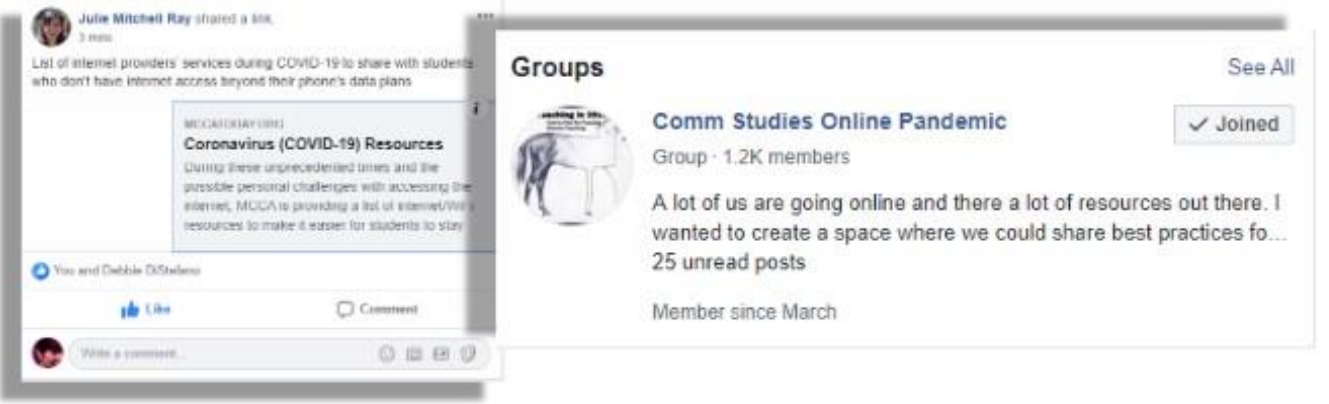




\section{Recommendations}

Department chairs can foster community building.

The participants' comments demonstrate that department chairs are instrumental in creating a culture of support. Specific actions chairs can take to create this culture range from community building, such as planning holiday parties or organizing potluck lunches, to reassurance of worth in the form of written and verbal commendations of department, student, and individual achievements, to tailored guidance.

\section{Recommendations}

Department chairs can foster community building.

Guidance doesn't always have to be praise to be kind, but can also be concise and specific feedback that addresses a concern (Brown, 2018). 


\section{Recommendations}

Department chairs can foster community building. Cake brings people together.

(Stop at 2:20)

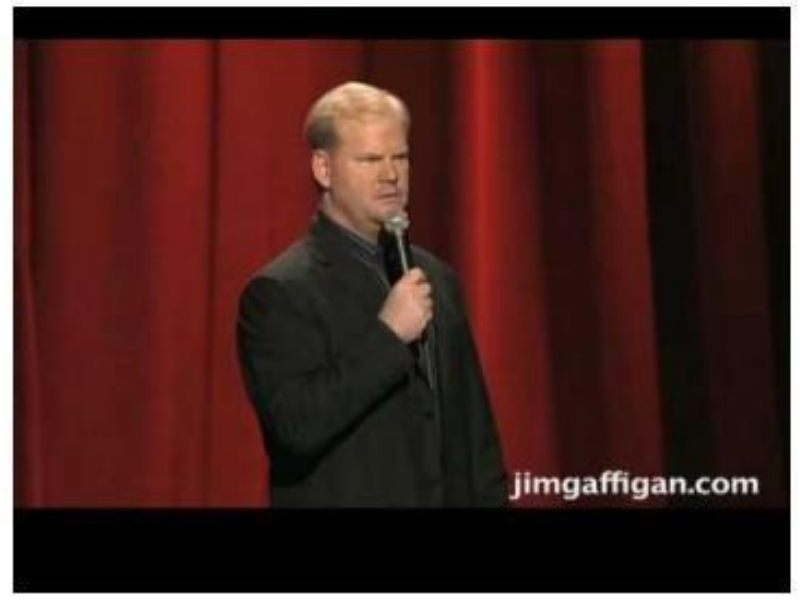

Gaffigan, J. Cake. From Beyond the Pale. [Video\}. YouTube.

https://youtu.be/-o-u4IwXkbE?t=112.

\section{Recommendations}

Upper administration should consider how they can increase institutional support even when they cannot increase salaries.

They should also look at what they can do to provide guidance, reassurance of worth, and increase the faculty's feelings of personal accomplishment. 


\section{Recommendations}

Upper administration should consider how they can increase institutional support even when they cannot increase salaries.

Participants continually brought up the idea that they were frustrated when they felt they were left out of the loop, not valued as content experts, not listened to, or told to continue promoting successful activities (such as student research) even when the resources to fund those activities were taken away.

\section{Recommendations}

Upper administration should consider how they can increase institutional support even when they cannot increase salaries.

This would suggest that anything upper administration can do to increase communication and demonstrate that faculty concerns are considered, faculty expertise is valued, and that they will give more than lip service to valuing certain activities would improve faculty's perception of institutional support. 


\section{Recommendations}

Personal Accomplishment isn't always personal.

It was related not only to personal achievements such as publications and presentations, but also to the success of the department and its students.

\section{Recommendations}

Personal Accomplishment isn't always personal.

COEHHS is unique in how many of its programs culminate in students becoming certified or credentialed as speech-language pathologists, nurses, dieticians, counselors, or teachers. Something to consider is how other colleges might feel this same accomplishment when their students aren't completing such milestones. 


\section{Recommendations}

Faculty Love in the Time of Coronavirus

Right now, in the midst of this pandemic:

Facetime or otherwise connect with colleagues and mentors while social distancing.

Create virtual community.

Utilize resources from local colleagues and those from afar...

...to make your $\mathrm{f} 2 \mathrm{f}$ courses GOOD ENOUGH online. Don't demand perfection from yourself or your students.

\section{Conclusion}

While there was not a relationship between salary and burnout score, institutional support, was a reliably significant mitigator of burnout. Social support in the form of guidance and reassurance of worth were also mitigating factors of burnout, with guidance being the most significant and reliable. 


\section{Conclusion}

The College of Education and Health and Human Studies had the lowest global burnout score and can provide a model for other colleges and their departments at this university.

\section{Conclusion}

Deans and department chairs play a critical role in creating the culture of support in their college and departments, but relationships with colleagues may be the most important ones faculty have in mitigating burnout. 


\section{Conclusion}

In 1967, The Beatles sang, "I get by with a little help from my friends." The refrain for faculty as they navigate academia and the completion agenda without succumbing to burnout may be, "I get by with a little help from my colleagues."

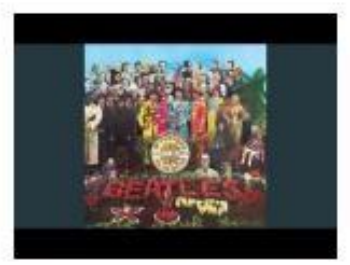

Beatles, The. I Get By With a Little Help from My Friends. [Song]. On Sgt. Pepper's Lonely Hearts Club Band. Capitol. YouTube. https://www.youtube.com/watch?v=0C58ttB2-Og

\section{Check out the videos}

Brooke created a short synopsis of her research.

Missy provides some thoughts on working well and provides a chair yoga demonstration.

Both of these videos are housed on the CSTL website. 


\section{Download the PDF}

A document with a summary of this presentation and links to resources is also provided on the CSTL website.

\section{References}

For a complete list of references used throughout this research, please contact Brooke Hildebrand Clubbs (bclubbs@semo.edu) 


\section{References}

Appleby, J. (2020 March 16). Self-quarantine? Isolation? Social

distancing? What they mean and when to do them. National Public

Radio.

https://www.npr.org/sections/healthshots/2020/03/16/816490025/q

uarantine-self-isolation-social-distancing-what-they-meanand-

when-to-do-them.

Beatles, The. (1967) I Get by With a Little Help from My Friends. [Song].

On Sgt. Pepper's Lonely Hearts Club Band.

Bermejo-Toro, L., Prieto-Ursúa, M., \& Hernández, V. (2016). Towards a model of teacher wellbeing: Personal and job resources involved in teacher burnout and engagement.

Educational Psychology, 36(3), 481-501.

Bowling, N. A., Alarcon, G. M., Bragg, C. B., \& Hartman, M. J. (2015).

A meta-analytic examination of the potential correlates and consequences of workload. Work \& Stress, 29(2), 95-113.

Center for Scholarship in Teaching and Learning. (n.d.). https://cstl.semo.edu/cstl/FacultyDevelopment/

Gaffigan, J. Cake. From Beyond the Pale. [Video]. YouTube. https://youtu.be/-ou4IwXkbE?t=112. 
Kamenetz, A. (2020, March 19). 'Panic-gogy': Teaching online classes during the coronavirus pandemic. National Public Radio. https://www.npr.org/2020/03/19/817885991/panicgogy-teachingonline-classes-during-the-coronavirus-pandemic.

Kim, H., \& Rehg, M. (2018). Faculty performance and morale in higher education: A systems approach. Systems Research \& Behavioral Science, 35(3), 308.

Larson, L. M., Seipel, M. T., Shelley, M. C., Gahn, S. W., Ko, S. Y., Schenkenfelder, M., ... Heitmann, M. M. (2019). The academic environment and faculty well-being: The role of psychological needs. Journal of Career Assessment, 27(1), 167-182. https://doi.org/10.1177/1069072717748667

Maslach, C., Schaufeli, W. B., \& Leiter, M. P. (2001). Job burnout. Annual Review of Psychology, 52(1), 397-423. https://doi.org/10.1146/annurev.psych.52.1.397

Moeller, C., \& Chung-Yan, G. A. (2013). Effects of social support on professors' work stress. The International Journal of Educational Management; Bradford, 27(3), 188-202.

River City University Office of the Provost (2019). New faculty orientation program: Thrive in five!. https://semo.edu/provost/faculty_info/newfaculty.html 
Sabagh, Z., Hall, N. C., \& Saroyan, A. (2018). Antecedents, correlates and consequences of faculty burnout. Educational Research, 60(2), 131-156. https://doi.org/10.1080/00131881.2018.1461573

World Health Organization (2020, March 9). What is COVID-19? https://www.who.int/newsroom/q-a-detail/q-a-coronaviruses

World Health Organization. (2020, March 11). WHO Director-General's opening remarks at the media briefing on COVID-19 - 11 March 2020. https://www.who.int/dg/speeches/detail/who-director-general-sopening-remarks-at-themedia-briefing-on-covid-19---11-march2020. 


\section{SECTION FIVE: CONTRIBUTION TO SCHOLARSHIP}

\section{Original Plan}

An important component of becoming a certified researcher and a burgeoning scholar as I complete my dissertation will be submitting to peer-reviewed journals. Before I begin that process with this study, I plan to submit a paper to the health communication division for the annual convention of the National Communication Association (NCA).

Submissions will be due in March of 2020 and the convention will take place in Indianapolis, IN from November 19 through November 22, 2020 (NCA, 2019). Papers are competitively selected and regardless of whether or not mine is chosen for inclusion at the convention, I will receive feedback from three reviewers that could help me prepare for publication. In addition to that feedback, if my paper is accepted, I will have the opportunity to present at the convention and receive feedback from the respondent, as well as session attendees. Going through this process will ensure I submit the most polished version of my work for publication.

\section{Target Journal}

When I first began developing my prospectus, my target journal was Burnout Research, which would have been ideal, as it was created in 2014 to provide a forum for a "targeted focus on the many facets of burnout"(Maslach \& Leiter, 2014, p. 1). Unfortunately, it ceased publication at the end of 2017 because its business model as an open- 
access journal did not work well with researchers who were not grantfunded and able to pay the open access fee

(Maslach \& Leiter, 2017). I felt that if I couldn't target a journal that specialized in burnout, the next best match because my research is interdisciplinary in nature, would be to focus on the population I am studying. Thus, I began to examine higher education publications.

Research in Higher Education, my new target journal, looks at a wide variety of topics in higher education, including faculty issues. Recent articles related to my subject area published in this journal include “Occupational Well-being among University Faculty: A Job DemandsResources Model” (Mudrak et al., 2018) and "The Professional Development Needs of Tenure Track Faculty at a Regional University" (Hott \& Tietjen-Smith, 2018). It is a top tier journal (Bray \& Major, 2011) with an impact rate of 1.7 and an acceptance rate of 10\% (“Cabell's International-Journals," n.d.). The director of our Cooperative Educational Leadership and Policy Analysis EdD program is also one of the consulting editors of this journal.

New Directions for Teaching and Learning would be another publication to consider, as it deals with theory and research as well as with practice, a format my dissertation-in-practice would fit well. Recent chapter titles related to my subject area in this publication are "When it Hurts to Work: Organizational Violations and Betrayals" (Frey, 2018) and 
"The Emotional Balancing Act of Teaching: A Burnout Recovery Plan" (Sproles, 2018). It is a second-tier journal (Bray \& Major, 2011) with an impact rate of .5 and an acceptance rate of 23\% ("Cabell's InternationalJournals," n.d.).

Following my defense, I would prepare my manuscript to submit online to Research in Higher Education during the Summer of 2020. Because this journal prefers quantitative research, I would focus on the results of my survey and any correlations I find between the variables and burnout levels. There is not a required length for the manuscript; however, most of their published articles are 5-10,000 words (Springer, n.d.).

\section{Current Plan for Submission}

I plan to submit this paper to the Health Communication division of the National Communication Association 2020 Convention by April 6, 2020. The theme of the convention this is year is "Communication at the CrossRoads" (NCA, 2020). The Health Communication Division encourages submissions that address the convention theme. Examples of the types of research the Health Communication division seeks include:

- Testing and/or introducing theories of health communication and behavior.

- Improving shared decision-making between patients and providers.

- Developing personalized self-management tools and resources.

- Understanding social support networks. 
- Delivering accurate, accessible, and actionable health information that is targeted or tailored.

- Facilitating the meaningful use of health IT and the exchange of health information among health care and public health professionals.

- Enabling quick and informed responses to health risks and public health emergencies.

- Improving health literacy skills.

- Providing new opportunities to connect with culturally diverse and hard-to-reach populations.

- Providing sound principles in the design of programs and interventions that result in healthier behaviors.

- Documenting content and effects of health-focused media.

- Increasing Internet and mobile access (NCA, 2020).

My research falls into the "Understanding social support networks" category and only complete papers will be considered. Papers should be no longer than 25 pages (abstract, references, tables, and figures are not included in the 25-page limit) and follow APA guidelines. Based on the feedback I receive on this submission from the reviewers (whether or not is accepted), and hopefully, the constructive suggestions that would follow my presentation at NCA, I plan to revise this paper with the help of the colleagues who will now be my co-authors, as they provided insight on the qualitative and quantitative research design.

\section{Submission Ready Article}




\title{
I Get by with a Little Help from my...Colleagues: \\ The Crossroads of Faculty Burnout, Social Support, and Institutional Support
}

\begin{abstract}
The purpose of this sequential explanatory study was to determine if there was a relationship between faculty burnout, social support, institutional support, or salary, as well as establish if any college within a regional public university in the Midwest was less burned out than the others. Participants $(n=111)$ completed a survey that contained qualifying as well as demographic questions, Maslach's Burnout Inventory, Cutrona \& Russell's Social Provisions Scale, and the institutional support section of Conklin \& Desselle's Multidimensional Work Satisfaction Scale. Social support in the form of guidance and reassurance of worth, as well as institutional support, were found to mitigate burnout. The College of Education, Health \& Human Studies had a lower burnout score than other colleges. In semi-structured interviews with faculty, it was determined that personal accomplishment, as well as colleagues, department chairs, and deans who create a culture of support, can reduce burnout.
\end{abstract}

Keywords: Faculty, Burnout, Social Support, Institutional Support

In his 2014 faculty time allocation study, John Ziker found that the average professor spent a little over 60 hours a week working. Thirty percent of that time was dedicated to email and meetings. There is a zeitgeist in higher education that has changed the demands on faculty and 
in turn, the composition of their work schedules. President Barack Obama brought significant national attention to the importance of postsecondary degree attainment in an address to Congress on February 24, 2009, which has been considered a focusing event for the current national college completion movement, or completion agenda (Horowitz \& Phillips, 2014; Rubin, 2018).

However, state governments continue to cut higher education funding to the point that the cost is split nearly equally between state appropriations and student payment of tuition and fees (Doyle, 2013; Fabricant \& Brier, 2016; Mueller, 2011). There is also a public demand for greater accountability from universities (Barrett, 2014; Rosser, 2004). Thus, contemporary faculty now find that the completion agenda has made the focus of academia improving student outcomes while also driving down costs (Conklin \& Desselle, 2007; Fabricant \& Brier, 2016; Gagliardi, et al., 2018). These cost-saving measures have decreased the number of full-time faculty even while the number of students continues to increase (Childress, 2019; Cooper, 2019; Fabricant \& Brier, 2016; Hill \& Spinella, 2018; Lounder et al., 2011; Zahneis, 2018). As a result, the amount of time available for faculty to spend per student, per paper, and per class has necessarily declined. This decline has led faculty to choose between two equally troubling outcomes: a decline in the quality of their teaching and advising work or a decline in their wellbeing as they attempt to manage a growing workload (Black, 2004; Sabagh, et al., 2018). 
Because of the increased time demand for teaching and related responsibilities, faculty have seen substantial reductions in the time available for research and service as well as creative, rather than taskoriented, engagement with colleagues (Padilla \& Thompson, 2016). It comes as little surprise then, that Lounder et al. found that as "autonomy decreases and faculty work becomes more technocratic, a propensity develops for the job to become less attractive. In turn, this suggests a likelihood of reduced investment in work by current faculty members, as well as discouraged aspirations for talented rising scholars" (2011, p.24).

In addition to disincentivizing the recruitment and retention of new faculty, cost-saving measures have also reduced the number of support staff. This creates additional burdens for already overworked faculty by adding administrative tasks to their growing list of duties. Heavy teaching loads, community-based research, and professional service responsibilities may constitute an overwhelming set of role expectations (Kingston-Mann \& Sieber, 2001). According to Newport's February 2019 piece in the Chronicle of Higher Education:

To keep up with this administrative overload, professors also often add a 'second shift' to their schedule, returning to work at night, as well as on weekends and vacations, to catch up on the never-ending onslaught of demands on their time and attention. In the short term, this scheduling sleight of hand keeps departments functioning without requiring 
additional faculty or support staff but at the expense of long-term burnout and dissatisfaction (para. 27).

Fifteen years ago, when careers in academia often still included the possibility of tenure and sabbaticals, Lackritz (2004) found burnout was already a concern for faculty. In his assessment of burnout at one public university, approximately $20 \%$ of all faculty members reported feeling the highest levels of burnout (Lackritz, 2004). With the emergence of the completion agenda and cost-saving measures in recent years, faculty burnout is more likely, and thus, the focus of this study.

Determining the greatest mitigator of faculty burnout, as well as best practices for colleges and departments to support faculty against burnout, could guide university leadership as they adapt to the completion agenda. It could also produce strategies to reduce some of the completion agenda's more deleterious effects: faculty burnout and turnover, the loss of positive relationships at work, negative impacts on faculty's physical, emotional, and social well-being, and, ultimately, a decrease in student retention.

\section{Purpose of the Present Study}

In the present study, we examined the relationship between faculty burnout, social support, and institutional support. We posed four quantitative questions. First, is there a relationship between social support and faculty burnout? Next, is there a relationship between institutional 
support and faculty burnout? Because salary is an element of institutional support, we also asked, is there a relationship between salary tier and faculty burnout? To further examine the variance of institutional support throughout an organization, we asked if some university colleges' faculty less likely to burnout than others? We also addressed the qualitative question, what are the characteristics of the college(s) that are less likely to have faculty burnout? We also hypothesized that institutional support would be the greatest mitigator of faculty burnout. To explore these questions, this study utilizes the following conceptual and theoretical frameworks: burnout, social support, the buffering hypothesis, and institutional support, which is also known as perceived organizational support.

\section{Burnout}

While the World Health Organization recently redefined burnout and clarified that it "refers specifically to phenomena in the occupational context and should not be applied to describe experiences in other areas of life" (2018), its casual use remains in the popular lexicon to describe everything from millennial ennui related to dating sites (Bolanos, 2019; Petersen, 2019) to a lack of enthusiasm for preparing healthy foods (Millard, 2019). This misuse can sometimes dilute the public's perception of the seriousness of burnout.

Unlike depression, which tends to pervade every domain of a person's life, burnout is a problem that is specific to the work 
environment (Freudenberger, 1977). Although it is unclear precisely what causes burnout, Maslach, et al. (2001) postulate that the best and most idealistic workers experience burnout — e.g., "You have to have been on fire to burn out" (p.405). This interpretation implies that dedicated people commit too much in support of their ideals, which leads to exhaustion, depersonalization, and the feeling of a lack of personal achievement when their sacrifice is insufficient to achieve their goals. Meaningful work can have a negative effect on employee's well-being, as employees feel so invested in their work that they push themselves beyond their limits resulting in strain and susceptibility to burnout (Jones \& Griep, 2018; Reevy \& Deason, 2014).

\section{Social Support and the Buffering Hypothesis}

The resource to prevent burnout that has been studied most extensively is social support. Specifically, consistent findings and a strong body of literature demonstrate that a lack of social support is linked to burnout (Bremer \& Brooks, 2018; Maslach, et al., 2001). Social support includes a broad category of communicative behaviors that are enacted to provide assistance to another person or persons (Moss, 1973; Thompson \& Thompson, 2014). Social support has also been defined as the exchange of resources with the intent to enhance well-being (Shumaker \& Brownell, 2010). Weiss (1974) characterized six categories of relational provisions of social support: attachment (a sense of security), social integration (network membership), opportunity for nurturance (taking 
responsibility for the well-being of a child), reassurance of worth (which attest to an individual's competence in a social role), a sense of reliable alliance (kin ties), and the obtaining of guidance (access to a trustworthy figure who can furnish emotional support and assist in developing a plan of action).

Social support from coworkers can buffer the effects of job stressors (Lee, et al., 2019; Schulz, et al., 2018). The role of social support on mitigating negative outcomes has been theorized extensively using the buffering hypothesis (Cassel, 1976; Cobb, 1976) which asserts that "social support provides protection against the stress that produces psychological or physiological disorder or disease or reduces job performance" (Craighead \& Numeroff, 2004, para. 1). Key sources of social support in the workplace include coworkers, leaders, and the organization itself (Lee, et al. 2019). According to the cross-domain buffering hypothesis of social support, social support from a different domain (e.g., coworker or organizational support) should be particularly effective at reducing the negative consequences of a stressor from another domain (Duffy, et al., 2002). For example, if a supervisor is alternately ambivalent and supportive, the support from the supervisor does not protect a worker from stress. However, if a coworker is supportive when a supervisor is ambivalent, the support does reduce the negative consequences of the stress the worker may experience (Lee, et al., 2019). 


\section{Institutional Support}

Several studies suggest that, in addition to social support, institutional or organizational support can have protective factors against faculty burnout. In 1986, Eisenberger, Huntington, Hutchison, \& Sowa developed a measurement for perceived organizational support (POS).

Their measurement was based on the social exchange view that:

employees' commitment to the organization is strongly influenced by their perception of the organization's commitment to them. Perceived organizational support is assumed to increase the employee's affective attachment to the organization and his or her expectancy that greater effort toward meeting organizational goals will be rewarded. (p.

$500)$.

Heffernan \& Heffernan (2019) found that professional development and career support available to academics played major roles in their career satisfaction. Djurkovic, et al. (2008) reported perceived organizational support moderates the relationship between workplace bullying and victims' intention to leave. While the terms “organizational support" and "institutional support" are often used interchangeably throughout the literature on work and wellbeing (Simmons, 2014), Conklin \& Desselle (2007) created a domain in their faculty work satisfaction scale entitled "Institutional Support and Reward" (p. 5), 
which is why we have chosen to use the term "institutional support" for this study.

These concepts — burnout, social support as well as the buffering hypothesis related to it, and institutional support - make up the framework of this study. Additionally, burnout serves as the dependent variable, while social support and institutional support serve as independent variables in the study design.

\section{Method}

This is a mixed-methods sequential explanatory study that began with the quantitative data collection and analysis in the form of a survey and proceeded to the qualitative data collection and analysis in the form of semi-structured interviews (Creswell, 2014; Ivankova, et al., 2006). Using this type of mixed methods research design provided a more complete understanding of the research problem than a quantitative or qualitative approach alone (Creswell, 2014).

\section{Sample}

Institutional Review Board approval was obtained before administering the survey to faculty at a regional public university in the Midwest. Recruitment e-mails with a link to the Qualtrics survey were sent via the provost's email listserv. Respondents were filtered by a qualifying question at the beginning of the survey so that only the faculty who have ever attended one of the faculty development days or any of the 
other professional development events hosted and organized by the institution's Center for Scholarship in Teaching and Learning would continue to the rest of the survey. Limiting survey respondents solely to those who have taken advantage of at least one of these professional development opportunities would provide a population that was, at least at one point in time, interested in improving in their roles as faculty. Thus, faculty who answered yes to the question about their participation in faculty development opportunities would likely be those who fit Maslach's description that "you have to have been on fire to burnout" (Maslach, et al., 2001, p. 405).

\section{Instruments}

The questionnaire was created by securing permission from the instruments' authors to adapt the following: the Maslach Burnout Inventory-Educators Survey (Maslach \& Jackson, 1981; Maslach, et al., 1996), the short form of the Social Provisions Scale (Cutrona \& Russell, 1987), and questions from the second domain of the Multidimensional Work Satisfaction Scale developed by Conklin \& Desselle (2007).

The 22-item MBI-Educators Survey (MBI-ES) addresses three scales: emotional exhaustion (EE) which measures feelings of being emotionally overextended and exhausted by one's work, depersonalization (DP) which measures an unfeeling and impersonal response toward recipients of one's instruction, and personal accomplishment (PA) which 
measures feelings of competence and successful achievement in one's work (Maslach, et al.,1996). Higher scores on the emotional exhaustion and depersonalization subscales indicate higher burnout, while higher scores on personal accomplishment indicate lower burnout (Szigeti et al., 2017). The global burnout score was determined by reversing the personal accomplishment scores and adding them with emotional exhaustion and depersonalization scores (Mészáros et al., 2014; Szigeti et al., 2017). The MBI is the most popular measurement of burnout and the validity of this scale has been confirmed through numerous studies, documented in the meta-analysis by Schaufeli, et al.in 2001. More recently, researchers have found that a model that yields a global burnout score is more reliable than the subscale scores (Mészáros et al., 2014; Periard, 2016; Szigeti et al., 2017).

The short version of the Social Provisions Scale (SPS) includes 10 items tapping five of the six types of provisions available from the general social network, including reliable alliance (practical help), guidance (informational support), attachment (emotional support), social integration (belonging to a group of similar peers), and reassurance of worth (esteem support) (Cutrona \& Russell, 1987). A score for each social provision was derived so that a high score indicates that the individual is receiving that provision and could be tabulated as a global social support score (Cutrona \& Russell, 1987). Based on samples of 1792 respondents across several studies, including students, nurses, and public school 
teachers, the SPS showed excellent overall internal consistency (Cutrona \& Russell, 1987; Gottlieb \& Bergen, 2010) and construct validity (Perera, 2016). The full Multidimensional Work Satisfaction Scale (MWSS) developed by Conklin \& Desselle (2007) has 6 domains and 25 items, but because we only used the second domain, "Institutional Support and Reward" (Conklin \& Desselle, 2007, p. 5) participants were asked to rate just 6 items within it: general support from my department/division chair, general support from my dean, general support from upper administration, including provost and president, institutional efforts in support of the career development of their faculty, salary competitive with other schools, and distribution of rewards (i.e., salary) based on merit. The average of these items created the institutional support score. While this scale is not as frequently cited as the other measures being used for the study, it has demonstrated high degrees of construct and discriminant validity (Conklin \& Desselle, 2007, 2010; Peirce, et al., 2012)

In addition to these scales, several demographic questions were included regarding faculty status, salary, and college. Status was required because, at this time, we only wanted to study full-time faculty, not adjunct faculty or graduate assistants. Salary was an important independent variable to measure because there was a possibility that the only support that might make a difference in reducing burnout would be salary. Though rewards can come to faculty in multiple forms other than monetary compensation, such as student learning and engagement, we know that salary, retirement, and job security are important issues that 
affect faculty satisfaction (Rosser, 2004). Participants were grouped by college to discover whether some university colleges were more resistant to burnout than others. In her studies on faculty intention to leave, Rosser found sources of support can vary dramatically by college, department, and discipline, and the perceived inequities can be demoralizing to faculty members (Johnsrud \& Rosser, 2002; Rosser, 2004; 2005).

\section{Design}

Based on the survey results, we determined if a particular college was associated with lower burnout scores. The primary author then interviewed faculty within the departments of that college to discover if any common factors could be responsible for a culture of institutional support that reduces burnout, as perceptions faculty members have of their worklife have a direct impact on their morale (Rosser, 2004). The semi-structured interviews were recorded and transcribed, using the Temi application on the iPhone (Rev, 2019). Temi protected participants' privacy, as recordings are securely stored and transmitted using TLS 1.2 encryption, the highest level of security available (Temi, 2019.)

\section{Data Analysis}

Data were analyzed with IBM SPSS Statistics (Version 25). Mean scores of burnout were cross-tabulated for each college. The college with the lowest burnout scores was singled out for semi-structured interviews. The primary author conducted semi-structured interviews with five faculty members using the following questions: How would you describe 
the culture of support in your department? How would you describe the culture of support in your college? What are some specific things colleagues have done to support you? What are some specific things your department chair has done to support you? What are some of the specific things upper administration has done to support you? What contributes to your feelings of personal accomplishment? The primary author then utilized open-coding of the interview data, looking for responses to the research questions and reoccurring themes. After that, she used analytical coding to develop the codes into large overarching ideas (Merriam \& Tisdell, 2016).

\section{Backward Chunkwise Elimination Procedure}

The quantitative data analysis was a backward chunkwise elimination procedure (Kleinbaum et al., 2008). The purpose of this procedure was to build a regression model that could predict global burnout with any (or all) of the following predictor variables: (1) five subscales obtained from the Social Provisions Scale, (2) four dummy variables created to represent the five colleges in the university (with the College of Education Health and Human Studies as the reference category), (3) institutional support scale, and (4) salary.

The backward chunkwise elimination procedure comprised two phases: the (1) backward chunkwise elimination procedure followed by (2) backward single variable elimination procedure. The first phase entails "chunking" (or grouping) variables to reduce the number of possible models tested to reduce the inflation of Type- 1 error rates due to multiple 
statistical tests. In this phase of the analysis, we treated the (1) social provision subscales and (2) dummy variables created for the different colleges as two chunks. Institutional support and salary were also considered two separate chunks. Thus, altogether, the maximum model had four "chunks".

The maximum model with all four chunks was treated as the base model. For each chunk, we examined the minimum (or smallest) test statistic, $F_{p}$, associated with a chunk. If the minimum test statistic was not significant $\left(F_{p}<F_{C R I T}\right)$, where $\alpha=.10$, we deleted the chunk with the smallest test statistic and reduced the total number of predictors in the model by one chunk. Subsequently, we fitted the reduced model with remaining chunks and repeated this chunking elimination process. If the minimum test statistic in a reduced model was significant $\left(F_{p}>F_{C R I T}\right)$, where $\alpha=.10$, we stopped the chunking elimination process and proceeded to the backward single variable elimination procedure.

In the first step of the backward single variable elimination procedure, the regression model with remaining chunks from the first part of the analysis was fitted as the base model. The predictors in the model, however, were treated as single variables as opposed to chunks. The second step includes fitting all $k$ - 1 variables models, defined by deleting one variable from the base model. For each model, the minimum test statistic, $F_{p}$, is examined for every single variable. If statistically significant $\left(F_{p}>F_{C R I T}\right)$, where $\alpha=.10$, the procedure stops and the 
reduced model is chosen as the final model. If not statistically significant $\left(F_{p}<F_{C R I T}\right)$, where $\alpha=.10$, the predictor is deleted with the minimum test statistic and $k$ is reduced by one. In this case, the second step is returned to and the process is repeated until a final model is determined.

\section{Results}

\section{Quantitative Response Rate}

According to the university's human resource office, in fall 2019, there were 393 permanent full-time faculty members. Of the 156 faculty who began the survey (39.7\% participation rate), 35 faculty members did not meet inclusion criteria for this study (e.g., were a department chair, never completed a CSTL workshop, or were a full-time faculty member not associated with a particular college, such as a library faculty), which left us with 121 eligible participants. Of the 121 participants, 17 participants (14\%) had one or more missing data points on the measures examined in this study, which left us with 104 participants with complete data. The previous academic year, the number of faculty who participated in the Chronicle of Higher Education's "Best Colleges to Work For" survey, conducted by ModernThink (Chronicle of Higher Education, 2018) and comment cards requested by the university's faculty senate (D. Powell, Personal Communication) yielded responses from $31 \%$ of the total full-time faculty population for the former and $35.1 \%$ for the latter. Thus, we were satisfied with this response rate. 


\section{Descriptive Statistics}

Of the 121 participants who answered the question regarding salary, $53.7 \%$ reported an annual gross salary of between $\$ 36,000$ and $\$ 56,000,38 \%$ reported that made more than $\$ 56,000$ but less than $\$ 86,000$, and $8 \%$ made over $\$ 86,000$. Of the 117 participants who answered the faculty status question, 32 were renewable non-tenure track (RNTT), 21 were tenure-track, and 54 were tenured. The 117 participants were made up of faculty from all five of the university's colleges: Business and Computing (13), Arts and Media (17), Education, Health, and Human Studies (39), Humanities and Social Sciences (28) and Science, Technology, Engineering, and Mathematics (20). The three different types of full-time faculty from the five different colleges are tabulated in Table 1.

\section{Global Burnout}

We tabulated global burnout scores by reverse scoring the items related to personal accomplishment (PA) and then adding those items to the emotional exhaustion (EE) and depersonalization (DP) scores. We then created the descriptive statistic of the average global burnout score by college (Table 2). A visual inspection of descriptive data suggested that the College of Education, Health, and Human Studies (COEHHS) had the lowest global burnout score-

It should be noted that the range of scores within the EE subscale was 0 to 16 (low); 17 to 26 (moderate) and >27 (high) (Garwood, et al., 
2018; Maslach, et al., 1986). Every college had an average EE score at 32 or above, indicating that all the faculty in these colleges have a high level of emotional exhaustion. The mean emotional exhaustion score of 36, can be compared to the mean of emotional exhaustion scores among faculty in the Lackritz 2004 study which was 19, and suggests that university faculty are at a higher risk of burnout now than 15 years ago.

\section{Data Screening and Regression Diagnostics}

We checked for univariate $(z$ score $\leq 3.00)$ and multivariate outliers (leverage > 0.21) among our participants. We also examined studentized residuals (jackknife residuals $>2$ ) to examine the distance between a predicted outcome value for each individual's score and the regression line and cook's distance (cook's $>1$ ) to examine the extent to which estimates of our regression coefficients change if any particular observation is deleted from the analysis (Mendenhall \& Sincich, 1996). An examination of the aforementioned indices did not suggest the need to remove any individuals from our sample. We also did not observe any gross violations of assumptions pertaining to the homogeneity of variance, linearity, and normality when reviewing residual and normal probability plots generated from the maximum and final models. Examination of Variance Inflation Factor (VIF) values and Condition Indices did not suggest the presence of collinearity among predictors in the maximum and final models as well. 


\section{Backward Chunkwise Elimination Procedure}

The backward chunkwise elimination procedure began with the chunkwise elimination procedure. Altogether the maximum model had four "chunks" of predictors (Table 3): (1) five subscales obtained from the Social Provisions Scale, (2) four dummy variables created to represent the five colleges in the university (with COEHHS as the reference category), (3) the institutional support scale, and (4) salary. The minimum test statistic, associated with salary, was not significant $\left[\left(F_{p}(1,92)=1.12, p=\right.\right.$ .29)]. Subsequently, we deleted salary from the model and reduced the total number of predictors in the model to three chunks. This result also negatively answers the third research question (Is there a relationship between salary tier and faculty burnout?).

After removing salary, we tested the remaining three chunks in a revised model. In this model, the minimum test statistic, associated with the dummy variables representing college, was not significant $\left[\left(F_{p}(4,98)\right.\right.$ $=1.81, p=.13)$. Subsequently, we deleted the dummy variables from the model and reduced the total number of predictors in the model to two chunks. In the next reduced model, the minimum test statistic, associated with institutional support, was significant $\left[\left(F_{p}(1,102)=8.60, p=.004\right)\right.$. Subsequently, we stopped the chunking elimination process and proceeded to the backward single variable elimination procedure. 


\section{Backward Single Variable Elimination Procedure}

In the first step of the backward single variable elimination procedure, the regression model with the two remaining chunks from the first part of the analysis was fitted as the base model. Specifically, we kept the SPS subscales and institutional support as predictors and examined single variables as opposed to chunks. Altogether, the base model included six predictors: (1) SPS guidance subscale, (2) SPS reassurance subscale, (3) SPS social integration subscale, (4) SPS attachment subscale, (5) SPS reliable alliance subscale, and (6) institutional support. The second step includes fitting all $k-1$ variable models defined by deleting one variable from the base model. For each model, the minimum test statistic, $F_{p}$, is examined for each single variable. If statistically significant $\left(F_{p}>F_{C R I T}\right)$, where $\alpha=.10$, the procedure stops and this reduced model is chosen as the final model. If not statistically significant $\left(F_{p}<F_{C R I T}\right)$, where $\alpha=.10$, the predictor is deleted with the minimum test statistic and $k$ is reduced by one. In this case, the second step is returned to and the process is repeated until a final model is determined.

Table 4 shows the regression parameters and statistical significance tests for all four models examined in this iterative, sequential procedure. SPS subscale of guidance, SPS subscale of reassurance of worth, and institutional support were the only remaining significant predictors in the final model, thus positively addressing RQ 1 (Is there a 
relationship between social support and faculty burnout?) and RQ 2 (Is there a relationship between institutional support and faculty burnout?). Specifically, for every point increase for SPS guidance, global burnout was lowered by 3.95 points. For every point increase of SPSS reassurance of worth, global burnout was lowered by 2.92 points. For every point increase of institutional support, global burnout was lowered by 0.75 points. This pattern of results does not support the hypothesis that institutional support would be the greatest mitigator of burnout. However, the next step in our analysis was to determine the "why" behind the numbers by conducting the qualitative stage of the study.

\section{Qualitative Response}

The primary author completed the five semi-structured interviews with faculty from the College of Education and Health and Human Studies. The participants represented five different departments (out of the seven: Child \& Family Studies, Communication Disorders, Elementary, Early \& Special Education, Kinesiology, Nutrition \& Recreation, Leadership, Middle \& Secondary Education, Nursing, and Psychology \& Counseling) in the college. All the participants volunteered via a recruitment e-mail. The participants included tenure-track, renewable non-tenure track (RNTT), and tenured faculty. All five of the volunteer participants were female. The interviews were transcribed with the Temi application for iPhone (Rev.com, 2019) during the interview and then edited by the primary author shortly after each session. 


\section{Themes}

After creating themes and subcategories, the primary author met with one of the coauthors who served as an inquiry auditor (Lincoln $\&$ Guba, 1985) and created the final table (Table 5). The themes that emerged were guidance, with the subcategories of colleague guidance, department chair guidance, and upper administration guidance; reassurance of worth with the subcategories of colleague, department chair and upper administration; personal accomplishment with the subcategories of discipline and research-related, student-related, and department-related; and institutional support with the subcategories of collegiality, family environment, collaboration, professional development, and respecting time.

Cutrona \& Russell (1987) describe social support in the form of guidance as informational support. Weiss (1974) referred to guidance as access to a trustworthy figure who can furnish emotional support and assist in developing a plan of action. This informational guidance was provided by trustworthy figures in the form of colleagues, department chairs, and upper administration, such as their dean, and the provost. For example, Participant 1 commented that a colleague provided "Guidance on how to fill out the (merit) form and what to include and things I hadn't thought of, there was just a lot of support there."

Reassurance of worth attests to an individual's competence in a social role (Weiss, 1974). Interview participants also felt this reassurance of worth from colleagues, department chairs, and upper administration, such as the dean or 
provost. Participant 4 described this, stating their department chair, "makes a deliberate effort to make sure that she checks in with people and makes them feel appreciated for the things that they do...there's all this invisible work and you feel like you grind and grind and grind and nobody notices and appreciates that. And I think that she's...aware of that."

The loss of feelings of personal accomplishment is associated with burnout (Maslach, et al., 2001). Participants described experiencing feelings of personal accomplishment for not only their own research and achievements but from the successes of their students and their departments as well. Participant 5 remarked, "We have a 100\% pass rate for our national certification exam, which is something that we are really proud of."

Employees form global beliefs concerning the extent to which the organization values their contributions and cares about their well-being (Eisenberger et al., 1986). This type of institutional support was identified by participants in the forms of collegiality (Participant 2 commented, "I feel safe with (the dean). I feel like they're approachable.”), family environment (Participant 1 described a "Christmas party every year and a summer party every year"), collaboration (Participant 4 referred to an atmosphere that was "Non-competitive...everybody is there hoping everyone succeeds"), professional development (Participant 5 noted, "I've been able to present at a national conference at least once every year and...haven't...had to pay out of my own pocket to go there"), and 
respecting time (Participant 3 remarked, "The chair... always did everything she could...to protect my time").

Following this audit, the process of member checking (Creswell, 2014; Lincoln \& Guba, 1985) was conducted. Member checks provide "the opportunity to assess intentionality" (Lincoln \& Guba, 1985, p. 314). Member checks ensured that the essence of the participants' meanings are articulated and interpreted accurately by the researcher. They also ensured that no participants' reality is ignored. The primary author sent each of the participants the table via email and asked for their feedback, checking to see if she had mischaracterized anything they said, if anything was inaccurate and if they agreed with the themes. All five participants responded and indicated the themes were consistent with their experiences and representations in the table provided. Other than one spelling correction, all of them have found the table to be accurate. Reflexive journaling was also utilized throughout the process to support the navigation of procedural and ethical challenges of being a participant researcher (Meyer \& Willis, 2019). By using these mixed methods, we were able to determine variables that mitigated faculty burnout, then gain a better understanding of what guidance, reassurance of worth, institutional support, and personal accomplishment looked like in the worklives of faculty in the College of Education, Health \& Human Studies.

\section{Discussion}

The themes discovered during the qualitative analysis meshed with the results of the quantitative analysis. When asked about support, participants repeatedly brought up guidance they received from 
colleagues, department chairs, and deans, as well as examples of times they experienced reassurance of their worth as scholars, teachers, and colleagues. When discussing institutional support, the concepts from the cross-domain buffering hypothesis of social support (Duffy, et al., 2002) were evident. Participants frequently commented on the stress of reorganization or frustration with upper administration, but then described how that was buffered by the supportive relationships they had with their colleagues and immediate supervisors.

While not a theme, something else that came up during the interviews reflected concerns about institutional support in the form of salary and how feelings of personal accomplishment reduced their intention to leave. Participant 2 commented, “We don't get paid enough. I mean, I could go become a (profession she prepares others for) and get paid more than I am right now... but because I feel like what I am doing is making a difference...some things are more important than money." Social support was also an important factor in the reduction of intention to leave, as Participant 3 shared, "I think the only thing that saves any of us is the culture of our department because I think we all would've been gone if it wasn't...for that." Multiple participants also mentioned upper administration, and sometimes not even their department chairs, understanding the difference between the types of work, or specialties in their discipline that would necessitate more faculty Full-Time Equivalent (FTE) hours, which represent the percent time a faculty member is paid to 
perform the teaching function (TAMU DARS, 2006), being given or higher salaries being offered to recruit faculty for new programs. One participant stated, "I mean it's really hard for us to recruit faculty, especially at the (names specific category of the profession) level because their salaries in the faculty position are so much less than what they can make in practice."

Based on these results, we find that our colleagues are a very specific kind of friend. Colleagues understand what each other are going through because they are going through it too. This supports Mark Granovetter's social networking theory $(1973,1983)$ which suggests that both strong ties (close friends and members of our inner circle) and weak ties (acquaintanceships) are important so that we can experience stability, loyalty, and comfort, as well as avoid having an isolated and insular perspective on the world (du Pre, 2017). Friends faculty have made through kids' playgroups or who they know from the gym can't offer advice on creating a merit binder; however, they can be a source of support when faculty need a break from the stressors their colleagues are experiencing as well.

We can also see that mentoring is vital in providing guidance and reassurance of worth. However, it also clear that there needs to be more consistent and careful programming in place to develop and foster these mentorships for university faculty. Research on other careers has shown formal mentoring programs can provide greater protection against burnout 
(Farnese, et al., 2017). The selection of mentors needs to be made carefully and it sometimes seems to be made randomly. For example, one participant reported that the original mentor she was assigned was not in the same building that she was and so they never met. She found someone willing to serve as her mentor who was in the same office suite. Another mentioned that she has been assigned to mentor someone who is also someone she supervises. This made it difficult for her to provide the type of support a mentor should when she, as a supervisor, also had to say "no" to some of her mentee's requests. Faculty location and roles are just a few of the considerations that should be made. Also, mentors should receive specific guidance as to what is expected of them and be supplied with resources to share with their mentees. Mentors should not be considered the only ones who can provide resources and guidance for their mentees. Time should be allocated for group mentoring activities that are very specific to each department, such as brown bag lunch sessions for tenure or merit binder advice. This would be consistent with Lunsford, et al.'s 2018 findings that the higher faculty mentors and mentees rate the quality of a mentoring relationship, the more job satisfaction they reported, as well as their suggestion that institutions may need to develop support for faculty members who may not desire to engage in mentoring, and create institutional supports focused on high-quality mentoring.

The participants' comments demonstrate that department chairs are instrumental in creating a culture of support. This aligns with Russell et al.'s 1987 study of public K12 school teachers which found the most 
important social provision was reassurance of worth from supervisors. Teachers who indicated that other people respected their skills and abilities reported less emotional exhaustion, more positive attitudes toward students, and greater personal accomplishment (Russell, et al., 1987). Specific actions chairs can take to create this culture range from community building, such as planning holiday parties or organizing potluck lunches, to reassurance of worth in the form of written and verbal commendations of department, student, and individual achievements, to tailored guidance. Guidance doesn't always have to be praise to be kind, but can also be concise and provide specific feedback that addresses a concern (Brown, 2018).

Upper administration should consider how they can increase institutional support even when they cannot increase salaries. They should also look at what they can do to offer guidance, provide reassurance of worth, and increase the faculty's feelings of personal accomplishment. Participants continually brought up the idea that they were frustrated when they felt they were left out of the loop, not valued as content experts, not listened to, or told to continue promoting successful activities (such as student research) even when the resources to fund those activities were taken away. This would suggest that anything upper administration can do to be approachable, increase communication, demonstrate that faculty concerns are considered, show faculty expertise is valued, and 
give more than lip service to valuing certain activities would improve faculty's perception of institutional support.

Finally, personal accomplishment emerged in both the survey and the interviews as being a key to reducing burnout. In the interviews, it became evident that personal accomplishment wasn't always "personal," as it was related not only to personal achievements such as publications and presentations but also to the success of the department and its students. Students' successful completion of credentialing and certification was a big component of participants' perceptions of accomplishment, as well as collaboration with their colleagues. However, the COEHHS is unique in how many of its programs culminate in becoming certified or credentialed as a speech-language pathologist, nurse, dietician, counselor, or teacher. Something to consider is how other colleges might feel this same accomplishment when their students aren't completing such milestones.

\section{Limitations and Future Directions}

One of the obvious limitations of this study is that it looks at only one regional public university in the Midwest. One of the inherent assumptions is that the authors are participant-observers (Yin, 2009) because the data were gathered at the institution where they are employed. Because all research is value-bound, our values needed to be examined (Lincoln \& Guba, 1985). The primary author engaged in reflexive journaling (Lincoln \& Guba, 1985) throughout the interview process, 
used one of the co-authors as an inquiry auditor (Lincoln \& Guba, 1985), and practiced member-checking (Lincoln \& Guba, 1985; Merriam \& Tisdell, 2016). Future research with other institutions' faculty will be valuable to compare our findings to larger and smaller public and private institutions, in different locations, where we are not participant-observers.

While the quantitative aspect of this study was vital in assuring our objectivity, the reliability of the SPS-short version subscales is a concern because they were each comprised of only two items each. We chose this version of the scale to reduce the length of the questionnaire (Fink, 2017). We checked the reliability using Cronbach's Alpha. Based on research one of the co-authors had previously done, we used the following guidelines to interpret this reliability coefficient (DeVellis, 2017): "below .60, unacceptable; between .60 and .65, undesirable; between .65 and .70, minimally acceptable; between .70 and .80 , respectable; between .80 and .90 , very good; above .90 , consider shortening the scale." We found that guidance was .695; reassurance of worth was .449. Comparatively, institutional support was .806. However, the themes of guidance and reassurance of worth were clearly communicated throughout the interviews, so we felt that this variable did have credence. In future studies, it might be desirable to use the full version of the SPS to alleviate this concern.

Finally, we chose to use the global burnout score to find the "least burned out" college, but we realize it would still be valuable to regress the 
data using the three burnout subscales (emotional exhaustion, depersonalization, and personal accomplishment) because each may have a different implication for the quality of work.

\section{Conclusion}

While there was not a relationship between salary and burnout score, institutional support was a reliably significant mitigator of burnout. Social support in the form of guidance and reassurance of worth were also mitigating factors of burnout, with guidance being the most significant and reliable. The College of Education and Health and Human Studies had the lowest global burnout score and can provide a model for other colleges and their departments at this university. The qualitative results from semi-structured interviews with COEHHS faculty supported the quantitative findings, revealing guidance, reassurance of worth, institutional support, and personal accomplishment to be mitigating factors of burnout. Deans and department chairs play a critical role in creating a culture of support in their college and departments, but relationships with colleagues may be the most important ones faculty have in mitigating burnout.

In 1967, The Beatles sang, "I get by with a little help from my friends." The refrain for faculty as they navigate academia and the completion agenda without succumbing to burnout may be, "I get by with a little help from my colleagues." 


\section{References}

Barrett, S. H. (2014). Accountability in higher education : A comparison of public perceptions to state higher education performance. ProQuest.

Beatles, The. (1967). I get by with a little help from my friends. [song]. On Sgt. Pepper's Lonely Hearts Club Band. Capitol.

Black, S. (2004). Stroking stressed-out teachers. Education Digest: Essential Readings Condensed for Quick Review, 69(5), 28-32.

Bolanos, H. (2019). Dating app burnout: When swiping becomes a chore. National Public Radio. https://www.npr.org/2019/06/26/736344196/dating-app-burnoutwhen-swiping-becomesa-chore

Bremer, B. A., \& Brooks, L. J. (2018). Social support as a coping strategy. In Salem Press Encyclopedia of Health. Salem Press.

Brown, B. (2018, October 15). Clear is Kind. Unclear is Unkind. Brené Brown. https://brenebrown.com/blog/2018/10/15/clear-is-kindunclear-is-unkind/

Cassel, J. (1976). The contribution of the social environment to host resistance. American Journal of Epidemiology, 104(2), 107-123. https://doi.org/10.1093/oxfordjournals.aje.a112281 
Childress, H. (2019, March 27). This is how you kill a profession. The Chronicle of Higher Education. https://www.chronicle.com/interactives/2019-03-27-childress

Chronicle of Higher Education, The. (2018). Great colleges to work for 2018. https://www.chronicle.com/interactives/greatcolleges 18

Cobb, S. (1995). Social support as a moderator of life stress. In A. M. Eward, J. E. Dimsdale, B. T. Engel, D. R. Lipsitt, D. Oken, J. D. Sapira, ... H. Weiner (Eds.), Toward an integrated medicine: Classics from "Psychosomatic Medicine," 1959-1979. (pp. 377397). American Psychiatric Association.

Conklin, M. H., \& Desselle, S. P. (2007). Development of a multidimensional scale to measure work satisfaction among pharmacy faculty members. American Journal of Pharmaceutical Education, 71(4), 1-9. https://www.ncbi.nlm.nih.gov/pmc/articles/PMC1959201/.

Cooper, E. (2019). Administration looks to move forward with changes to Saluki Success Program despite campus pushback. The Daily Egyptian. https://dailyegyptian.com/94241/showcase/administration-looksto-move-forward-withchanges-to-saluki-success-program-despitecampus-pushback/ 
Craighead, W.E. \& Nemeroff, C.B. (Eds.). (2004). The concise Corsini encyclopedia of psychology and behavioral science (3rd ed.). Wiley.

Creswell, J. W. (2014). Research design: Qualitative, quantitative and mixed methods approaches (4th ed.). SAGE.

Cutrona, C.E., \& Russell, D. W., (1987). The provisions of social relationships and adaptation to stress. In W.H Jones \& D. Perlman (Eds.), Advances in Personal Relationships. A Research Annual. (Vol. 1, pp. 37-67). JAI Press.

DeVellis, R. F. (2017). Scale development: Theory and applications. $\left(4^{\text {th }} \mathrm{ed}.\right)$ SAGE.

Djurkovic, N., McCormack, D., \& Casimir, G. (2008). Workplace bullying and intention to leave: The moderating effect of perceived organisational support. Human Resource Management Journal, 18(4), 405-422. https://doi.org/10.1111/j.1748-8583.2008.00081.x

Doyle, W.R. (2013). Playing the numbers: State funding for higher education: Situation normal? Change, 45(6), 58. https://doi.org/10.1080/00091383.2013.842112

Duffy, M.K., Ganster, D.C., \& Pagon, M. (2002). Social undermining in the workplace. The Academy of Management Journal, 45(2), 331. 
du Pre, A. (2017). Communicating About Health: Current Issues and Perspectives (5th ed.). Oxford University Press.

Eisenberger, R., Huntington, R., Hutchison, S., \& Sowa, D. (1986).

Perceived organizational support. Journal of Applied Psychology, 71(3), 500-507. https://doi.org/10.1037/0021-

9010.71 .3 .500

Eisenberger, R., \& Stinglhamber, F. (2011). Perceived organizational support: Fostering enthusiastic and productive employees. American Psychological Association.

Fabricant, M., \& Brier, S. (2016). Austerity blues: Fighting for the soul of public higher education. Johns Hopkins University Press.

Farnese, M. L., Barbieri, B., Bellò, B., \& Bartone, P. T. (2017). Don’t abandon hope all ye who enter here: The protective role of formal mentoring and learning processes on burnout in correctional officers. Work, 58(3), 319-331. https://doi.org/10.3233/WOR172628

Fink, A. (2017). How to conduct surveys: A step-by-step guide (6th ed). SAGE.

Freudenberger, H. J. (1977). Speaking from experience. Training \& Development Journal, 31(7), 26. 
Gagliardi, J.S., Parnell, A., \& Carpenter-Hubin, J. (2018). The analytics revolution in higher education: Big data, organizational learning, and student success.: Stylus.

Garwood, J. D., Werts, M. G., Varghese, C., \& Gosey, L. (2018). Mixedmethods analysis of rural special educators' role stressors, behavior management, and burnout. Rural Special Education Quarterly, 37(1), 30-43. https://doi.org/10.1177/8756870517745270.

Gottlieb, B. H., \& Bergen, A. E. (2010). Social support concepts and measures. Journal of Psychosomatic Research, 69(5), 511-520. https://doi.org/10.1016/j.jpsychores.2009.10.001

Granovetter, M.S. (1973). The strength of weak ties. American Journal of Sociology, 78, 1360-1380.

Granovetter, M.S. (1983). The strength of weak ties: A network theory revisited. Sociological Theory, 1, 201-233.

Heffernan, T. A., \& Heffernan, A. (2019). The academic exodus: The role of institutional support in academics leaving universities and the academy. Professional Development in Education, 45(1), 102113. https://doi.org/10.1080/19415257.2018.1474491

Hill, B., \& Spinella, S. (2018, March 8). The employment picture at MU: More departures than hires. The Columbia Missourian. 
https://www.columbiamissourian.com/news/higher_education/theemployment-pictureat-mu-more-departures-thanhires/article_841c090c-2234-11e8-8fc9-4ffea3b094f1.html

Horowitz, J., \& Phillips, B. C. (2014). The college completion agenda : Practical approaches for reaching the big goal. Jossey-Bass.

Ivankova, N. V., Creswell, J. W., \& Stick, S. L. (2006). Using mixedmethods sequential explanatory design: From theory to practice. Field Methods, 18(1), 3-20. https://doi.org/10.1177/1525822X05282260

Johnsrud, L.K., \& Rosser, V.J. (2002). Faculty members' morale and their intention to leave: A multilevel explanation. The Journal of Higher Education, 73(4), 518.

Jones, S., \& Griep, Y. (2018) "I can only work so hard before I burn out." A time-sensitive conceptual integration of ideological psychological contract breach, work effort, and burnout. Frontiers in Psychology 9 (131), 1-14. https://doi.or/10.3389/fpsyg.2018.00131

Kingston-Mann, E. \& Sieber, T. (Eds.). (2001). Achieving against the odds: How academics become teachers of diverse students. Temple University Press. 
Kleinbaum, D. G., Kupper, L. L., Nizam, A., Muller, K. E. (2008). Applied regression analysis and other multivariable methods (4th ed.). Duxbury Press.

Lackritz, J. R. (2004). Exploring burnout among university faculty: Incidence, performance, and demographic issues. Teaching and Teacher Education, 20(7), 713-729. https://doi.org/10.1016/j.tate.2004.07.002

Lee, A., Thomas, G., Martin, R., \& Guillaume, Y. (2019). LeaderMember Exchange (LMX) ambivalence and task performance: The cross-domain buffering role of social support. Journal of Management, 45(5), 1927-1957. https://doi.org/10.1177/0149206317741190

Lincoln, Y.S., \& Gouba, E.G. (1985). Naturalistic Inquiry. SAGE.

Lounder, A., Wagaman, C., Kenyon, M., Levine, A., Meekins, M., \& O'Meara, K. (2011). Following the cuts: How is the recession affecting faculty work?. Liberal Education, 97(1), 20-29.

Lunsford, L., Baker, V., Pifer, M. (2018). Faculty mentoring faculty: Career stages, relationship quality, and job satisfaction. International Journal of Mentoring and Coaching in Education, 7(2), 139-154.

Maslach, C., \& Jackson, S. E. (1981). The measurement of experienced burnout. Journal of Organizational Behavior 2(2): 99-113. 
Maslach, C., Jackson, S.E., \& Schwab, R.L. (1986). MBI-educator survey. Mind Garden.

Maslach, C., Jackson, S.E. \& Leiter, M.P. (1996). MBI: Maslach burnout inventory: CPP, Incorporated.

Maslach, C., Schaufeli, W. B., \& Leiter, M. P. (2001). Job burnout. Annual Review of Psychology, 52(1), 397-423. https://doi.org/10.1146/annurev.psych.52.1.397

Merriam, S. B., \& Tisdell, E.J. (2016). Qualitative research: A guide to design and interpretation. (4th ed.). Jossey-Bass.

Mészáros, V., Ádám, Sz., Szabó, M., Szigeti, R., and Urbán, R. (2014). The bifactor model of the Maslach Burnout Inventory-Human Services Survey (MBI-HSS)-An alternative measurement model of burnout." Stress \& Health: Journal of the International Society for the Investigation of Stress. 30(1), 82-88.

Mendenhall, W. \& Sincich, T. (1996). A Second Course in Statistics: Regression Analysis (5th ed.). Prentice-Hall.

Millard, E. (2019). 5 Ways to avoid healthy food burnout. My Fitness Pal. https://blog.myfitnesspal.com/5-ways-to-avoid-healthy-foodburnout/

Moss, G. E. (1973). Illness, immunity and social interaction. Wiley Interscience. 
Mueller, L. (2011). Higher education funding in Missouri. [Doctoral dissertation, University of Missouri]. ProQuest Dissertations and Theses Global.

Padilla, M. A., \& Thompson, J. N. (2016). Burning out faculty at doctoral research universities. Stress and Health, 32(5), 551-558. https://doi.org/10.1002/smi.2661

Peirce, G. L., Desselle, S. P., Draugalis, J. R., Spies, A. R., Davis, T. S., \& Bolino, M. (2012). Identifying psychological contract breaches to guide improvements in faculty recruitment, retention, and development. American Journal of Pharmaceutical Education, 76(6), 108. https://doi.org/10.5688/ajpe766108

Perera, H. N. (2016). Construct validity of the Social Provisions Scale: A bifactor exploratory structural equation modeling approach. Assessment, 23(6), 720-733.

Periard, D. A. (2016). A bifactor model of burnout? An item response theory analysis of the Maslach Burnout Inventory - Human Services Survey. [Doctoral Dissertation, Wright State University]. ProQuest Dissertations and Theses Global.

Petersen, A. H. (2019). How millennials became the burnout generation. Buzz Feed. https://www.buzzfeednews.com/article/annehelenpetersen/millenn ials-burnoutgeneration-debt-work 
Reevy, Gretchen M., and Deason, G. (2014) Predictors of depression, stress, and anxiety among non-tenure track faculty. Frontiers in Psychology 5, 1-17. https://doi.org/10.3389/fpsyg.2014.00701.

Rev.com, Inc. (2019). Temi (version \# 1.12) [Mobile application software].

https://itunes.apple.com/us/app/temi-record-andtranscribe/id1269856195

Rosser, V.J. (2004). Faculty members' intentions to leave: A national study on their worklife and satisfaction. Research in Higher Education. 45(3): 285-309. https://doi.org/10.1023/B:RIHE.0000019591.74425.f1 .

Rosser, V.J. (2005). Measuring the change in faculty perceptions over time: An examination of their worklife and satisfaction." Research in Higher Education. 46(1) 81-107. https://doi.org/10.1007/s11162-004-6290-y.

Rubin, P. G. (2018). The policy filtering process: Understanding distinctive state responses to the national college completion agenda in the United States. Education Policy Analysis Archives, $26(60)$

Russell, D.W., Altmaier, E., Van Velzen, D. (1987). Job-Related stress, social support, and burnout among classroom teachers. Journal of Applied Psychology. 72(2). 269-274. 
Sabagh, Z., Hall, N. C., \& Saroyan, A. (2018). Antecedents, correlates, and consequences of faculty burnout. Educational Research, 60(2), 131-156. https://doi.org/10.1080/00131881.2018.1461573

Schaufeli, W. B., Bakker, A. B., Hoogduin, K., Schaap, C., \& Kladler, A. (2001). On the clinical validity of the Maslach Burnout Inventory and the Burnout Measure. Psychology \& Health, 16(5), 565.

Schulz, A. D., Schöllgen, I., \& Fay, D. (2018, July 12). The role of resources in the stressor- detachment model. International Journal of Stress Management.

http://dx.doi.org/10.1037/str0000100

Shumaker, S., \& Brownell, A. (2010). Toward a theory of social support: Closing conceptual gaps. Journal of Social Issues, 40, 11-36. https://doi.org/10.1111/j.15404560.1984.tb01105.x

Simmons, B. L. (2014). Organizational characteristics of happy organizations. In C. L. Cooper (Ed.), Wellbeing: a complete reference guide. Wiley.

Szigeti, R., Noémi B., Réka B., \& Urbán R. (2017). Burnout and depressive symptoms in teachers: Factor structure and construct validity of the Maslach Burnout Inventory - Educators Survey among elementary and secondary school teachers in Hungary. Stress 
and Health: Journal of the International Society for the Investigation of Stress. 33(5), 530-39. https://doi.org/10.1002/smi.2737.

Temi. Are my files private and secure? (2019, September 22). Temi. http://help.temi.com/en/articles/1594946-are-my-files-private-andsecure

Texas A\&M University Data and Research Services. Calculation of Faculty Full-Time Equivalent (FTE). TAMU-DARS. https://dars.tamu.edu/Data-andReports/Miscellaneous/files/faculty-fte-calculation.aspx

Thompson, T., \& Thompson, T. (Eds.). (2014). Encyclopedia of health communication. SAGE.

Weiss, R. (1974) The provisions of social relationships. In: Rubin, Z., Ed., Doing unto others, (pp. 17-26). Prentice Hall.

World Health Organization. (2018). International statistical classification of diseases and related health problems (11th Revision). https://icd.who.int/browse11/l-m/en

Yin, R. K. (2009). Case study research: Design and methods. SAGE.

Zahneis, M. (2018, June 29). As word of layoffs spreads, Western Illinois faculty members brace for the worst. The Chronicle of Higher Education. https://www.chronicle.com/article/AsWord-of-Layoffs-Spreads/243810 
Ziker, J. (2014, April 13). How professors use their time: Faculty time allocation. The Blue Review. https://thebluereview.org/facultytime-allocation/ 


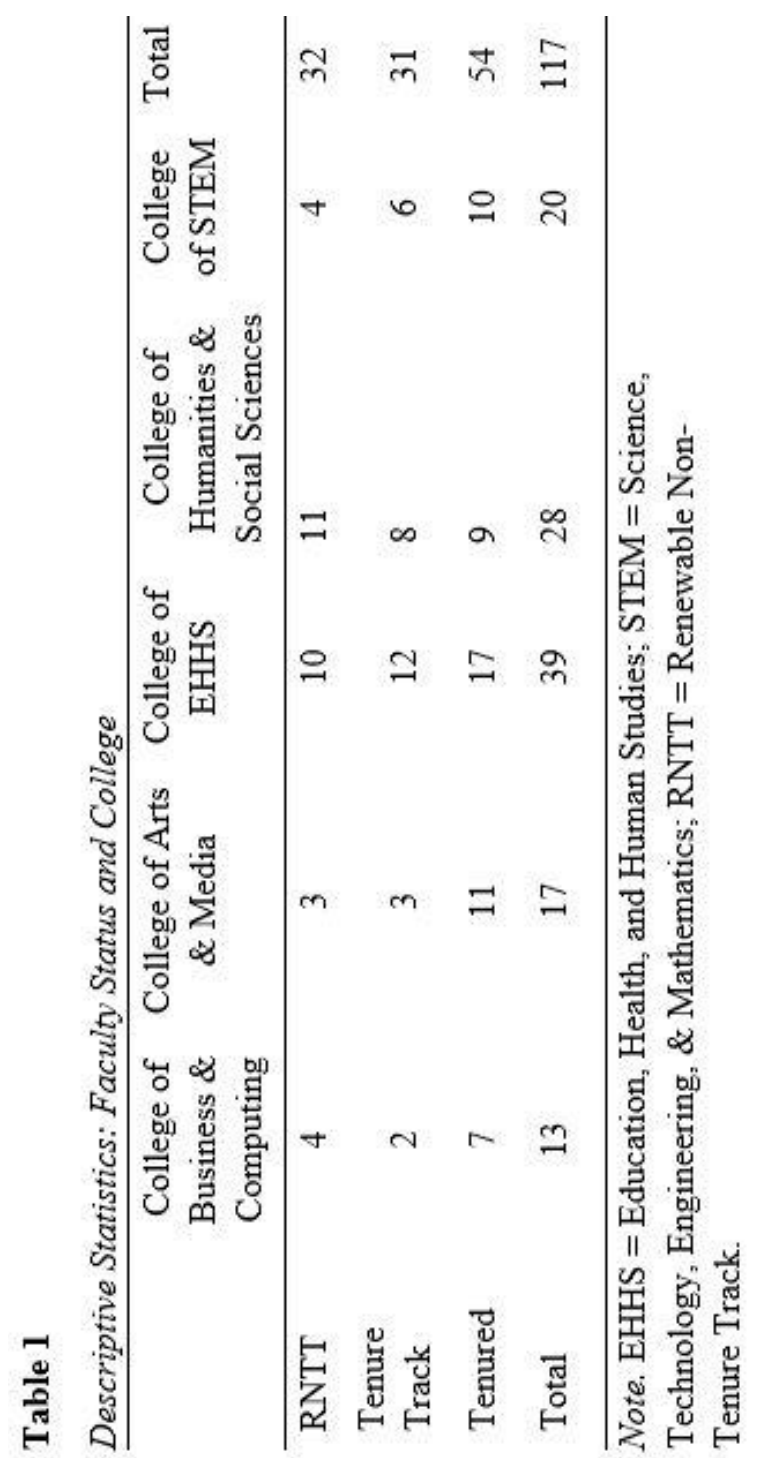




\section{Table 2}

College and Average Global Burnout Score

\begin{tabular}{lcccc}
\hline & $M$ & $N$ & $S D$ & Range \\
\hline College of Business \& & 73.33 & 12 & 22.93 & $39-107$ \\
Computing & 82.65 & 17 & 14.33 & $59-111$ \\
College of Arts \& Media & 68.89 & 36 & 19.13 & $25-111$ \\
College of EHHS & 69.38 & 26 & 17.08 & $25-99$ \\
College of Humanities \& & 77.20 & 20 & 15.60 & $48-111$ \\
Social Sciences & 73.09 & 111 & 18.26 & $25-111$ \\
College of STEM & Total &
\end{tabular}

Note. EHHS = Education, Health, and Human Studies; STEM = Science, Technology, Engineering, \& Mathematics 


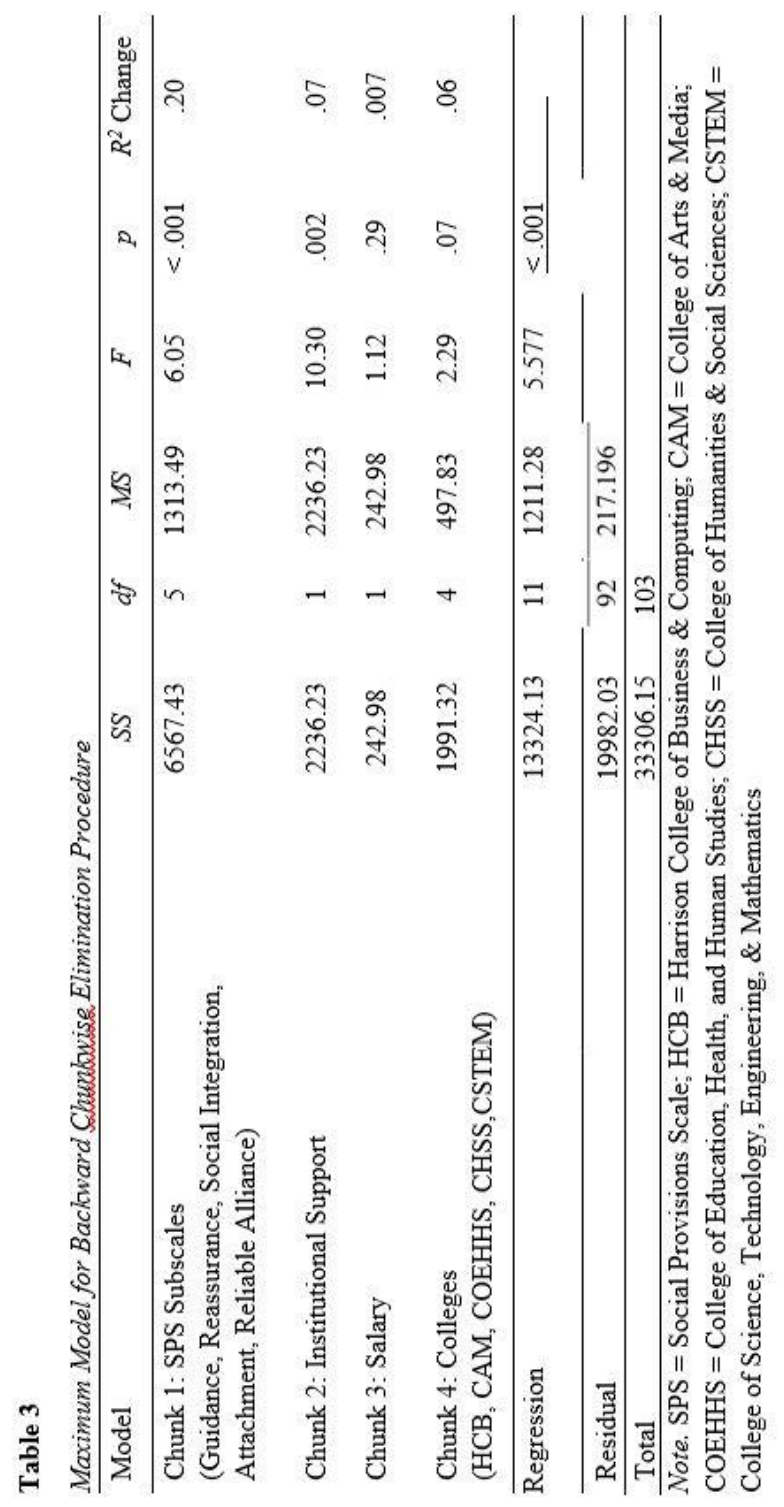




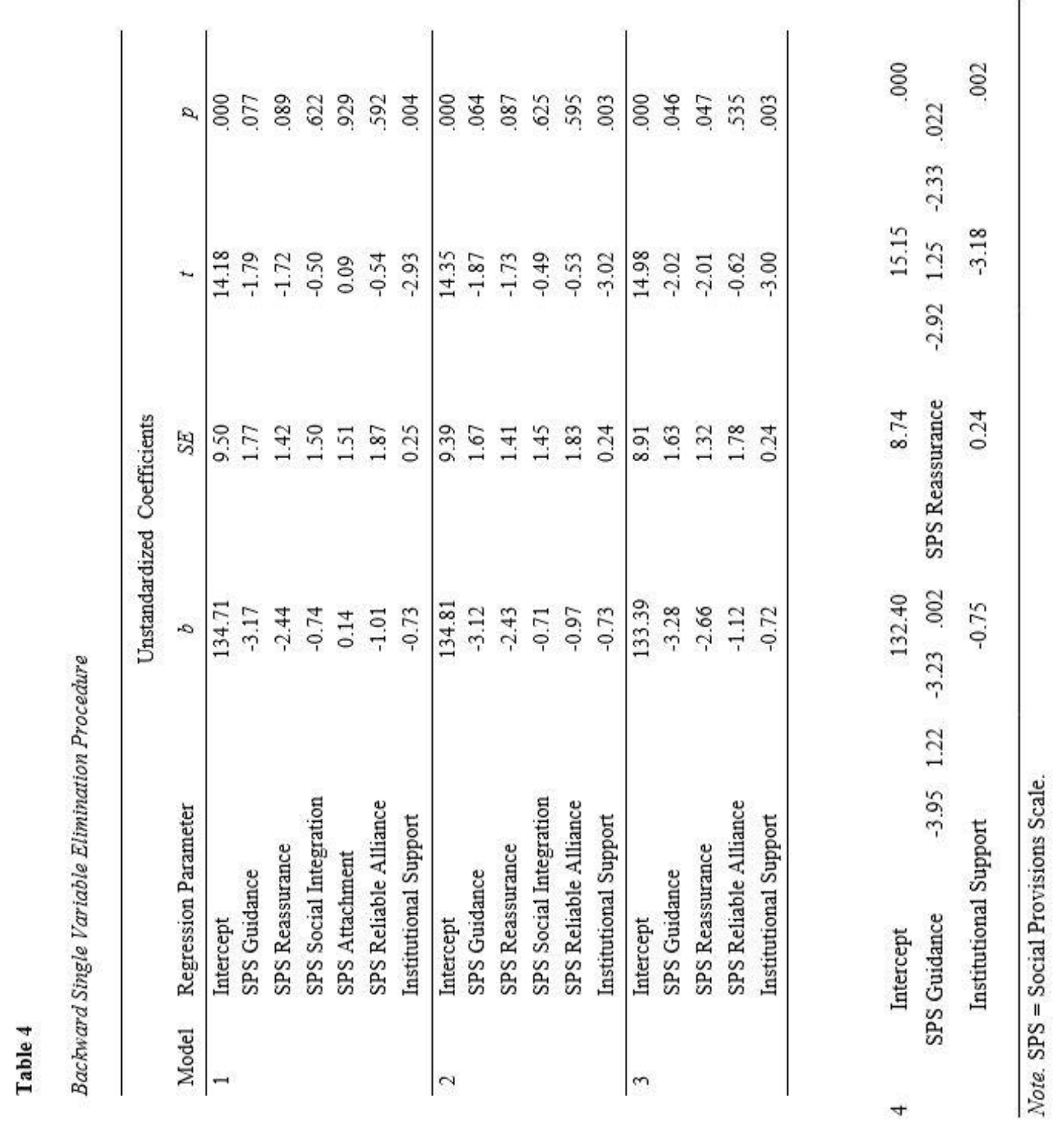


Table 5

Themes and Subcategories from Interviews

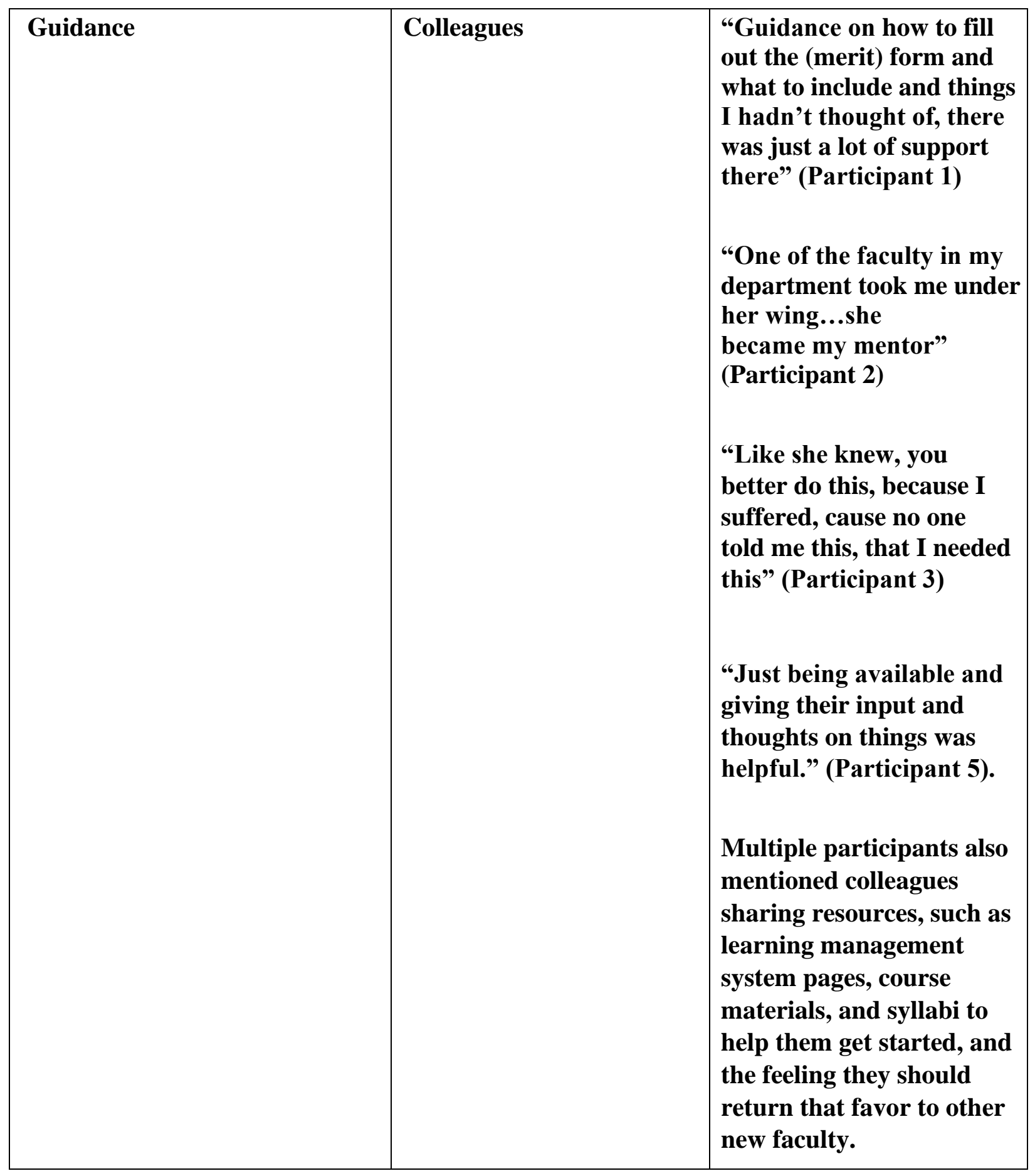




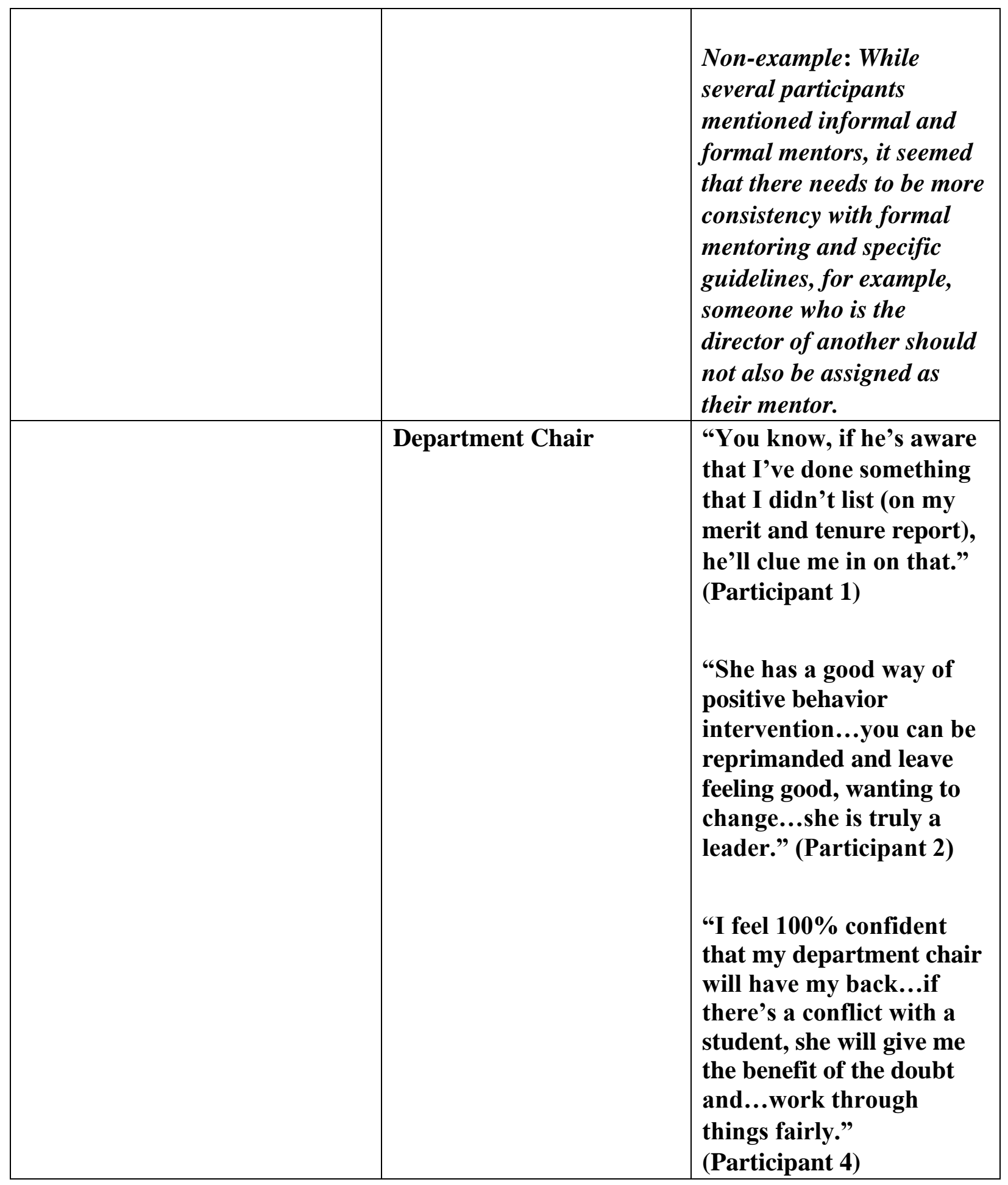




\begin{tabular}{|l|l|l|}
\hline & Upper Administration & $\begin{array}{l}\text { 'I feel like they're (chair } \\
\text { and dean) globally } \\
\text { looking at the best } \\
\text { interest of...the } \\
\text { institution and the } \\
\text { people...in their } \\
\text { particular roles on our }\end{array}$ \\
\hline
\end{tabular}

\begin{tabular}{|c|c|c|}
\hline & & $\begin{array}{l}\text { teams." (Participant 2) } \\
\text { "I feel like the interim } \\
\text { dean has fostered a lot of } \\
\text { that collaboration." } \\
\text { (Participant 3) } \\
\text { "I really felt (the dean) } \\
\text { did a nice job of } \\
\text { acknowledging what we } \\
\text { want to do when we're } \\
\text { looking at how we're } \\
\text { going to grow." } \\
\text { (Participant 5). }\end{array}$ \\
\hline \multicolumn{3}{|l|}{ Reassurance of Worth } \\
\hline & Colleagues & $\begin{array}{l}\text { "We disagree about } \\
\text { things but in the best way } \\
\text { possible. And we can sit } \\
\text { and have conversations } \\
\text { and I can be like, 'why } \\
\text { did you do this?' And she } \\
\text { kind of does the same } \\
\text { thing with me and we } \\
\text { keep each other in check." } \\
\text { (Participant 3). } \\
\text { Multiple participants also } \\
\text { mentioned working } \\
\text { together on projects with } \\
\text { colleagues, serving as } \\
\text { guest speakers for each } \\
\text { other. }\end{array}$ \\
\hline
\end{tabular}




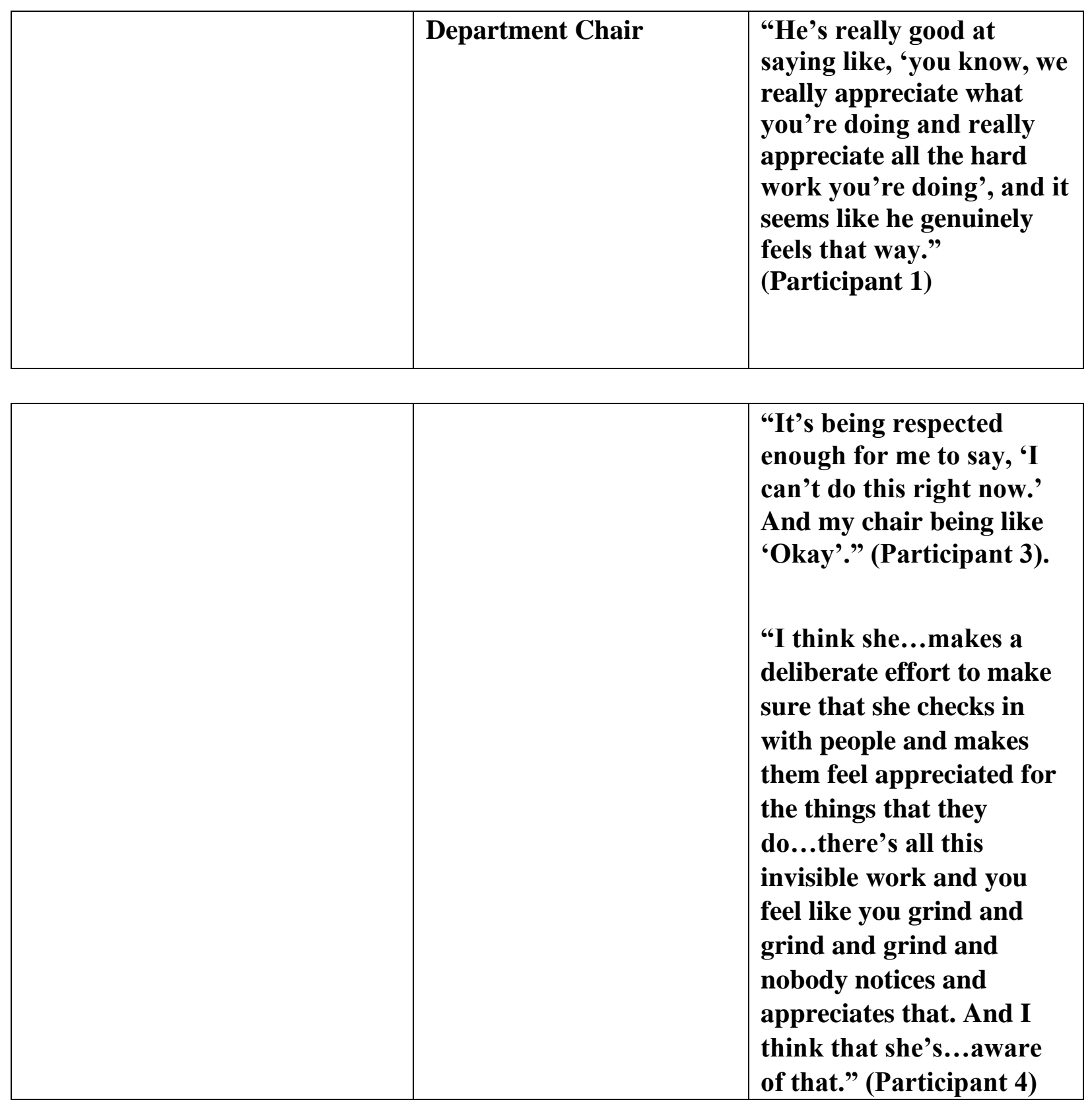




\begin{tabular}{|l|l|l|}
\hline & Upper Administration & $\begin{array}{l}\text { "The provost did have } \\
\text { two other things to do } \\
\text { that day too, and he } \\
\text { squeezed (her students } \\
\text { special project) in and } \\
\text { didn't make it seem like } \\
\text { he was in a rush. So I was } \\
\text { impressed." (Participant } \\
\text { 2) }\end{array}$ \\
& $\begin{array}{l}\text { 'I think it shows that } \\
\text { whether or not we get the } \\
\text { (financial) support, (the } \\
\text { provost)...at least he's } \\
\text { interested in hearing what } \\
\text { we want to do." } \\
\text { (Participant 5) }\end{array}$ \\
\hline Personal Accomplishment & Discipline and Research \\
& Related & $\begin{array}{l}\text { "We...invest so much of } \\
\text { our lives into our field and } \\
\text { we become, it becomes } \\
\text { much more than }\end{array}$ \\
\hline
\end{tabular}




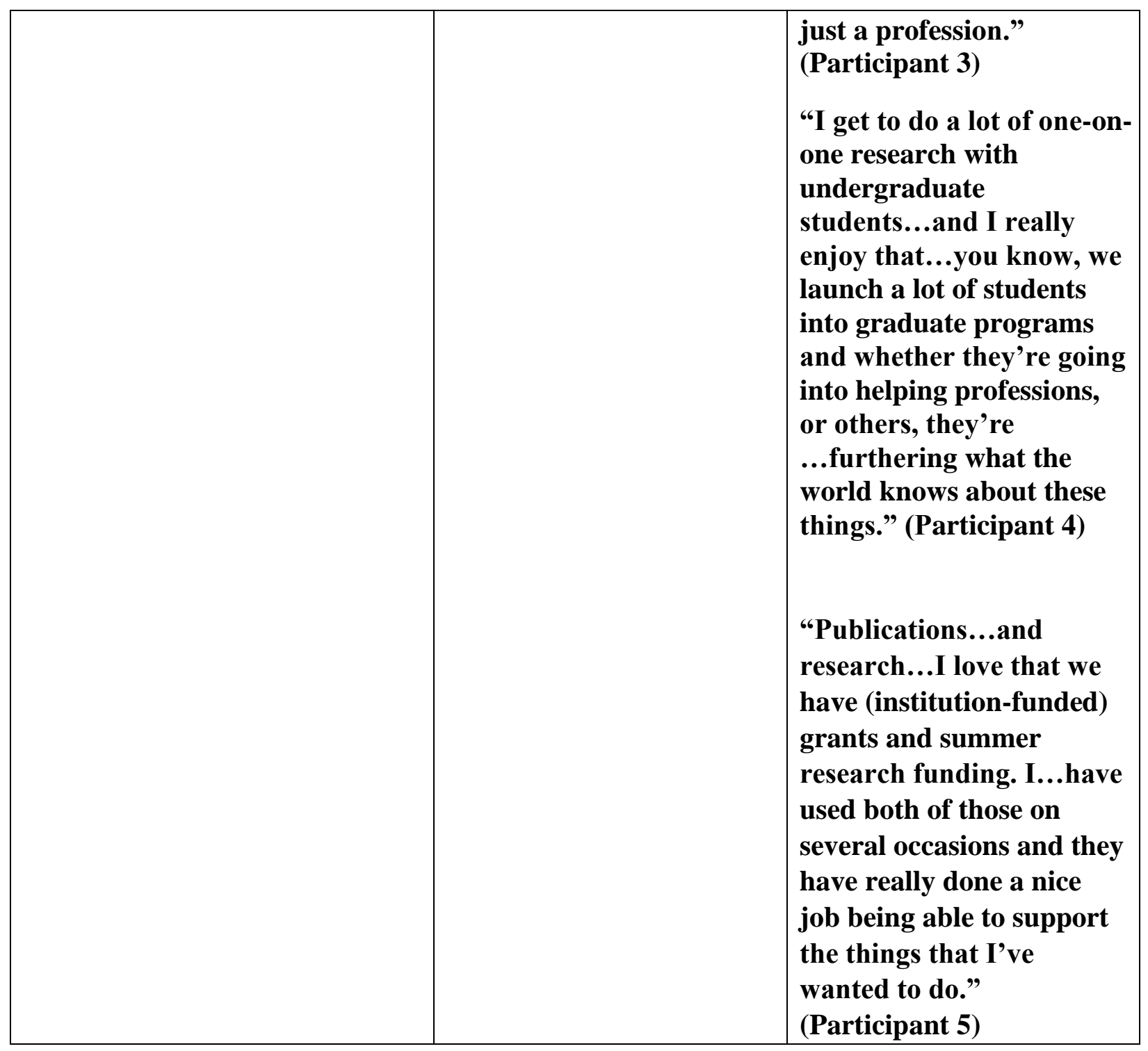




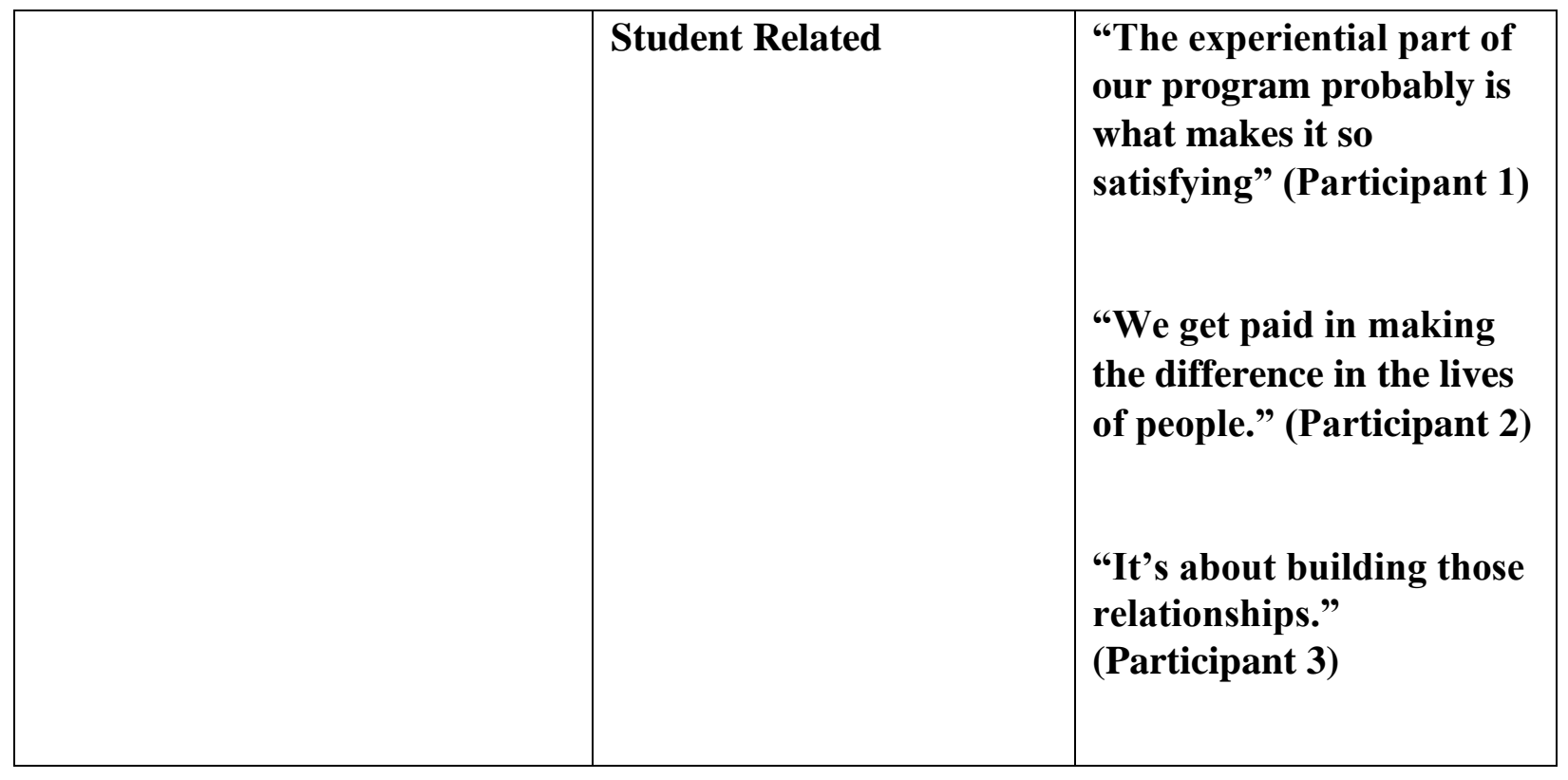

\begin{tabular}{|l|l|}
\hline & $\begin{array}{l}\text { "I feel like the nature of } \\
\text { our classes and the kinds } \\
\text { of relationships that I can } \\
\text { have with students make } \\
\text { me feel like there are } \\
\text { times when I can really } \\
\text { make a difference with } \\
\text { the student." (Participant } \\
\text { 4) }\end{array}$ \\
& $\begin{array}{l}\text { "Course evaluations...and } \\
\text { their responses to what } \\
\text { you're doing...like I was } \\
\text { nominated for an } \\
\text { (institution) award from } \\
\text { one of my students." } \\
\text { (Participant 5) } \\
\text { (artud }\end{array}$ \\
\hline
\end{tabular}




\begin{tabular}{|c|c|c|}
\hline & $\begin{array}{l}\text { Related to Department } \\
\text { Accomplishments }\end{array}$ & $\begin{array}{l}\text { "Every Monday, our } \\
\text { chair puts out... a Monday } \\
\text { morning message and it's } \\
\text { all really positive. And it } \\
\text { talks about the } \\
\text { accomplishments we all } \\
\text { have. And she will call out } \\
\text { people by } \\
\text { name...whoever went to } \\
\text { this conference and } \\
\text { represented us..." } \\
\text { (Participant } 2 \text { ) } \\
\\
\text { "I actually got a } \\
\text { text...from one of our } \\
\text { external supervisors...she } \\
\text { said, 'I obviously don't } \\
\text { know you but I just want } \\
\text { to tell you that whatever } \\
\text { you're doing is amazing in } \\
\text { this one class because I } \\
\text { have never had students } \\
\text { come out of there that can } \\
\text { do these things...and } \\
\text { we're getting that kind of }\end{array}$ \\
\hline & & $\begin{array}{l}\text { feedback not just about } \\
\text { my class" (Participant 3) } \\
\text { "We have a 100\% pass } \\
\text { rate for our national } \\
\text { certification exam, which } \\
\text { is something that we are } \\
\text { really proud of." } \\
\text { (Participant 5) } \\
\text { Several participants } \\
\text { mentioned getting } \\
\text { students credentialed. }\end{array}$ \\
\hline Institutional Support & & \\
\hline
\end{tabular}




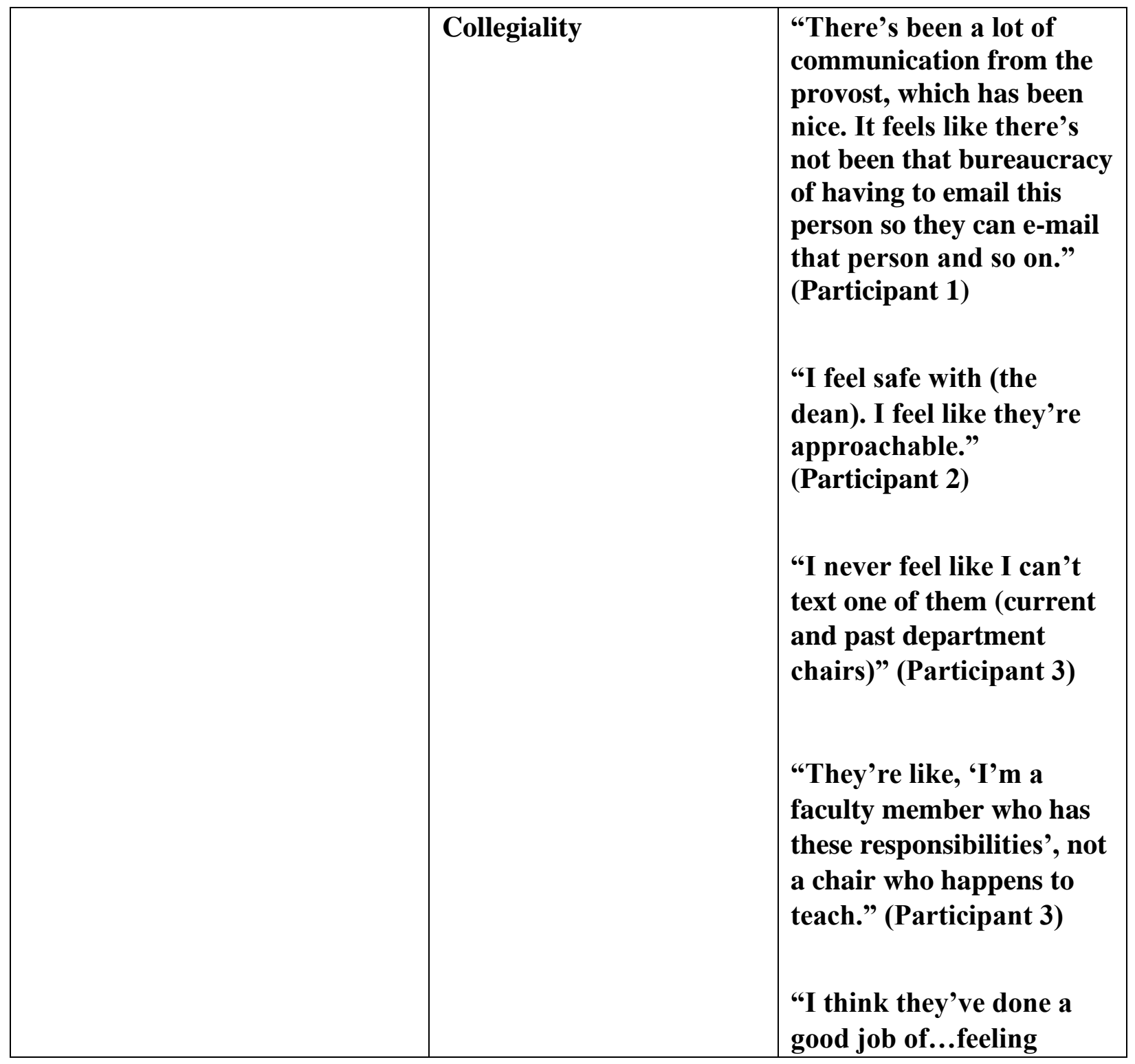




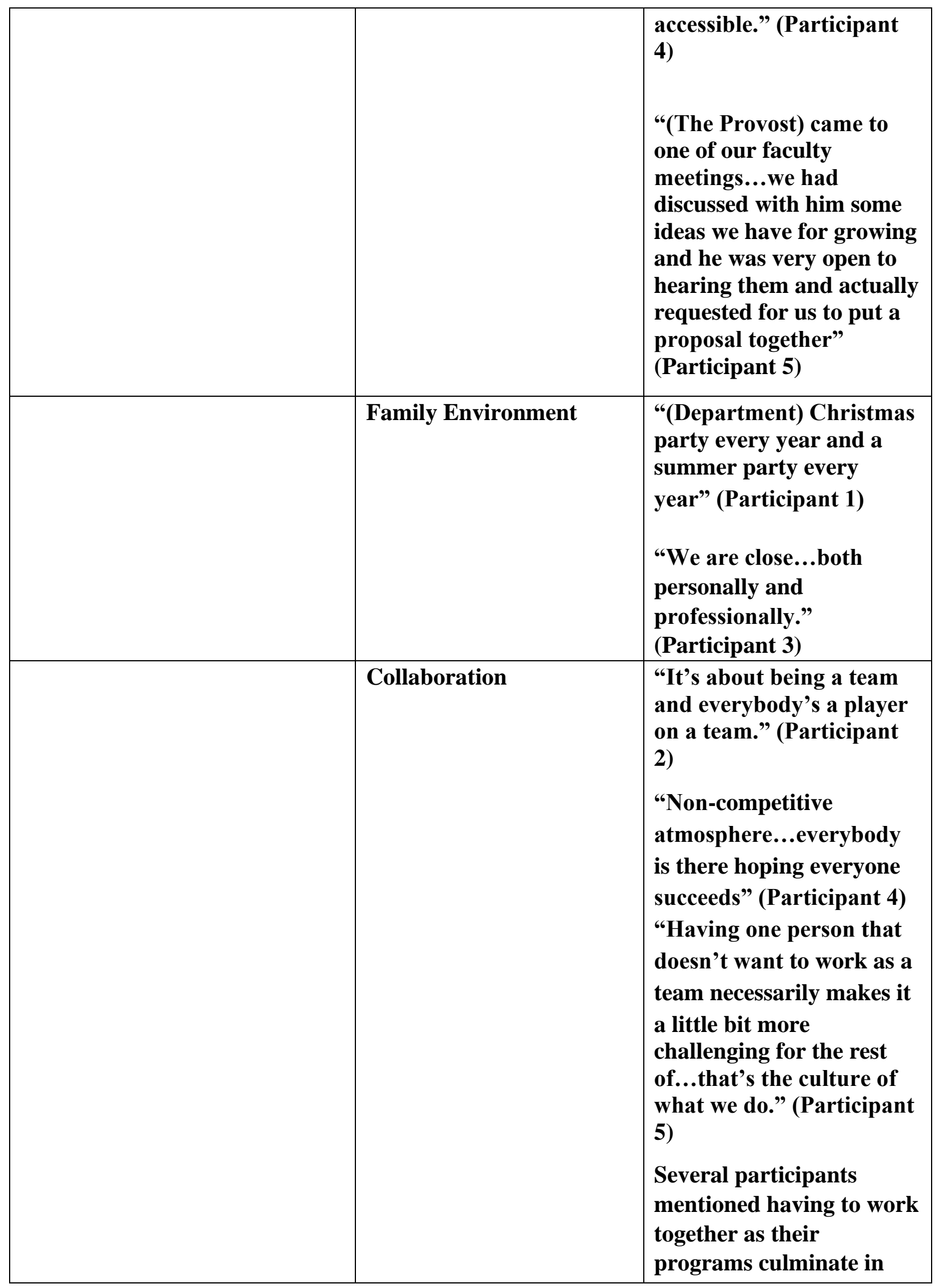




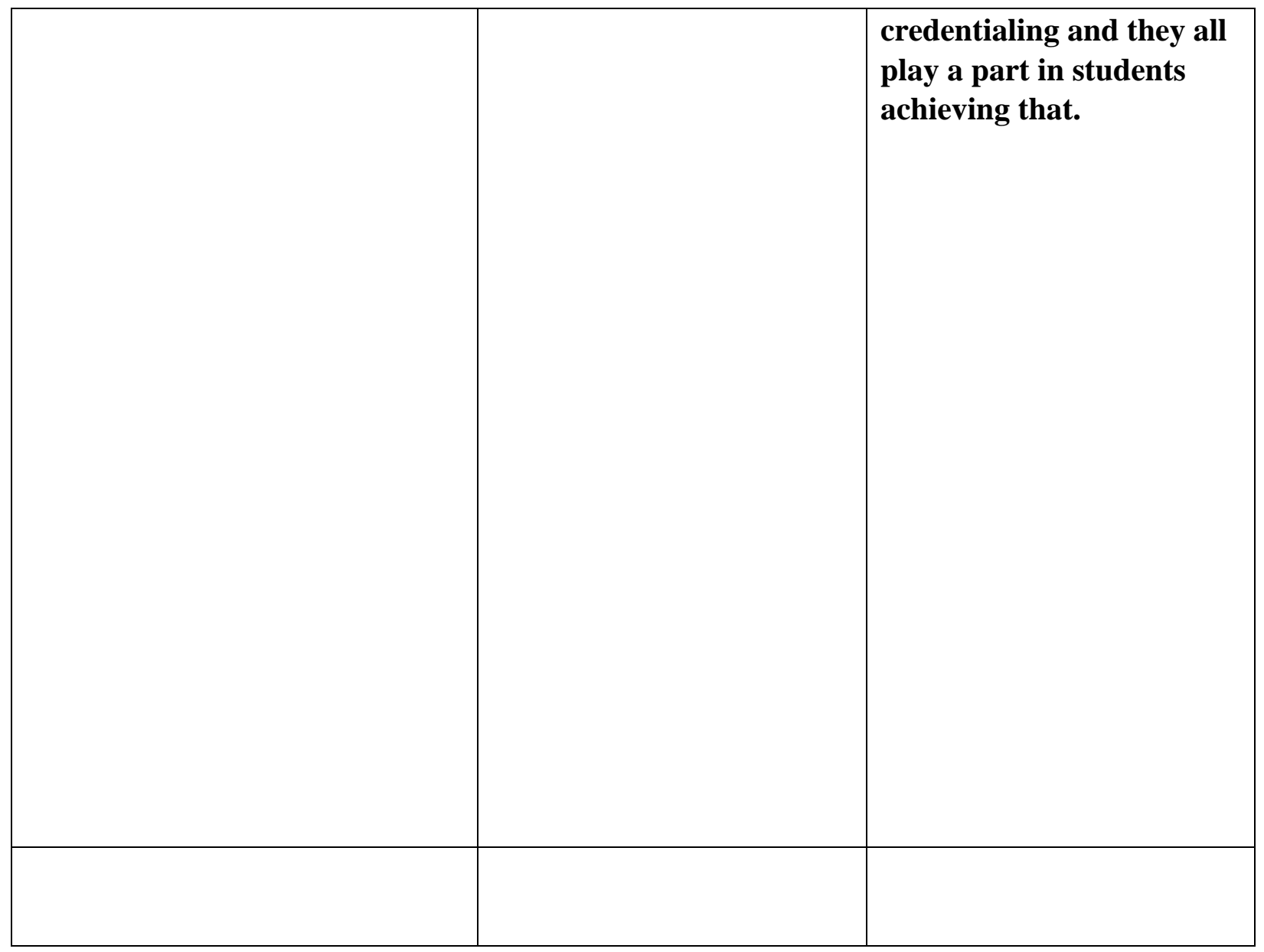




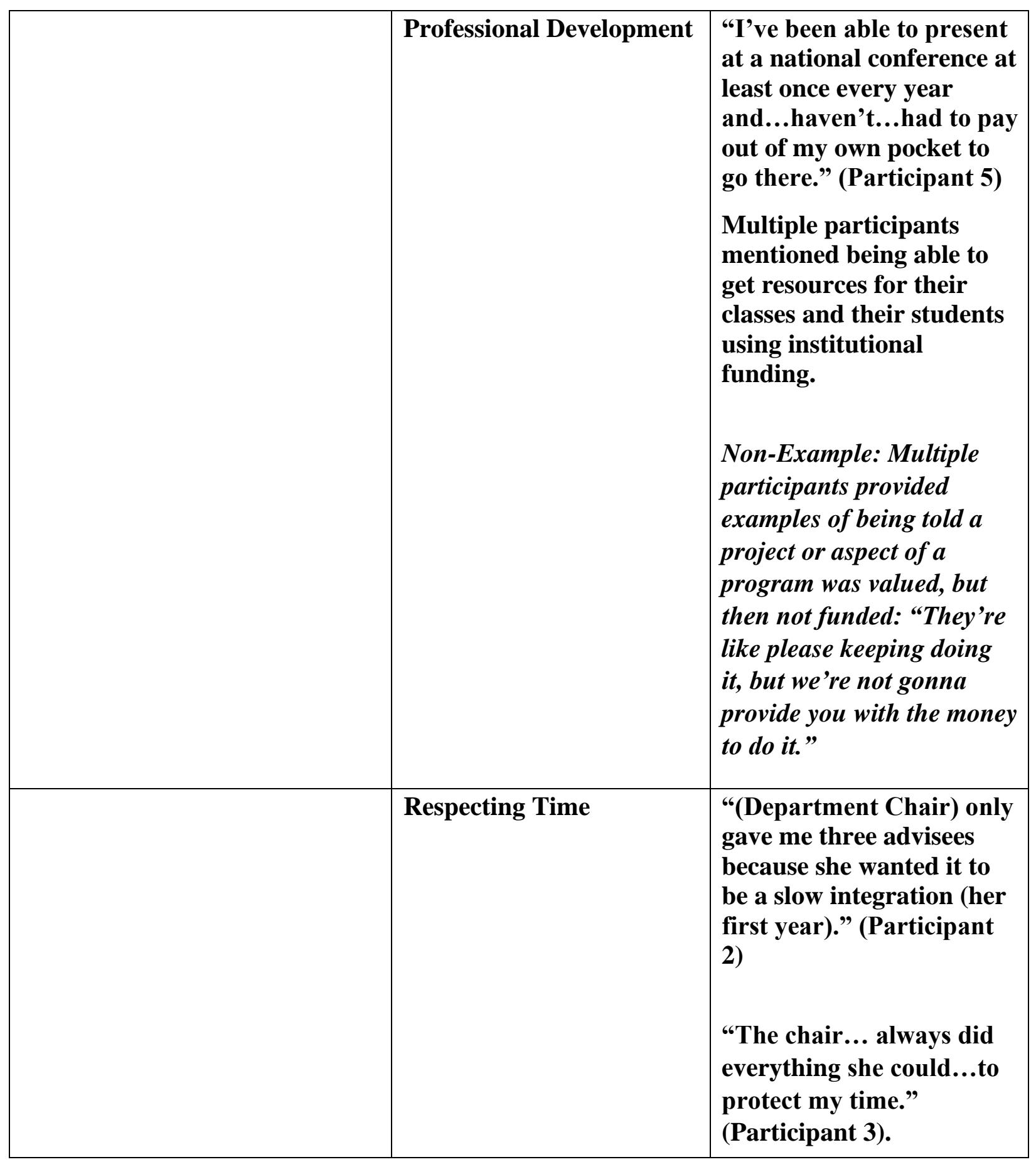




\section{References for Section Five Narrative}

Bray, N. J., \& Major, C. H. (2011). Status of journals in the field of higher education. The Journal of Higher Education, 82(4), 479-503. https://doi.org/10.1353/jhe.2011.0020

Cabell's International-Journals. (2019, August 28). http://www2.cabells.com.proxy.mul.missouri.edu/journals

Frey, L. L. (2018). When it hurts to work: Organizational violations and betrayals. New Directions for Teaching \& Learning, 2018(153), 87-98. https://doi.org/10.1002/t1.20284

Hott, B. L., \& Tietjen-Smith, T. (2018). The professional development needs of tenure track faculty at a regional university. Research in Higher Education Journal, 35.

Maslach, C. \& Leiter, M.P. (2014). Editorial. Burnout Research, 1. 1-2.

Maslach, C. \& Leiter, M.P. (2017). Editorial: The final volume of our journal, Burnout Research. Burnout Research, 7, 47. https://doi.org/10.1016/j.burn.2017.12.001

Mudrak, J., Zabrodska, K., Kveton, P., Jelinek, M., Blatny, M., Solcova, I., \& Machovcova, K. (2018). Occupational well-being among university faculty: A job demands-resources model. Research in Higher Education, 59(3), 325-348. https://doi.org/10.1007/s11162017-9467-x

National Communication Association (2019). Past \& future conventions. NCA. 
https://www.natcom.org/convention-events/convention-resources/archiveshistoricalinformation/past-future-conventions

National Communication Association (2020). NCA 106th Annual Convention:

Communication at the Crossroads Call for Papers: Health Communication Division. NCA.

https://ww4.aievolution.com/nca2001/index.cfm?do=pln.viewPlanner\&plannerID $=1383$.

Springer. (n.d). Research in Higher Education.

https://www.springer.com/education+\%26+language/higher+education/journal/11 162?de tailsPage $=$ pltci_1401270

Sproles, K. Z. (2018). The emotional balancing act of teaching: A burnout recovery plan. New Directions for Teaching \& Learning, 2018(153), 99-107. https://doi.org/10.1002/tl.20285 


\section{SECTION SIX: SCHOLARLY PRACTITIONER REFLECTION}

As I reflect on my growth as a leader since beginning the EdD program, I am reminded that there is not a "one size fits all" model of leadership. While there are some common characteristics of good leaders, leadership is a "complex process having multiple dimensions" (Northouse, 2016, p. 1). In Marron and Cunniff's 2014 article, they describe innovative educational leaders as individuals who have inspired trust among their fellow workers, have been effective team members, served well in past leadership roles as a collaborator, and have taken extra steps to make certain that the team mission is accomplished. They also posit that an innovative educational leader "uses assessment data to make organizational decisions and strives for continuous improvement, providing credit where credit is due" (Marron \& Cunniff, 2014, p. 148). An educational leader is also tasked with being a "scholarly practitioner", a term relatively unique to the Carnegie Project on the Education Doctorate (CPED) and its affiliate institutions (Zambo, Russ \& Zambo, 2015). Scholarly practitioners have knowledge, skills, and dispositions to solve the problems of practice they routinely encounter (CPED, 2010) and are tasked with disseminating their work in multiple ways (MacGregor \& Fellabaum, 2016). An essential skill for the scholarly practitioner is "the ability to use/generate "real world" data, qualitative and quantitative" (MacGregor \& Fellabaum, 2016, p. 60).

In this reflection, I will focus on how the dissertation process has influenced me as a scholarly practitioner by examining the impact it had on me as an educational leader, as well as a scholar. To do this, I will contemplate the theme of connectedness and incorporate excerpts from the reflexive journal I kept during the data collection and analysis process. 


\section{The influence of the dissertation process on my practice as an educational leader}

My StrengthsQuest results as I began the EdD program listed my top five strengths as connectedness, input, intellection, learner, and empathy (Gallup, 2000). I see the connectedness traits reflected in my leadership, as well as my content areas. I teach my institution's course on intercultural communication and consider cultural humility to be a significant component of my health communication curriculum, thus the idea that "Certain of the unity of humankind, you are a bridge builder for people of different cultures" (Gallup, 2020; para. 9) resonates with me. However, the CliftonStrengths Connectedness theme description begins with "Things happen for a reason. You are sure of it. You are sure of it because in your soul you know that we are all connected" (Gallup, 2020; para. 6). I feel it is important to clarify that I do not feel that connectedness means everything happens for a reason in the same way fatalistic people believe that everything is preordained, and they have no locus of control. I always try to figure out why things happen, looking at what Maslow referred to as the biological, cultural, and situational determinants that may have motivated a behavior (as cited in Shafritz, et al., 2005). I don't think believing there is a reason for a behavior is the same as believing every behavior is serendipitous or determined by destiny. I relate more to the idea that connectedness is about relationship-building (Gallup, 2020). Thus, I think my connectedness is informed by my other strengths---adding information through my input, intellection, and learner strengths while gaining emotional understanding through my empathy.

It was this connectedness that led me to the topic for this dissertation: faculty burnout. I saw my colleagues battling burnout and recognized its symptoms---emotional 
exhaustion, depersonalization, and a reduced sense of personal accomplishment (Maslach, et al., 2001)---in myself. It was a moment of "health communicator, heal thyself" as I decided to stop complaining and start researching. Bill George theorized that authentic leaders have a genuine desire to serve others, know themselves, and feel free to lead from their core values (2003; Northouse, 2016). This leadership style appeals to me because I desire to act in a way that is consistent with my expressed beliefs and morals, as well as to communicate openly and "be real" in relationships. (Northouse, 2016). Keeping a reflexive journal not only was part of the successful navigation of the procedural and ethical challenges (Meyer \& Willis, 2019) of being a participant researcher, but also part of my commitment to being "real." After I had defended my proposal, received IRB approval, and was on the cusp of sending out the questionnaire, I wrote:

As I prepare to send out the surveys and eventually conduct the interviews, I have to take a look at my own biases as a participant-observer. I struggle with burnout. I struggle with this dichotomy of being perceived as lazy or lucky by the public as I enjoy my long breaks (I feel like I have to point out that I teach during the summer and wintersessions too) and like a sucker by other academics, who wonder why I teach so much, why I didn't get the right degrees to get a tenuretrack position, etc. I feel like I have to work hard because that is who I am, but I also feel like there are diminishing returns given my position. I know what I perceive as good institutional support and the qualities I desire in a chair. (January 14, 2020). 
I think these biases were more evident for me because we were coming off of winter break. In the same grocery trip, I could encounter someone from church who would ask me if I had enjoyed all my time off and a colleague from another department who would ask me why in the world I would teach a wintersession class. At that moment, I would think, "maybe salary will be the only mitigator of burnout if she doesn't know the answer to that question is 'well, I could use the money!"” However, I transitioned from this attitude as response collection began and I once again felt a connection.

I felt connected to my colleagues as the completed surveys rolled in and the data analysis began. I observed the contrast of collecting this data while being on the search committee for our new department chair:

Today, the candidate mentioned on the way to lunch that she thought everyone was "pretty down" here. I told her that I think she was picking up on frustrated idealists. We still love our subjects, love teaching, have passion, but we see how things could be better and it frustrates us that we can't make them so. Because after sending out the reminder today, I am up to 122 responses...I think those are my peeps. The frustrated idealists who want to vent, but who also want some hope...something to restore the joy and balance they know can exist in doing what they love. (January 28, 2020)

I had no way of knowing how many of my fellow faculty were too burned out to participate or how many were feeling so satisfied, they didn't think they would have anything to contribute to the study. This also reminded me that when I think of faculty, I tend to think of the ones I interact with or am friends with, and also that I can tend to assume my experience is pretty similar to other faculty. 
Recognizing that my experiences are not the same as other faculty meant I also had to acknowledge that, when I began interviewing the participants who were faculty in the "least burned out college", in addition to gaining ideas about best practices to mitigate burnout, I would be feeling a little jealous.

(My advisor) picked up on the fact that I was surprised by some of the things that the participants said and I had to admit I was jealous. I was jealous that some chairs organize parties for their faculty and that faculty can text their chairs at any time. I was jealous of the family and team atmosphere some departments seem to have. I was jealous of the concept of being collegial with your dean and not feeling like you need to go through an intermediary to reach them. I was chewed out once by (my previous dean) because a candidate on a search committee I was chairing was not escorted to his office while I was teaching a class. Saying jealous sounds sort of childish and petty...I don't begrudge them any of these things. I just wished we had them too. (March 3, 2020)

My reflexive journaling enabled me to examine how as a participant-observer I could feel alternately connected and distant with the subjects of my study, sometimes experiencing empathy, but other times feeling jealous. It was a great reminder of the importance of considering others' realities. I often joke with my students who want to make assumptions based on their personal experiences ("There are employees of different races at my job, so discrimination isn't a problem anymore") by asking them "So, if you ate a sandwich, would world hunger be solved?" While the study expanded my perspective on all my faculty colleagues — not just the ones I am most familiar 
with-I recognized all this pointed to the importance of examining the personal, by also utilizing objective methods in this study.

Evidence-based education (EBE) is the assimilation of empirical evidence and professional wisdom to make informed decisions about educational practices, programs, and policies (Rozalski \& Rozalski, 2010). At the level of practice, evidence-based education is an attempt to encourage professionals to move away from reliance on personal experience as the basis for making decisions and toward incorporating research results. (Rozalski \& Rozalski, 2010). The ultimate goal of evidence-based education is to create a cycle in which research moves seamlessly to influence practice. Data can guard us against our own intuitive perceptions or ideas, as well as lead us to try to find out the stories behind the numbers. Thus, it was especially delightful for me to realize all of my research results were matching up with my lived experience and I was excited to share it with my colleagues, noting on February 27, 2020, "So far my data and my personal experience all support my hypothesis" and on March 3, 2020, "My findings ring true for me...my burnout is definitely mitigated by guidance, reassurance of worth, and institutional support!"

\section{The influence of the dissertation process on me as a scholar}

I have heard that as we age, we become "more so" and this would certainly apply to me and the assumptions about adult learners explored in Merriam \& Bierema's 2014 text, Adult Learning: Linking Theory and Practice. From when I started my undergraduate degree as an eighteen-year-old, to going into an MFA acting program right after getting my B.S.Ed., to returning for my MS in Health Communication a decade after receiving my MFA, to entering this EdD program four years after getting 
my MS, I have become increasingly independent, have used my life experiences as a resource, grown more focused on social roles of adult life, and find myself more problem-centered (Merriam \& Bierema, 2014). I am a very self-motivated and selfdirected learner, which served me well as I transitioned from coursework to comprehensive exams and the dissertation-in-practice.

Since I have been in the EdD program, I have gained theoretical insight and practical tools which can help me better lead in my classroom and my department. As I worked on the dissertation, I found that despite "working on my own," I was gaining insight into the connectedness of scholars. A faculty member from another department became a friend and future research partner as he helped me with my statistical analysis. I got excited talking about my subject and my research methods with other colleagues, experiencing the esprit de corps that comes from having gone through the same rite of passage. In the final chapter of Privilege, Power, and Difference, the author, Allan G. Johnson (2018) urges his readers, to "never doubt our potential to join with others in ways that make a difference." These words echoed in my head as I completed my first summer in ELPA's EdD program and have become a mantra for me, the thread of connectedness woven into all I have done.

Whether it is trying to develop strategies to mitigate the burnout my colleagues and I experience, or fighting for social justice, I feel as a scholar, I now have an angry hope, what Preskill \& Brookfield describe as a "clear-sighted view of how great the obstacles are, how daunting the challenges continue to be, but also an attainable strategic vision of what can be done to create communities where everyone has a fair chance of becoming their best selves as learners, active participants, and leaders" (2009, p. 184). I 
look forward to continuing my work as an advocate of connection, an authentic leader, a reflective person, and a scholarly practitioner. 


\section{References}

Gallup, Inc. (2000). StrengthsQuest [online survey]. https://strengthsquest.com.

Gallup, Inc. (2020). An Introduction to Connectedness: The CliftonStrengths Theme. Gallup. https://www.gallup.com/cliftonstrengths/en/252197/connectednesstheme.aspx

George, B. (2003). Authentic leadership: Rediscovering the secrets to creating lasting value. Jossey-Bass.

Johnson, A.G. (2018). Privilege, power, and difference. McGraw Hill.

MacGregor, C. J., \& Fellabaum, J. (2016). Dissertation redesign for scholarly practitioners in educational leadership: Increasing impact through disseminationready sections. In V. A. Storey \& K. A. Hesbol (Eds.), Contemporary approaches to dissertation development and research methods (pp. 53-69). Information Science Reference.

Marron, J. M., \& Cunniff, D. (2014). What is an innovative educational leader? Contemporary Issues in Education Research (Online), 7(2), 145.

Maslach, C., Schaufeli, W. B., \& Leiter, M. P. (2001). Job burnout. Annual Review of Psychology, 52(1), 397-423. https://doi.org/10.1146/annurev.psych.52.1.397

Merriam, S. B., \& Bierema, L. L. (2014). Adult learning: Linking theory to practice. Jossey-Bass. 
Meyer, K., \& Willis, R. (2019). Looking Back to Move Forward: The Value of Reflexive Journaling for Novice Researchers. Journal of Gerontological Social Work, 62(5), 578-585.

https://doi.org/10.1080/01634372.2018.1559906

Northouse, P.G. (2016) Leadership: Theory and practice $\left(7^{\text {th }}\right.$ ed.). SAGE.

Preskill, S., \& Brookfield, S. (2009). Learning as a way of leading: Lessons from the struggle for social justice. Jossey-Bass.

Rozalski, M., \& Rozalski. (2010). Evidence-based education (EBE). In T. C. Hunt, J. C. Carper, \& T. J. Lasley (Eds.), Encyclopedia of educational reform and dissent. SAGE.

Shafritz, J., Ott, S., \& Jang, Y. (Eds.). (2005). Classics of organization theory $\left(6^{\text {th }}\right.$ ed.). Wadsworth.

Zambo, D., Buss, R. R., \& Zambo, R. (2015). Uncovering the identities of students and graduates in a CPED-influenced EdD program. Studies in Higher Education, 40(2), 233252. https://doi.org/10.1080/03075079.2013.823932. 


\section{Appendix A: References}

Akgunduz, Y., Alkan, C., \& Gök, Ö. A. (2018). Perceived organizational support, employee creativity, and proactive personality: The mediating effect of meaning of work. Journal of Hospitality and Tourism Management, 34, 105-114. https://doi.org/10.1016/j.jhtm.2018.01.004

Appleby, J. (2020 March 16). Self-quarantine? Isolation? Social distancing? What they mean and when to do them. National Public Radio. https://www.npr.org/sections/healthshots/2020/03/16/816490025/quarantine-selfisolation-social-distancing-what-theymean-and-when-to-do-them

Are my files private and secure? (2019, September 22). Temi.

http://help.temi.com/en/articles/1594946-are-my-files-private-and-secure

Avanzi, L., Schuh, S. C., Fraccaroli, F., \& van Dick, R. (2015). Why does organizational identification relate to reduced employee burnout? The mediating influence of social support and collective efficacy. Work \& Stress, 29(1), 1-10. https://doi.org/10.1080/02678373.2015.1004225

Barrera, M., Sandler, I. M., \& Ramsay, T. B. (1981). Preliminary development of a scale of social support: Studies on college students. American Journal of Community Psychology,

9(4), 435-446. https://doi.org/10.1007/BF00918174

Barrera, M. (1986). Distinctions between social support concepts, measures, and models. American Journal of Community Psychology, 14, 413-445.

Barrett, S. H. (2014). Accountability in higher education : A comparison of public perceptions to state higher education performance. ProQuest. 
Beatles, The. (1967). I get by with a little help from my friends. [song]. On Sgt. Pepper's Lonely Hearts Club Band. Capitol.

Belcastro, P. A., \& Gold, R. S. (1983). Teacher stress and burnout: Implications for school health personnel. Journal of School Health, 53(7), 404-407. https://doi.org/10.1111/j.1746-1561.1983.tb03148.x

Bennett, E. A. (2017). The relationship between first-year student retention and type of faculty at a four-year public research university: A profile of three academic colleges. [Doctoral dissertation, Ohio University]. https://etd.ohiolink.edu/.

Bermejo-Toro, L., Prieto-Ursúa, M., \& Hernández, V. (2016). Towards a model of teacher wellbeing: Personal and job resources involved in teacher burnout and engagement.

Educational Psychology, 36(3), 481-501.

Bianchi, R., \& Janin, L. (2019). Burnout, depression and paranoid ideation: A clusteranalytic study. Occupational Medicine, 69(1), 35-38. https://doi.org/10.1093/occmed/kqy 150

Bianchi, R., Schonfeld, I. S., \& Laurent, E. (2019). Burnout: Moving beyond the status quo. International Journal of Stress Management, 26(1), 36-45. https://doi.org/10.1037/str0000088

Black, S. (2004). Stroking stressed-out teachers. Education Digest: Essential Readings Condensed for Quick Review, 69(5), 28-32.

Bliss, M. (2019). RCU sees enrollment decline even with record retention rate. The Southeast Missourian. https://www.semissourian.com/story/2636602.html 
Bolanos, H. (2019). Dating app burnout: When swiping becomes a chore. National Public Radio. https:/www.npr.org/2019/06/26/736344196/dating-app-burnoutwhen-swipingbecomes-a-chore

Bolman, L. G., \& Deal, T. E. (2013). Reframing Organizations: Artistry, choice, and leadership (5th ed.). Jossey-Bass.

Bowling, N. A., Alarcon, G. M., Bragg, C. B., \& Hartman, M. J. (2015). A meta-analytic examination of the potential correlates and consequences of workload. Work \& Stress, 29(2), 95-113.

Bray, N. J., \& Major, C. H. (2011). Status of journals in the field of higher education. The Journal of Higher Education, 82(4), 479-503. https://doi.org/10.1353/jhe.2011.0020

Bremer, B. A., \& Brooks, L. J. (2018). Social support as a coping strategy. In Salem Press Encyclopedia of Health. Salem Press.

Brian, A., \& Carter, E. S. (2004). Once again, Vanderbilt NICU in Nashville leads the way in nurses' emotional support. Pediatric Nursing, 30(6), 471-472. https://www.ncbi.nlm.nih.gov/pubmed/15704595

Bryan F. J., Hester, K., Barnett, T., Frey, L., \& Relyea, C. (2006). Perceived organizational support and perceived external prestige: Predicting organizational attachment for university faculty, staff, and administrators. Journal of Social Psychology, 146(3), 327-347. https://doi.org/10.3200/SOCP.146.3.327-347

Brown, B. (2018, October 15). Clear is Kind. Unclear is Unkind. Brené Brown. https://brenebrown.com/blog/2018/10/15/clear-is-kind-unclear-is-unkind/ 
Brown, S. (2017). How generations $X, Y$, and $Z$ may change the academic workplace. Chronicle of Higher Education, 64(4). https://www.chronicle.com/article/HowGenerations-X-YZ-/241185.

Cabell's International—Journals. (2019, August 28). http://www2.cabells.com.proxy.mul.missouri.edu/journals

Cahalin, L. P., Kaminsky, L., Lavie, C. J., Briggs, P., Cahalin, B. L., Myers, J., ... Arena, R. (2015). Development and implementation of worksite health and wellness programs: A focus on non-communicable disease. Progress in Cardiovascular Diseases, 58, 94-101.

Ada Calhoun. (2020). Why we can't sleep. Grove Press.

Card, A. J. (2018). Physician burnout: Resilience training is only part of the solution. Annals of Family Medicine, 16(3), 267-270. https://doi.org/10.1370/afm.2223

Cassel, J. (1976). The contribution of the social environment to host resistance. American Journal of Epidemiology, 104(2), 107-123. https://doi.org/10.1093/oxfordjournals.aje.a112281

Center for Scholarship in Teaching and Learning. (n.d.). https://cstl.semo.edu/cstl/FacultyDevelopment/

Chao S. F., McCallion P., \& Nickle, T. (2011). Factorial validity and consistency of the Maslach Burnout Inventory among staff working with persons with intellectual disability and dementia. Journal of Intellectual Disability Research 55(5), 529536.

https://www.ncbi.nlm.nih.gov/pubmed/21418367 
Chatterjee, R., \& Wroth, C. (2019, May 28). WHO redefines burnout as a "syndrome" linked to chronic stress at work. National Public Radio. https://www.npr.org/sections/healthshots/2019/05/28/727637944/who-redefinesburnout-as-a-syndrome-linked-to-chronicstress-at-work

Childress, H. (2019, March 27). This is how you kill a profession. The Chronicle of Higher Education. https://www.chronicle.com/interactives/2019-03-27-childress

Chronicle of Higher Education, The. (2018). Great colleges to work for 2018. https://www.chronicle.com/interactives/greatcolleges18

Cobb, S. (1995). Social support as a moderator of life stress. In A. M. Eward, J. E. Dimsdale, B. T. Engel, D. R. Lipsitt, D. Oken, J. D. Sapira, ... H. Weiner (Eds.), Toward an integrated medicine: Classics from "Psychosomatic Medicine," 1959-1979. (pp. 377-397). American Psychiatric Association.

Cockerham, T. (2016). Improving the compensation process in higher education: Fostering a high performing organization. [Doctoral dissertation, Capella University] ProQuest Dissertations and Theses Global.

Cohen, S., \& McKay, G. (1984). Social support, stress, and the buffering hypothesis. In S. E. Taylor \& J. E. Singer (Eds.), Handbook of psychology and health (Vol. 4, pp. 253-267). Erlbaum Associates.

Cohen, S., \& Pressman, S. (2004). Stress-buffering hypothesis. In N. B. Anderson (Ed.), Encyclopedia of health and behavior (Vol. 2, pp. 780782). SAGE. 
Cohen, S., \& Wills, T. A. (1985). Stress, social support, and the buffering hypothesis. Psychological Bulletin, 98(2), 310-357. https://doi.org/10.1037/0033-2909.98.2.310

Conklin, M. H., \& Desselle, S. P. (2007). Development of a multidimensional scale to measure work satisfaction among pharmacy faculty members. American Journal of Pharmaceutical Education, 71(4), 1-9. https://www.ncbi.nlm.nih.gov/pmc/articles/PMC1959201/.

Cooper, E. (2019). Administration looks to move forward with changes to Saluki Success Program despite campus pushback. The Daily Egyptian. https://dailyegyptian.com/94241/showcase/administration-looks-tomove-forward-withchanges-to-saluki-success-program-despite-campuspushback/

Cox, A., Solomon, B., \& Parris, D. (2018, May 8). Teacher well-being is a critical and often overlooked part of school health. Child Trends. https://www.childtrends.org/teacher-wellbeing-is-a-critical-and-often-overlookedpart-of-school-health

Craighead, W.E. \& Nemeroff, C.B. (Eds.). (2004). The concise Corsini encyclopedia of psychology and behavioral science (3rd ed.). Wiley.

Creswell, J. W. (2014). Research design: Qualitative, quantitative, and mixed methods approaches (4th ed.). Thousand Oaks, CA: SAGE.

Criblez, A., \& Dunn, R. (2019). The History of River City University. In First-Year Seminar: Connecting to RCU (3rd ed., pp. 17-33). Fountain Head Press. 
Cutrona, C.E., \& Russell, D. W., (1987). The provisions of social relationships and adaptation to stress. In W.H Jones \& D. Perlman (Eds.), Advances in Personal Relationships. A Research Annual. (Vol. 1, pp. 37-67). JAI Press.

Daly, C. J., \& Dee, J. R. (2006). Greener Pastures: Faculty turnover intent in urban public universities. The Journal of Higher Education, 77(5), 776803.

Demerouti, E., Nachreiner, F., Bakker, A. B., \& Schaufeli, W. B. (2001). The job demands resources model of burnout. Journal of Applied Psychology, (3), 499. https://doi.org/10.1037//0021-9010.86.3.499

DeVellis, R. F. (2017). Scale development: Theory and applications. (4 $4^{\text {th }}$ ed.) SAGE.

Dir, A. L., Saldana, L., Chapman, J. E., \& Aalsma, M. C. (2019). Burnout and mental health stigma among juvenile probation officers: The moderating effect of participatory atmosphere. Administration and Policy in Mental Health and Mental Health Services Research, 46(2), 167-174. https://doi.org/10.1007/s10488-018-0902-x

Djurkovic, N., McCormack, D., \& Casimir, G. (2008). Workplace bullying and intention to leave: The moderating effect of perceived organisational support. Human Resource Management Journal, 18(4), 405-422. https://doi.org/10.1111/j.17488583.2008.00081.x

Doyle, W.R. (2013). Playing the numbers: State funding for higher education: Situation normal? Change, 45(6), 58. https://doi.org/10.1080/00091383.2013.842112

Duffy, M.K., Ganster, D.C., \& Pagon, M. (2002). Social undermining in the workplace. The Academy of Management Journal, 45(2), 331. 
du Pre, A. (2017). Communicating About Health: Current Issues and Perspectives (5th ed.). Oxford University Press.

Dutton, J.E. \& Ragins, B. R. (Eds.) (2007). Exploring positive relationships at work. Lawrence Erlbaum Associates.

Eisenberger, R., Huntington, R., Hutchison, S., \& Sowa, D. (1986). Perceived organizational support. Journal of Applied Psychology, 71(3), 500-507. https://doi.org/10.1037/0021-

9010.71 .3 .500

Eisenberger, R., \& Stinglhamber, F. (2011). Perceived organizational support: Fostering enthusiastic and productive employees. American Psychological Association.

Fabricant, M., \& Brier, S. (2016). Austerity blues : Fighting for the soul of public higher education. Johns Hopkins University Press.

Farnese, M. L., Barbieri, B., Bellò, B., \& Bartone, P. T. (2017). Don’t abandon hope all ye who enter here: The protective role of formal mentoring and learning processes on burnout in correctional officers. Work, 58(3), 319-331. https://doi.org/10.3233/WOR-172628

Faulkner, M., \& Davies, S. (2005). Social support in the healthcare setting: the role of volunteers. Health \& Social Care in the Community, 13(1), 38-45. https://www.doi: 10.1111/j.1365-2524.2005.00526.x

Fila, M. J. (2016). The job demands, control, support model: Where are we now? TKM International Journal for Research in Management, 1(1), 15-44. 
Fink, A. (2017). How to conduct surveys: A step-by-step guide (6th ed). SAGE.

Finkelstein, M. J., Conley, V. M., \& Schuster, J. H. (2016). The faculty factor : Reassessing the American academy in a turbulent era. Johns Hopkins University Press.

Flaherty, C. (2013, January 11). After a professor's suicide. Inside Higher Ed. https://www.insidehighered.com/news/2013/01/11/campus-and-academiccommunities-left-wonder-why-after-professors-suicide

Flaherty, C. (2017a, April 21). Aftermath of a professor's suicide. Inside Higher Ed. https://www.insidehighered.com/news/2017/04/21/recent-suicideprofessorsparksrenewed-discussions-about-access-mental-health

Flaherty, C. (2017b, June 8). Portrait of faculty mental health. Inside Higher Ed. https://www.insidehighered.com/news/2017/06/08/study-facultymembers-mentalhealthissues-finds-mix-attitudes-disclosing-and

Fogg, P. (2009). When generations collide. Education Digest, 74(6), 25-30.

Fradelos, E., Mpelegrinos, S., Mparo, C., Vassilopoulou, C., Argyrou, P., Tsironi, M., \& Theofilou, P. (2014). Burnout syndrome impacts on quality of life in nursing professionals: The contribution of perceived social support. Progress in Health Sciences, 4(1), 102-109.

Freudenberger, H. J. (1977). Speaking from experience. Training \& Development Journal, 31(7), 26. 
Frey, L. L. (2018). When it hurts to work: Organizational violations and betrayals. New Directions for Teaching \& Learning, 2018(153), 87-98. https://doi.org/10.1002/tl.20284

Gaffigan, J. Cake. From Beyond the Pale. [Video]. YouTube. https://youtu.be/ou4IwXkbE?t=112.

Gagliardi, J.S., Parnell, A., \& Carpenter-Hubin, J. (2018). The analytics revolution in higher education: Big data, organizational learning, and student success. Stylus.

Gallup, Inc. (2000). StrengthsQuest [online survey]. https://strengthsquest.com.

Gallup, Inc. (2020). An Introduction to Connectedness: The CliftonStrengths Theme. Gallup. https://www.gallup.com/cliftonstrengths/en/252197/connectednesstheme.aspx

Gamson, Z. F., \& Chickering, A. W. (1991). Applying the seven principles for good practice in undergraduate education. Jossey-Bass Higher and Adult Education Series.

Garwood, J. D., Werts, M. G., Varghese, C., \& Gosey, L. (2018). Mixed-methods analysis of rural special educators' role stressors, behavior management, and burnout. Rural Special Education Quarterly, 37(1), 30-43. https://doi.org/10.1177/8756870517745270.

Geertz, C. (1973). The interpretation of cultures: Selected essays. Basic Books. 
Geist-Martin, P., \& Scarduzio, J. A. (2011). Working well: Reconsidering health communication at work. In The Routledge handbook of health communication (2nd ed., pp. 117-131). Routledge.

George, B. (2003). Authentic leadership: Rediscovering the secrets to creating lasting value. Jossey-Bass.

Goldsmith, D. J., \& Albrecht, T. L. (2011). Social support, social networks, and health. In The Routledge handbook of health communication (2nd ed., pp. 335-348). Routledge.

Golonka, K., Mojsa-Kaja, J., Blukacz, M., Gawłowska, M., Marek, T., \& Gawłowska, M. (2019). Occupational burnout and its overlapping effect with depression and anxiety. International Journal of Occupational Medicine \& Environmental Health, 32(2), 229-244. https://doi.org/10.13075/ijomeh.1896.01323

Golonka, K., Mojsa-Kaja, J., Gawlowska, M., \& Popiel, K. (2017). Cognitive impairments in occupational burnout: Error processing and its indices of reactive and proactive control. Frontiers in Psychology, 8(May). https://doi.org/10.3389/fpsyg.2017.00676

Gooblar, D. (2018a, April 3). 4 ideas for avoiding faculty burnout. The Chronicle of Higher Education. https://www.chronicle.com/article/4-Ideas-for-AvoidingFaculty/243010 
Gooblar, D. (2018b, April 17). 3 ways colleges can help faculty members avoid burnout. The Chronicle of Higher Education. https://www.chronicle.com/article/3-WaysCollegesCan-Help/243134.

Gottlieb, B. H., \& Bergen, A. E. (2010). Social support concepts and measures. Journal of Psychosomatic Research, 69(5), 511-520. https://doi.org/10.1016/j.jpsychores.2009.10.001

Granovetter, M.S. (1973). The strength of weak ties. American Journal of Sociology, 78, 1360-1380.

Granovetter, M.S. (1983). The strength of weak ties: A network theory revisited. Sociological Theory, 1, 201-233.

Hartnett, K. (2018, January 22). Restructuring proposal merges colleges, realigns departments. The Arrow. https://www.southeastarrow.com/story/2479770.html

Häusser, J., Mojzisch, A., Niesel, M., \& Schulz-Hardt, S. (2010). Ten years on: A review of recent research on the Job Demand-Control (-Support) model and psychological wellbeing. Work \& Stress, 24(1), 1-35.

Heffernan, T. A., \& Heffernan, A. (2019). The academic exodus: The role of institutional support in academics leaving universities and the academy. Professional Development in Education, 45(1), 102-113. https://doi.org/10.1080/19415257.2018.1474491

Heinemann, L. V., \& Heinemann, T. (2017). Burnout research: Emergence and scientific investigation of a contested diagnosis. SAGE Open, 7(1), 1-12. https://doi.org/10.1177/2158244017697154 
Henry, B. J. (2014). Nursing burnout interventions. Clinical Journal of Oncology Nursing, 18(2), 211-214. https://doi.org/10.1188/14.CJON.211-214.

Hicklin, C. (Winter 2020). Start the year right with self-care. School \& Community. 32-35.

Hill, B., \& Spinella, S. (2018, March 8). The employment picture at MU: More departures than hires. The Columbia Missourian. https://www.columbiamissourian.com/news/higher_education/the-employmentpictureat-mu-more-departures-than-hires/article_841c090c-2234-11e8-8fc94ffea3b094f1.html

Hock, R. R. (1988). Professional burnout among public school teachers. Public Personnel Management, 17(2), 167. https://doi.org/10.1177/009102608801700207

Horowitz, J., \& Phillips, B. C. (2014). The college completion agenda : Practical approaches for reaching the big goal. Jossey-Bass.

Hott, B. L., \& Tietjen-Smith, T. (2018). The professional development needs of tenure track faculty at a regional university. Research in Higher Education Journal, 35.

House, J. S. (1981). Work stress and social support. Addison-Wesley.

Huang Chih-Hsuan (2012). The relationships between organizational commitment and satisfaction on financial compensation: A study of full-time faculty at the 
TransWorld University. [Doctoral dissertation, TransWorld University]. Pro Quest Dissertations and Theses Global.

Ivankova, N. V., Creswell, J. W., \& Stick, S. L. (2006). Using mixed-methods sequential explanatory design: From theory to practice. Field Methods, $18(1), 3-20$.

https://doi.org/10.1177/1525822X05282260

Jackson, S.E., \& Maslach, C. (1982). After-effects of job-related stress: Families as victims. Journal of Occupational Behaviour, 3(1), 63.

Jennings, P.A., Snowberg, K.E., Coccia, M.A., \&Greenberg, M.T.. (2011). Improving classroom learning environments by cultivating awareness and resilience in education (CARE): Results of two pilot studies. The Journal of Classroom Interaction, 46(1), 37.

Johnson, A.G. (2018). Privilege, power, and difference. McGraw Hill.

Johnsrud, L. K., \& Heck, R. H. (1998). Faculty worklife: Establishing benchmarks across groups. Research in Higher Education, 39(5), 539.

Johnsrud, L.K., \& Rosser, V.J. (2002). Faculty members' morale and their intention to leave: A multilevel explanation. The Journal of Higher Education, 73(4), 518.

Jones, S., \& Griep, Y. (2018) "I can only work so hard before I burn out." A timesensitive conceptual integration of ideological psychological contract breach, work effort, and burnout. Frontiers in Psychology 9 (131), 1-14. https://doi.org/ 10.3389/fpsyg.2018.00131

Kabat-Zinn, J. (2015). Mindfulness. Mindfulness, 6(6), 1481-1483. 
https://doi.org/10.1007/s12671-015-0456-X

Kim, H., \& Rehg, M. (2018). Faculty performance and morale in higher education: A systems approach. Systems Research \& Behavioral Science, 35(3), 308.

King, N. (2016). When a psychologist succumbed to stress, he coined the term “burnout.” National Public Radio. https://www.npr.org/2016/12/08/504864961/when-apsychologistsuccumbed-to-stress-he-coined-the-term-burnout

Kingston-Mann, E. \& Sieber, T. (Eds.). (2001). Achieving against the odds: How academics become teachers of diverse students. Temple University Press.

Kleinbaum, D. G., Kupper, L. L., Nizam, A., Muller, K. E. (2008). Applied regression analysis and other multivariable methods (4th ed.). Duxbury Press.

Lackritz, J. R. (2004). Exploring burnout among university faculty: Incidence, performance, and demographic issues. Teaching and Teacher Education, 20(7), $713-729$. https://doi.org/10.1016/j.tate.2004.07.002

Lammers, J. C., Atouba, Y. L., \& Carlson, E. J. (2013). Which identities matter? A mixedmethod study of group, organizational, and professional identities and their relationship to burnout. Management Communication Quarterly, 27(4), $503-536$. https://doi.org/10.1177/0893318913498824

LaRocco, J. M., House, J. S., \& John R. P. French, Jr. (1980). Social support, occupational stress, and health. Journal of Health and Social Behavior, 21(3), $202-218$. 
https://doi.org/10.2307/2136616

Larson, L. M., Seipel, M. T., Shelley, M. C., Gahn, S. W., Ko, S. Y., Schenkenfelder, M., ... Heitmann, M. M. (2019). The academic environment and faculty well-being: The role of psychological needs. Journal of Career Assessment, 27(1), 167-182.

https://doi.org/10.1177/1069072717748667

Lee, A., Thomas, G., Martin, R., \& Guillaume, Y. (2019). Leader-Member Exchange (LMX) ambivalence and task performance: The cross-domain buffering role of social support. Journal of Management, 45(5), 1927-1957.

https://doi.org/10.1177/0149206317741190

Levin, J. S., \& Shaker, G. G. (2011). The hybrid and dualistic identity of full-time nontenuretrack faculty. American Behavioral Scientist, 55(11), 1461-1484. https://doi.org/10.1177/0002764211409382

Lincoln, Y.S., \& Gouba, E.G. (1985). Naturalistic Inquiry. SAGE.

Lounder, A., Wagaman, C., Kenyon, M., Levine, A., Meekins, M., \& O'Meara, K. (2011). Following the cuts: How is the recession affecting faculty work? Liberal Education, 97(1), 20-29.

Lunsford, L., Baker, V., Pifer, M. (2018). Faculty mentoring faculty: Career stages, relationship quality, and job satisfaction. International Journal of Mentoring and Coaching in Education, 7(2), 139-154.

MacGregor, C. J., \& Fellabaum, J. (2016). Dissertation redesign for scholarly practitioners in educational leadership: Increasing impact through disseminationready sections. In V. A. Storey \& K. A. Hesbol (Eds.), Contemporary 
approaches to dissertation development and research methods (pp. 53-69). Information Science Reference.

Marron, J. M., \& Cunniff, D. (2014). What is an innovative educational leader? Contemporary Issues in Education Research (Online), 7(2), 145.

Maslach, C., \& Jackson, S. E. (1981). The measurement of experienced burnout. Journal of Organizational Behavior, 2(2): 99-113.

Maslach, C., Jackson, S.E., \& Schwab, R.L. (1986). MBI-educator survey. Mind Garden.

Maslach, C., Jackson, S.E. \& Leiter, M.P. (1996). MBI: Maslach burnout inventory: CPP, Incorporated.

Maslach, C., Schaufeli, W. B., \& Leiter, M. P. (2001). Job burnout. Annual Review of Psychology, 52(1), 397-423. https://doi.org/10.1146/annurev.psych.52.1.397

Maslach, C. \& Leiter, M.P. (2014). Editorial. Burnout Research, 1. 1-2.

Maslach, C. \& Leiter, M.P. (2017). Editorial: The final volume of our journal, Burnout Research. Burnout Research, 7, 47. https://doi.org/10.1016/j.burn.2017.12.001

Mayoh, J., \& Onwuegbuzie, A. J. (2015). Toward a conceptualization of mixed methods phenomenological research. Journal of Mixed Methods Research, 9(1), 91-107. 
Maxwell, J.A. (2005). Qualitative research design: An interactive approach. ( $2^{\text {nd }}$ ed.) SAGE.

Mendenhall, W. \& Sincich, T. (1996). A Second Course in Statistics: Regression Analysis (5th ed.). Prentice-Hall. p. 422. ISBN 0-13-396821-9.

Merriam, S. B., \& Bierema, L. L. (2014). Adult learning: Linking theory to practice. Jossey-Bass.

Merriam, S. B., \& Tisdell, E.J. (2016). Qualitative research: A guide to design and interpretation. (4th ed.). Jossey-Bass.

Mészáros, V., Ádám, Sz., Szabó, M., Szigeti, R., and Urbán, R. (2014). The bifactor model of the Maslach Burnout Inventory-Human Services Survey (MBI-HSS)An alternative measurement model of burnout." Stress \& Health: Journal of the International Society for the Investigation of Stress. 30(1), 82-88.

Meyer, K., \& Willis, R. (2019). Looking Back to Move Forward: The Value of Reflexive Journaling for Novice Researchers. Journal of Gerontological Social Work, 62(5), 578-585.

https://doi.org/10.1080/01634372.2018.1559906

Millard, E. (2019). 5 Ways to avoid healthy food burnout. My Fitness Pal. https://blog.myfitnesspal.com/5-ways-to-avoid-healthy-food-burnout/ Mobley, W. (1982). Employee turnover: Causes, consequences, and control. AddisonWesley. 
Moeller, C., \& Chung-Yan, G. A. (2013). Effects of social support on professors' work stress. The International Journal of Educational Management; Bradford, 27(3), 188-202.

Moen, P., Kelly, E. L., Fan, W., Lee, S.-R., Almeida, D., Kossek, E. E., \& Buxton, O. M. (2016). Does a flexibility/support organizational initiative improve high-tech employees' well-being? Evidence from the work, family, and health network. American Sociological

Review, 81(1), 134-164.

Mountz, A. (2016). Women on the edge: Workplace stress at universities in North America. Canadian Geographer, 60(2), 205-218. https://doi.org/10.1111/cag.12277

Montoya, Y. L., \& Trethewey, A. (2009). Rethinking good work: Developing sustainable employees and workplaces. ASU.

http://humancommunication.clas.asu.edu/aboutus/Rethinking\%20Work\%20Devel opingS ustainableSelf.pdf

Moss, G. E. (1973). Illness, immunity, and social interaction. Wiley Interscience.

Mudrak, J., Zabrodska, K., Kveton, P., Jelinek, M., Blatny, M., Solcova, I., \& Machovcova, K. (2018). Occupational well-being among university faculty: A job demands-resources model. Research in Higher Education, 59(3), 325-348. https://doi.org/10.1007/s11162-

$017-9467-\mathrm{x}$ 
Mueller, L. (2011). Higher education funding in Missouri. [Doctoral dissertation, University of Missouri]. ProQuest Dissertations and Theses Global.

Mullen, P. R., Malone, A., Denney, A., \& Dietz, S. S. (2018). Job stress, burnout, job satisfaction, and turnover intention among student affairs professionals. College Student Affairs Journal, 36(1), 94-108. https://doi.org/10.1353/csj.2018.0006

National Center for Education Statistics (2018). Characteristics of DegreeGranting Postsecondary Institutions. U.S. Department of Education. Institute of Education Sciences, National Center for Education Statistics. https://nces.ed.gov/programs/coe/indicator_csa.asp.

National Communication Association (2019). Past \& future conventions. NCA. https://www.natcom.org/convention-events/convention-resources/archiveshistoricalinformation/past-future-conventions

National Communication Association (2020). NCA 106th Annual Convention:

Communication at the Crossroads Call for Papers: Health Communication Division. NCA.

https://ww4.aievolution.com/nca2001/index.cfm?do=pln.viewPlanner\&plannerID $=1383$.

Newport, C. (2019, February 12). Is email making professors stupid? The Chronicle of Higher Education. https://www.chronicle.com/interactives/is-email-makingprofessors-stupid

Northouse, P.G. (2016) Leadership: Theory and practice ( $7^{\text {th }}$ ed.). SAGE. 
Okeson-Haberman, A. If Missouri college students could party like its 1999, they'd save about $61 \%$ on tuition. National Public Radio. https://news.stlpublicradio.org/post/if-missouricollege-students-could-party-its1999-theyd-save-about-61-tuition

Padilla, M. A., \& Thompson, J. N. (2016). Burning out faculty at doctoral research universities. Stress and Health, 32(5), 551-558. https://doi.org/10.1002/smi.2661

Kamenetz, A. (2020, March 19). 'Panic-gogy': Teaching online classes during the coronavirus pandemic. National Public Radio. https://www.npr.org/2020/03/19/817885991/panicgogy-teaching-online-classesduring-the-coronavirus-pandemic.

Peirce, G. L., Desselle, S. P., Draugalis, J. R., Spies, A. R., Davis, T. S., \& Bolino, M. (2012). Identifying psychological contract breaches to guide improvements in faculty recruitment, retention, and development. American Journal of Pharmaceutical Education, 76(6), 108. https://doi.org/10.5688/ajpe766108

Perera, H. N. (2016). Construct validity of the Social Provisions Scale: A bifactor exploratory structural equation modeling approach. Assessment, 23(6), 720-733. https://doi.org/10.1177/1073191115589344

Periard, D. A. (2016). A bifactor model of burnout? An item response theory analysis of the Maslach Burnout Inventory - Human Services Survey. [Doctoral dissertation, Wright State University]. ProQuest Dissertations and Theses Global.

Petersen, A. H. (2019). How millennials became the burnout generation. Buzz Feed. 
https://www.buzzfeednews.com/article/annehelenpetersen/millennialsburnoutgeneration-debt-work

Pew Research Center (2019, January 17). The generations defined. Pew Research. https://www.pewresearch.org/fact-tank/2019/01/17/wheremillennials-end-andgeneration-z-begins/ft_19-01-17_generations_2019/.

Preskill, S., \& Brookfield, S. (2009). Learning as a way of leading: Lessons from the struggle for social justice. Jossey-Bass.

Price, J. (1997). Handbook of organizational measurement. International Journal of Manpower, 18(4/5/6), 303-558.

Price, M. \& Kerschbaum, S.L. (2017). Promoting supportive academic environments for faculty with mental illnesses: Resource guide and suggestions for practice. http://tucollaborative.org/wp-content/uploads/2017/05/Faculty-with-MentalIllness.pdf

Ramasamy, V., \& Abdullah, N. H. B. (2017). Faculty’s turnover in private higher learning Institutions: A phenomenal inquiry. Business and Economic Horizons; Prague, 13(2), 169-181.

Ray, E. B., \& Apker, J. (2011). Stress, burnout, and supportive communication: A review of research in health organizations. In The Routledge Handbook of Health Communication (2nd ed., pp. 428-440). Routledge.

Reevy, Gretchen M., and Deason, G. (2014) Predictors of depression, stress, and anxiety among non-tenure track faculty. Frontiers in Psychology 5, 1-17. https://doi.org/10.3389/fpsyg.2014.00701.

Rev.com, Inc. (2019). Temi (version \# 1.12) [Mobile application software]. 
https://itunes.apple.com/us/app/temi-record-and-transcribe/id1269856195

Roeser, R. W., Schonert-Reichl, K. A., Jha, A., Cullen, M., Wallace, L., Wilensky, R., Oberle, E., Thomson, K., Taylor, C., \& Harrison, J. (2013). Mindfulness training and reductions in teacher stress and burnout: Results from two randomized, waitlist-control field trials. Journal of Educational Psychology, 105(3), 787-804. https://doi.org/10.1037/a0032093

Rosser, V.J. (2004). Faculty members' intentions to leave: A national study on their worklife and satisfaction. Research in Higher Education. 45(3): 285-309. https://doi.org/10.1023/B:RIHE.0000019591.74425.f1.

Rosser, V.J. (2005). Measuring the change in faculty perceptions over time: An examination of their worklife and satisfaction." Research in Higher Education. 46(1) 81-107. https://doi.org/10.1007/s11162-004-6290-y.

Rhoades, L., \& Eisenberger, R. (2002). Perceived organizational support: A review of the literature. Journal of Applied Psychology, 87(4), 698-714. https://doi.org/10.1037/00219010.87 .4 .698

River City University Faculty Senate. (2019). https://semo.edu/facultysenate/handbook/1f.html

River City University Mission and Vision Statements (2019). https://semo.edu/planning/mission-vision.html 
River City University Newswire (2017). Rucker named Asst. To the President for Equity and Diversity, Dean of Students. https://news.semo.edu/rucker-named-asst-tothe-presidentfor-equity-and-diversity-dean-of-students-at-southeast/

River City University Newswire (2018). Regents approve major academic reorganization. https://news.semo.edu/regents-approve-major-academicreorganization/

River City University Office of Institutional Research. (2017). Fast facts. http://www.semo.edu/ir/facts.html

River City University Office of the Provost (2019). New faculty orientation program: Thrive in five!. https://semo.edu/provost/faculty_info/newfaculty.html

Rozalski, M., \& Rozalski. (2010). Evidence-based education (EBE). In T. C. Hunt, J. C. Carper, \& T. J. Lasley (Eds.), Encyclopedia of educational reform and dissent. SAGE.

Rubin, P. G. (2018). The policy filtering process: Understanding distinctive state responses to the national college completion agenda in the United States. Education Policy Analysis Archives, 26(60).

Russell, D.W., Altmaier, E., Van Velzen, D. (1987). Job-Related stress, social support, and burnout among classroom teachers. Journal of Applied Psychology. 72(2). 269-274. 
Sabagh, Z., Hall, N. C., \& Saroyan, A. (2018). Antecedents, correlates, and consequences of faculty burnout. Educational Research, 60(2), 131-156. https://doi.org/10.1080/00131881.2018.1461573

Shafritz, J., Ott, S., \& Jang, Y. (Eds.). (2005). Classics of organization theory $\left(6^{\text {th }}\right.$ ed.). Wadsworth.

Schaufeli, W. B., Bakker, A. B., Hoogduin, K., Schaap, C., \& Kladler, A. (2001). On the clinical validity of the Maslach Burnout Inventory and the Burnout Measure. Psychology \& Health, 16(5), 565.

Schonfeld, I. S., Verkuilen, J., \& Bianchi, R. (2019). Inquiry into the correlation between burnout and depression. Journal of Occupational Health Psychology. https://doi.org/10.1037/ocp0000151

Schulz, A. D., Schöllgen, I., \& Fay, D. (2018, July 12). The role of resources in the stressor- detachment model. International Journal of Stress Management. http://dx.doi.org/10.1037/str0000100

Seidman, I. (2013). Interviewing as qualitative research: A guide for researchers in education and the social sciences. Teachers College Press.

Seipel, M. T., \& Larson, L. M. (2018). Supporting non-tenure-track faculty well-being. Journal of Career Assessment, 26(1), 154-171.

https://doi.org/10.1177/1069072716680046

Shumaker, S., \& Brownell, A. (2010). Toward a theory of social support: Closing conceptual gaps. Journal of Social Issues, 40, 11-36.

https://doi.org/10.1111/j.1540- 
4560.1984.tb01105.x

Simmons, B. L. (2014). Organizational characteristics of happy organizations. In C. L. Cooper (Ed.), Wellbeing: a complete reference guide. Wiley.

Slate, R. N., \& Vogel, R. E. (1997). Participative management and correctional personnel: A study of the perceived atmosphere for participation in correctional decision making and its impact on employee stress and thoughts about quitting. Journal of Criminal Justice,

25(5), 397-408. https://doi.org/10.1016/S0047-2352(97)00023-8

Sottimano, I., Guidetti, G., Converso, D., \& Viotti, S. (2018). We cannot be "forever young," but our children are: A multilevel intervention to sustain nursery schoolteachers' resources and well-being during their long work life cycle. Plos One, 13(11), e0206627- e0206627.

https://doi.org/10.1371/journal.pone.0206627

Springer. (n.d). Research in Higher Education.

https://www.springer.com/education+\%26+language/higher+education/journal/11 162?de tailsPage $=$ pltci_1401270

Sproles, K. Z. (2018). The emotional balancing act of teaching: A burnout recovery plan. New Directions for Teaching \& Learning, 2018(153), 99-107. https://doi.org/10.1002/tl.20285

Stahl, R. (2017, November 17). What if I invest in them, and then they leave? Fund the People. http://fundthepeople.org/what-if-i-invest-in-them-and-then-they-leave/

Strauss, A., \& Corbin, J. (1998). Basics of qualitative research: Techniques and procedures for developing grounded theory (2nd ed.). SAGE. 
Sutton, T. P., \& Bergerson, P. J. (2001). Faculty compensation systems. [electronic resource] : Impact on the quality of higher education. ERIC Clearinghouse on Higher Education.

Szigeti, R., Noémi B., Réka B., \& Urbán R. (2017). Burnout and depressive symptoms in teachers: Factor structure and construct validity of the Maslach Burnout Inventory - Educators Survey among elementary and secondary school teachers in Hungary. Stress and Health: Journal of the International Society for the Investigation of Stress. 33(5), 530-39. https://doi.org/10.1002/smi.2737.

Taris, T.W.. (2006). Bricks without clay: On urban myths in occupational health psychology. Work and Stress, 99. https://doi.org/10.1080/02678370600893410

Temi. Are my files private and secure? (2019, September 22). Temi. http://help.temi.com/en/articles/1594946-are-my-files-private-and-secure

Texas A\&M University Data and Research Services. Calculation of Faculty FullTime Equivalent (FTE). TAMU-DARS. https://dars.tamu.edu/Data-andReports/Miscellaneous/files/faculty-fte-calculation.aspx

Thompson, T., \& Thompson, T. (Eds.). (2014). Encyclopedia of health communication. SAGE.

Tinto, V., \& Goodsell-Love, A. (1993). Building community. Liberal Education, 79(4), 16. 
Tollinche, S. (2013). Stress buster: Introducing quiet time for neonatal nurses. JOGNN: Journal of Obstetric, Gynecologic \& Neonatal Nursing, 42 (1), S69. https://doi.org/ 10.1111/1552-6909.12154.

Umbach, P. D., \& Wawrzynski, M. R. (2005). Faculty do matter: The role of college faculty in student learning and engagement. Research in Higher Education, 46(2), 153-184. https://doi.org/10.1007/s11162-004-1598-1

Walkey, F. H., Siegert, R. J., McCormick, L. A., \& Taylor, A. J. W. (1987). Multiple replication of the factor structure of the Inventory of Socially Supportive Behaviors. Journal of Community Psychology, 15(4), 513.

Watanabe, M., \& Falci, C. D. (2016). A demands and resources approach to understanding faculty turnover intentions due to work-family balance. Journal of Family Issues, 37(3), 393-415. https://doi.org/10.1177/0192513X14530972

Watts, J., \& Robertson, N. (2011). Burnout in university teaching staff: A systematic literature review. Educational Research, 53(1), 33-50. https://doi.org/10.1080/00131881.2011.552235

Wei, Y., Chu, H., Chen, C., Hsueh, Y., Chang, Y., Chang, L., \& Chou, K. (2012). Support groups for caregivers of intellectually disabled family members: Effects on physical, psychological health and social support. Journal of Clinical Nursing, 21(11/12), 16661677.

Weiss, R. (1974) The provisions of social relationships. In: Rubin, Z., Ed., Doing unto others, (pp. 17-26). Prentice Hall. 
World Health Organization. (2018). International statistical classification of diseases and related health problems (11th Revision). https://icd.who.int/browse11/1-m/en

World Health Organization (2020, March 9). What is COVID-19? https://www.who.int/newsroom/q-a-detail/q-a-coronaviruses

World Health Organization. (2020, March 11). WHO Director-General's opening remarks at the media briefing on COVID-19 - 11 March 2020. https://www.who.int/dg/speeches/detail/who-director-general-s-opening-remarksat-themedia-briefing-on-covid-19---11-march-2020

Yin, R. K. (2009). Case study research: Design and methods. SAGE.

Zahneis, M. (2018, June 29). As word of layoffs spreads, Western Illinois faculty members brace for the worst. The Chronicle of Higher Education. https://www.chronicle.com/article/As-Word-of-Layoffs-Spreads/243810

Zambo, D., Buss, R. R., \& Zambo, R. (2015). Uncovering the identities of students and graduates in a CPED-influenced EdD program. Studies in Higher Education, 40(2), 233252. https://doi.org/10.1080/03075079.2013.823932.

Ziker, J. (2014, April 13). How professors use their time: Faculty time allocation. https://thebluereview.org/faculty-time-allocation/ 


\section{Appendix B: Recruitment Letters}

\section{Survey Recruitment E-Mail}

Dear Colleague,

I am asking you to participate in a research study I am conducting as part of my doctoral dissertation. My goal is to measure the burnout of full-time faculty at this institution and determine what factors, if any, may mitigate that burnout. This study has been approved by both the Institution Review Board at the University of Missouri and the IRB at Southeast Missouri State University.

The research consists of two parts. The first part is a survey that you can complete by clicking this link: https://missouri.qualtrics.com/jfe/form/SV_6X8JHDCnwBobNkN Your identity and participation will remain confidential. No direct or indirect identifiers will be collected in the questionnaire. You may also be invited to participate in the second part of this research which consists of semi-structured interviews. Your participation is voluntary. Informed consent will be completed as part of the survey, and provided again before interviews are conducted.

One survey participant will be selected at random for a \$25 Tango gift card using Qualtrics

"rewards genius". Interview participants will receive small snack items. All university faculty will be invited through the Center for Scholarship in Teaching and Learning to attend a retreat at the end of the Spring 2020 semester. At the retreat, the results of the study will be shared and discussed. There are no costs to the participant that may result from participation in the research. 
If you have any questions, you may consult me at bclubbs@ @emo.edu or my dissertation advisor, Dr. Melissa Odegard-Koester at modegard@ semo.edu. Please go to https://missouri.qualtrics.com/jfe/form/SV_6X8JHDCnwBobNkN to complete the informed consent and the survey. It should take less than 20 minutes of your time.

With sincere thanks, Brooke 


\section{Interview Recruitment E-Mail}

Dear Colleague,

I am asking you to participate in the second stage of a faculty burnout study I am

conducting as part of my doctoral dissertation. My goal is to measure the burnout of fulltime faculty at this institution and determine what factors, if any, may mitigate that burnout. This study was approved by both the IRB at the University of Missouri (Project \#2018155) and the IRB at Southeast Missouri State University (Project \#2020020). This is a mixed-methods study. The first part was a quantitative survey. You may or may not have participated in that survey, but based on the results, I am reaching out to faculty in your college because the faculty who did complete the survey and indicated they were in the College of Education, Health \& Human Studies had the lowest average burnout score. The second part is qualitative and involves semistructured interviews. Your participation is voluntary. Informed consent will be completed before interviews are conducted.

The interviews will last approximately 45 minutes and will be held in a private room in the library. After the interview, I will contact you to complete member checking of the themes I have identified. Responding to this member check should take no more than 30 minutes. Interview participants will receive small snack items. When we set up the time for the interview, you can let me know if you would like fruit, cookies, or chips. My goal is to complete our interviews by the end of February and our member-checks within the first week of March. All university faculty will be invited through the Center for Scholarship in Teaching and Learning to attend a retreat at the end of the 
Spring 2020 semester. At the retreat, the results of the study will be shared and discussed. There are no costs to you that may result from participation in the research.

Please contact me with any questions or to let me know you are interested in being an interview participant at bclubbs@semo.edu.

If you have other questions, you may also contact my dissertation advisor, Dr. Melissa Odegard-

Koester at modegard@ semo.edu.

With sincere thanks,

Brooke

Brooke Hildebrand Clubbs

Department of Communication Studies \& Modern Languages 


\section{Appendix C: Informed Consent}

MU IRB Project Number: 2018155 SEMO IRB Project Number: 20200020

Faculty Burnout and Its Relationship to Social and Institutional Support

Statement of Informed Consent

Key Information:

1. I am seeking your consent to participate in research. Your participation is voluntary and you may refuse to participate or withdraw from participation at any time without consequence.

2. The purpose of this research is to investigate the relationship between faculty burnout, social support, and institutional support. You will be asked to fill out an online questionnaire, which will take approximately 30 minutes and includes questions about the topics of this research as they pertain to your role as a faculty member, as well as optional demographic questions such as age, gender, ethnicity, and sexual orientation. You may also be asked to complete a face-to-face, semistructured interview, at which you will be presented with this informed consent document again before being asked questions about institutional support within your department and college. That interview should take approximately 45 minutes. If you participate in that interview, you may be contacted a final time to participate in another face-to-face interview referred to as "member checking" that will be used to double-check the accuracy of our results. The member check should take no more than 30 minutes. 
3. You will be asked to share your feelings about institutional support in both the survey and interviews, and this could be interpreted as being harmful to your employment or your employer. You may also experience negative or unwelcome feelings as you describe your experiences with burnout. To mitigate these risks, no direct identifiers will be collected in the questionnaire, and data will only be reported in aggregate. Your confidentiality will be maintained by meeting in a private room at the library for the interviews. The transcripts from these interviews will be labeled with a color rather than a name and the key, as well as the interview appointment schedule, will be kept in a password-protected electronic file, which will be secured in a locked office. Please see the "Other Information" section of this document for important information about how your data may be used in future research.

4. Your participation may benefit university faculty. Determining the extent of burnout, as well as what may mitigate or prevent it, could help improve the physical, mental, and social well-being of faculty.

Detailed Study Description:

If you choose to participate, you will be asked to complete this questionnaire and may possibly be asked to schedule an interview. There are 2 phases to this project. Phase I will be the questionnaire, which will ask for information regarding your job title/rank, which college you are part of, and your feelings about the role of institutional and social support in your job satisfaction and level of burnout experienced. There will also be optional demographic questions regarding things like your age, gender, ethnicity, and 
sexual orientation. Phase I will take approximately 30 minutes. Data will be reported in aggregate and no direct identifiers will be recorded or reported.

Phase 2 will be semi-structured interviews based on the results of the questionnaire. You might be invited to participate in this interview, but most participants who fill out the questionnaire will not be asked to interview. Only a sample of faculty from one or more colleges that are characterized by a low level of faculty burnout will be asked to interview. Thus, people who did not fill out the questionnaire but are from a particular college may be asked to interview just based on being part of a college whose faculty had lower burnout scores. No individually identifying information will be collected during the interview. If you choose to participate, the interviews will last approximately 45 minutes and you will be asked about institutional support from your college and department. This interview will be recorded using an audio recording iPhone app. Your name or the name of your department will not be audio recorded or transcribed, and any potentially identifying information inadvertently provided during the interview will be redacted in the transcript.

After the interview, the researcher will contact the interviewed faculty to complete member checking of the identified themes. Member checking occurs when the researcher takes the major findings, such as the identified themes, back to interview participants to see if they feel they are accurate. This will be in the form of a face-to-face interview. Member checking ensures that the essence of the participants' meanings are articulated and interpreted accurately by the researcher. They also ensure that no participants' reality is ignored. Responding to this member check should take approximately 30 minutes. 
Faculty will have the opportunity to refuse to participate in any of the above phases of the research project without penalty. Risks and Benefits of Participation:

Because you will be asked to share your feelings about institutional support in both the survey and interviews, this could be interpreted as being harmful to your employment or your employer. You may also experience negative or unwelcome feelings as you describe

your experiences with burnout. If you experience distress, be aware that Southeast faculty and staff have access to the Employee Assistance Program which provides access to mental health/counseling services. This service may be utilized at any time by contacting Southeast's Human Resources department for more information.

There may also be other risks that we cannot predict.

It is reasonable to expect the following benefits from participation in the study: Determining the extent of burnout, as well as what may mitigate or prevent it, could help improve the physical, mental, and social well-being of faculty. However, we can't guarantee that you personally will experience benefits from your participation. Others may benefit in the future from the information we gather in this study. Confidentiality:

We will take the following steps to keep information about you confidential, and to prevent it from unauthorized disclosure: Your identity and participation will remain confidential. No direct or indirect identifiers will be 
collected in Phase I questionnaire. Qualtrics is the survey platform being used for the first phase of this study. The Qualtrics online privacy statement covers the use and disclosure of personal information that may be collected anytime a user interacts with Qualtrics. Such interactions include visiting any of Qualtrics websites, using the service, or when calling the Qualtrics sales and support departments. You can read the more detailed Qualtrics privacy statement and the Qualtrics Terms of Service for more information from the Qualtrics vendor here: https://www.qualtrics.com/privacy-statement/ The data collected through Qualtrics will be transferred to SPSS for analysis. Only the primary researcher and her dissertation committee will have access to this data. The analyzed data will be published in the researcher's dissertation in aggregate form only, with no direct or indirect identifiers or optional demographic information reported. The raw data will be stored for seven years before it is destroyed. Please see "Other Information" section of this document for important information about how your data may be used in future research.

Your confidentiality will be maintained if you choose to participate in the Phase 2 interviews by conducting the interview in a private room at Kent Library. These interviews will be recorded and transcribed using the Temi iPhone application. The recordings will be destroyed after transcription, and the transcripts will be stored for seven years before they are destroyed. Transcripts from these interviews will be labeled with a color rather than a name and the key to the colors and names, as well as the interview appointment schedule, will be kept in a password-protected file on the Principal Investigator's computer, which is contained in her office that is locked when she is not present. The name 
of your department will not be recorded or linked to your responses in any way, and any potentially identifying information inadvertently provided during the interview will be redacted in the transcript. The code linking the transcripts to your name and interview schedule will be destroyed at the completion of data analysis. Please see

"Other Information" section of this document for important information about how your data may be used in future research.

Withdrawal from the Study:

Your participation in this research is completely voluntary. If you decide to participate, you may change your mind and cease participating at any time. If you stop participating, you will not be penalized in any way or lose any benefits, and it will not harm your relationship with the researchers. For Phase I of the study, we will not be able to remove your data

after you submit your responses, as no identifying information will be collected. For Phase 2, we will not be able to remove your data after data analysis is complete, which is expected to occur around 3/15/2020.

Other Information:

The information you provide at any phase of this research, including the demographic information you may choose to provide (which includes age, gender, ethnicity, and sexual orientation) may be retained and used for future research projects by the current investigators for up to seven years without obtaining further informed consent from you. An example of a potential future research project is an investigation of the relationship between age, gender, 
sexual orientation, and/or ethnicity in faculty experience of burnout or institutional/social support. After seven years, all data will be destroyed and will no longer be available to any researcher. Your consent for each stage of this process represents broad consent to use your information for future research as long as any future research protocol is approved by an appropriate Institutional Review Board.

One survey participant will be selected at random for a \$25 Tango gift card. Interview participants will receive small snack items. All university faculty will be invited through the Center for Scholarship in Teaching and Learning to attend a retreat at the end of the Spring 2020 semester. At the retreat, the results of the study will be shared and discussed. There are no costs to the participant that may result from participation in the research.

Contact Information:

You may ask questions, voice concerns or complaints to the research team.

Brooke Hildebrand Clubbs (573) 651-2521; bclubbs@ semo.edu; Academic Hall 237E

Dr. Melissa Odegard-Koester: modegard@ semo.edu

Dr. Bret Cormier: bcormier@ semo.edu

Dr. Kirsten LaMantia: klamantia@ semo.edu

Dr. John Lammers: jclammer@illinois.edu

This project was approved by the Southeast Missouri State University Institutional Review Board on 12/19/19, so you may also contact the Southeast IRB at irb@semo.edu or call Jennifer Bengtson, IRB chair, at (573) 651-2146. 
Additionally, The University of Missouri Campus Institutional Review Board approved this research study on 11/25/19. You may contact the Campus Institutional Review Board if you have questions about your rights, concerns, complaints or comments as a research participant. You can contact the Campus Institutional Review Board directly by telephone or email to voice or solicit any concerns, questions, input or complaints about the research study.

Campus Institutional Review Board

483 McReynolds Hall

Columbia, MO 65211

$573-882-9585$

E-Mail: umcresearchcirb@missouri.edu

Website: http://www.research.missouri.edu/cirb/index.htm

FOR PHASE 1: I have read this consent form and my questions have been answered. Clicking "I agree" below means that I do want to be in the study and that I consent to participate in the questionnaire portion of this study. I know that I can remove myself from the questionnaire portion of this study by simply exiting the questionnaire without submitting it. I can print and save this informed consent document.

FOR PHASE 2: I have read this consent form and my questions have been answered. By signing and dating below, I am indicating my consent to participate. I know that I can request that my data be removed from the study at any time up until data analysis is complete, on approximately 3/15/2020. 


\section{Appendix D: Survey}

Note: Mind Garden copyright requires that I only include 3 of the questions from

Maslach's Burnout Inventory

mind garden

www.mindgarden.com

To Whom It May Concern,

The above-named person has made a license purchase from Mind Garden, Inc. and has permission to administer the following copyrighted instrument up to that quantity purchased:

Maslach Burnout Inventory forms: Human Services Survey, Human Services Survey for Medical Personnel, Educators Survey, General Survey, or General Survey for Students.

The three sample items only from this instrument as specified below may be included in your thesis or dissertation. Any other use must receive prior written permission from Mind Garden. The entire instrument form may not be included or reproduced at any time in any other published material. Please understand that disclosing more than we have authorized will compromise the integrity and value of the test.

Citation of the instrument must include the applicable copyright statement listed below. Sample Items:

MBI - Human Services Survey - MBI-HSS:

I feel emotionally drained from my work.

I have accomplished many worthwhile things in this job.

I don't really care what happens to some recipients.

Copyright (C1981 Christina Maslach \& Susan E. Jackson. All rights reserved in all media.

Published by Mind Garden, Inc., www.mindgarden.com

MBI - Human Services Survey for Medical Personnel - MBI-HSS (MP):

I feel emotionally drained from my work.

I have accomplished many worthwhile things in this job.

I don't really care what happens to some patients.

Copyright (C1981, 2016 by Christina Maslach \& Susan E. Jackson. All rights reserved in all media. Published by Mind Garden, Inc., www.mindgarden.com

MBI - Educators Survey - MBI-ES:

I feel emotionally drained from my work.

I have accomplished many worthwhile things in this job.

I don't really care what happens to some students.

Copyright (1986 Christina Maslach, Susan E. Jackson \& Richard L. Schwab. All rights reserved in all media. Published by Mind Garden, Inc., www. mindgarden.com 
Q1 - Thank you for participating in this study. Please look over this informed consent form: Informed Consent with MU and SEMO approval and then indicate your consent by clicking "Yes" (you consent) or "No" (you do not consent) below.

Q2 - Have you ever attended a faculty development day or another workshop or event sponsored by the Center for Scholarship in Teaching \& Learning (CSTL)? Q3 - Please indicate your faculty status:

Q4 - Please indicate which college your department is housed in:

Q7_1 - I feel emotionally drained from my work.

Q7_19 - I have accomplished many worthwhile things in this job.

Q7_15 - I don't really care what happens to some students.

Q8 - Indicate your satisfaction with the following institutional factors here

General support from my department

chair (for example, values my

contributions in department decisionmaking)

General support from my dean (for example, supports my scholarly endeavors, advocates to the provost) General support from upper administration, including provost and president (for example, champions the faculty) 
Institutional efforts in support of the career

development of faculty (for example,

administrative support, professional

development funds, or release time)

Salary competitive with other schools

Distribution of rewards (for example, salary based on

merit) Q17 - Because salary is a measure of your institutional

support please provide an estimate of your gross base salary.

Q10 - In answering the following questions, think about your current

relationship...

There are people I can depend on to

help me if I really need it.

I feel that I do not have close

personal relationships with other

people. There is no one I can turn

to for guidance in times of stress.

There are people who enjoy the same social

activities that I do.

I do not think other people respect my

skills and abilities.

If something went wrong, no one would

come to my assistance.

I have close relationships that provide

me with a sense of emotional security 
and wellbeing. I have relationships

where my competence

and skills are recognized.

There is no one who shares my interests and

concerns.

There is a trustworthy person I could

turn to for advice if I were having

problems.

Q11 - The following demographic questions are optional but could aid in further research about which faculty groups are more likely to experience burnout.

What best describes your gender?

Q12 - If you prefer to self describe your gender, please

enter that description. Q13 - What categories best

describe you? (select all that apply)

Q14 - Do you consider yourself a member of the Lesbian, Gay, Bisexual, Transgender and/or Queer (LGBTQ+) community?

Q15 - Please enter the year you were born.

Q18 - Do you wish to be eligible to receive the Tango gift card

incentive for completing this survey? If you answer "yes" you will

be taken to a second survey so that you can enter your e-mail

address. 


\section{Appendix E: IRB permission letters}

Institutional Review Board

University of Missouri-Columbia

FWA Number: 00002876

IRB Registration Numbers: 00000731,00009014
482 McReynolds Hall

Columbia, MO 65211

573-882-3181

irb@missouri.edu

November 25, 2019

Principal Investigator: Brooke Clubbs (MU-Student)

Department: Educational Leadership-EDD

Your IRB Application to project entitled Faculty Burnout and Its Relationship to Social and Institutional Support was reviewed and approved by the MU Institutional Review Board according to the terms and conditions described below:

$\begin{array}{ll}\text { IRB Project Number } & 2018155 \\ \text { IRB Review Number } & 255703 \\ \text { Initial Application Approval Date } & \text { November 25, } 2019 \\ \text { IRB Expiration Date } & \text { November 25, 2020 } \\ \text { Level of Review } & \text { Exempt } \\ \text { Project Status } & \text { Active - Exempt } \\ \text { Exempt Categories (Revised Common Rule) } & 45 \text { CFR 46.104d(2)(ii) } \\ \text { Risk Level } & \text { Minimal Risk }\end{array}$

The principal investigator (PI) is responsible for all aspects and conduct of this study. The PI must comply with the following conditions of the approval:

1. No subjects may be involved in any study procedure prior to the IRB approval date or after the expiration date.

2. All changes must be IRB approved prior to implementation utilizing the Exempt Amendment Form.

3. The Annual Exempt Form must be submitted to the IRB for review and approval at least 30 days prior to the project expiration date to keep the study active or to close it.

4. Maintain all research records for a period of seven years from the project completion date.

If you are offering subject payments and would like more information about research participant payments, please click here to view the MU Business Policy and Procedure: $\underline{\mathrm{http}: / /}$ bppm.missouri.edu/chapter2/2_250.html

If you have any questions or concerns, please contact the MU IRB office at 573-882-3181 or email to muresearchirb@missouri.edu.

Thank you,

MU Institutional Review Board 


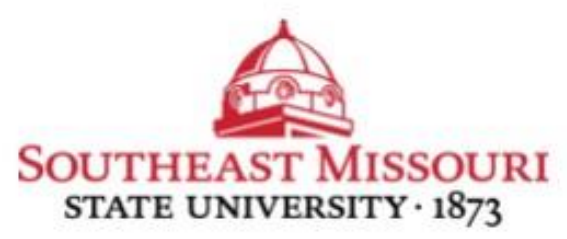

Memo to: Brooke Clubbs and Melissa Odegard-Koester

From: Jennifer Bengtson, Chair, IRB

Re: IRB proposal 20200020, "Faculty Burnout and Its Relationship to Social and Institutional Support"

Date: December 19, 2019

The IRB received your proposal 20200020, "Faculty Burnout and Its Relationship to Social and Institutional Support" and has determined that it is eligible for expedited review under category 7 , "research on individual or group characteristics or behavior." It has been accordingly reviewed and determined that it presents minimal risk to the participants. It is hereby approved.

This approval is effective for a period of one year from the date of this memo. If any unforeseen events occur or if your research protocol changes in any way, you are obligated to contact the IRB immediately at irb@semo.edu. Please refer to the proposal number above in any communication regarding this research. Best wishes in your research endeavors. 


\section{Appendix F: Example of Interview Transcripts}

\section{Participant 1}

Speaker 1 (00:02):

Okay. So we're recording. Um, so thank you for agreeing to be a part of this. And I'm going to ask you six different questions and obviously there's no right or wrong answer, I'm just trying to get some more information based on the quantitative data that I found that showed that your college overall had the lowest, um, global burnout score. And so first I was wondering if you could describe the culture of support in your department. Thinking about your unit, um, can you describe the culture of support there?

Speaker 2 (200:38):

Um, so I would say in our department there is a pretty intense focus on collegiality. Um, even them saying that we love each other like family. That was kind of a really important, that's a really important thing to the more senior members in the department. Um, and our program is actually a new program in that department since the reorganization. Um, and so it's a completely different culture than the department we were in. Um, this one, like I said, is very much focused on collegiality. So there's, um, we have a Christmas party every year and a summer party every year and do gift exchanges. And things like that. So there is a lot of focus on, um, on us getting along and being friends and, um, doing things outside of work, which I do think stimulates things inside of work too, in terms of identifying potential research areas or areas we can teach, uh, in an interdisciplinary way. And so I would say that, yeah, our department has, has really 
focused on the collegiality part side of things, which does really support, um, which does make us feel supportive.

\section{Participant 2}

Speaker $1(\underline{00: 00)})$ :

Alright, there we go. We're recording. Okay. So, um, as you may have seen my study's about faculty burnout and so I'm just going to be asking you a couple of different questions and they're going to go from sort of a, a smaller level like your department and then up to a bigger level like the college, then up to administration. And so the first question is a really global kind of question. Um, how would you describe the culture of support in your department?

Speaker $2(\underline{00: 32})$ :

In my department, I believe it's, it's very strong. Um, I have full faith in my department chair. Um, yeah, the, I know that, um, she has the, she has this great, um, sorry, but uh, this great way of taking the students, um, perspectives, but also the faculty's perspectives. And I dunno, she's good at just combining everything too. Sorry, this, I'm glad you're not having to type this [laughs] anyway. I know, I know that she has my back and I know that I can go talk to her in confidentiality and I know if I have any issue I can go and talk to her and, um, and I'll receive, um, uh, timely feedback and feedback that truly is supportive.

\section{Participant 3}

Speaker $1(\underline{00: 01})$ :

Here we go. So we're recording. So I have just a few different questions. We're going to start on sort of a global scale and then we're going to narrow it down a little bit. And so the first question that I'm going to ask is how would you describe the 
culture of support in your department? When you think of your department? Um, how would you describe the support that's there?

\section{Speaker 2:}

Well, um, historically my department has been very consistent and we've had a ton of turnover within the last five years. Um, we have completely transitioned almost every faculty member I believe in our department nearly anyway, and if not, we haven't yet, but will within the next year or so. Um, and so we've had a ton of transition, but in our department we have a really strong culture of support, I would say. Um, and I think that's what makes us such a strong department because we are close, um, both professionally and personally. Um, many of us have known even the younger faculty coming in because many of us graduated from this program. And so we have that history as well as the history of now being colleagues. And so, um, along with everyone else who has worked together for 30 years prior to me entering, um, so everyone is very supportive. We work very, very well together. Um, frequently people in our college, I feel like we'll even say things like, uh, to our chairs. Um, I say chairs cause we've had a transition in there too, but they will say things like, "Oh my goodness, if I could get my faculty together like yours is". And things like that because we are, we're very unique and that we don't always necessarily have the same opinions, but we all are very supportive and we all were very, very, very well together.

\section{Participant 4}

Speaker 1 (00:00): 
Go ahead and get us recording, but go ahead, eat whatever you would like to do. Um, I have six questions that we're going to go through and I'm going to be talking about, um, first sort of in general, the culture of your department and the culture of your college and then it's going to get more specific. I'm going to ask you about specific supportive behaviors. Um, so first off, how would you describe the culture of support in your department culture and support?

Speaker 2:

Well, I, I think I'm pretty fortunate in that regard in my department, you know, [names department]. I'm surrounded by [names profession]. I'm not one myself, but you know, yeah. Um, and, and while there are always some outliers on a whole, I think that the culture of my department is, is, uh, very supportive of one another. There is, um, uh, people are always on hand to, to, to be sounding boards or to vent and to, to give support. And there are members of my department, you know, there's stuff at a faculty meeting that, you know, doesn't bother me at all. Yeah. Still afterwards, I'll have a colleague that'll come and say, “Oh, I just hope you didn't get upset about that". If there's a perceived slight sometimes and to some degree I'm like, "no, it's, it's, it's, it's, it's fine" because there is a tendency for, um, it, I am often frustrated personally, I'm probably getting off topic here, but I'm frustrated personally by, um, the difficulty sometimes of just having a constructive debate about policy-related matters in the department and that if I disagree with what you're proposing, I'm not insulting you. I'm saying, well, let's talk about this. Let's, let's work it out. Um, and I'm not at all bothered when I propose something and somebody has an, uh, 
uh, comment on the, on the other side because that's, you know, that's what we're all supposed to be academics here.

\section{Participant 5}

Speaker $1(\underline{00: 01})$ :

Um, so I'm gonna ask you five questions that are all sort of dealing with support. And then my last question is going to deal with personal accomplishment or personal achievement. And so we start off on sort of this broad level. Um, how would you describe the culture of support in your department?

Speaker 2 (00:37):

Okay. Um, I think that overall it's a very, it's a pretty supportive, um, department, um, as far as what, um, kind of things we want to do. And, um, I, I say that I guess, um, with some limited ability to do some of the things we want to do. 


\section{VITA}

Brooke Hildebrand Clubbs was born in Kankakee, Illinois. She graduated from Herscher High School in 1994 and earned her Bachelor of Science in Speech and Theatre Education at Southeast Missouri State University, Cape Girardeau in 1998. She graduated with a Master of Fine Arts in Acting from Western Illinois University, Macomb in 2001 and a Master of Science in Health Communication from the University of Illinois at Urbana-Champaign in 2013. She completed her Doctorate of Education in Educational Leadership and Policy Analysis from the University of Missouri-Columbia in 2020. She and her family live in Jackson, Missouri. She is currently an instructor for the Department of Communication Studies \& Modern Languages at Southeast Missouri State University and serves as the Director of Health Communication. 